\title{
Local and Landscape Effects on Arthropod Communities along an Arable-Urban Gradient
}

\author{
Dissertation \\ to obtain the Dr. sc. agr. \\ in the Ph. D. Program for Agricultural Sciences in Göttingen (PAG) \\ at the Faculty of Agricultural Sciences, \\ Georg-August-University Göttingen, Germany
}

presented by

Hannah Reininghaus

born in St. Augustin

(Germany)

Göttingen, May 2017 
D7

1. Name of supervisor: Prof. Dr. Christoph Scherber

2. Name of co-supervisor: Prof. Dr. Teja Tscharntke

Date of dissertation: 11 July 2017 


\section{Table of Contents}

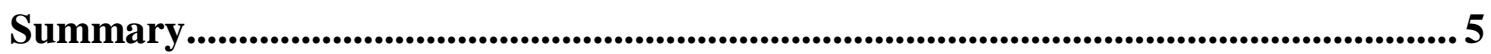

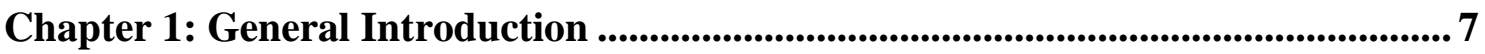

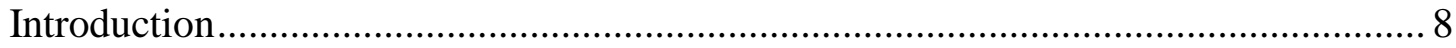

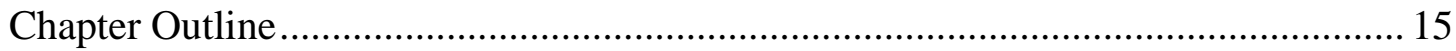

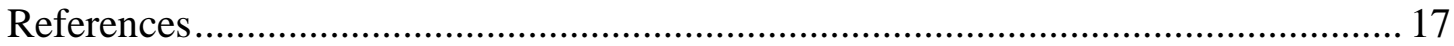

Chapter 2: Reversed Importance of Local vs. Landscape Flower Resources for

Bumblebee Foraging and Colony Performance along Farmland-Urban Gradients.... 20

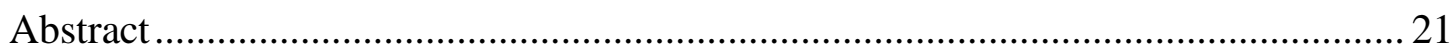

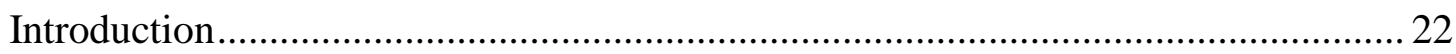

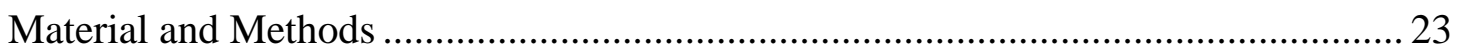

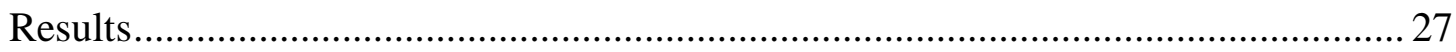

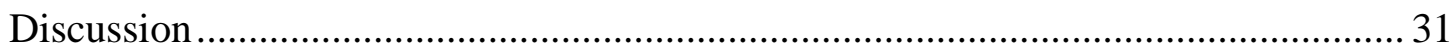

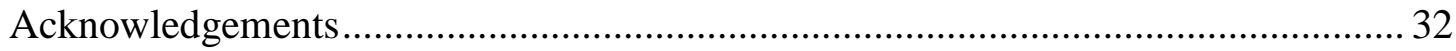

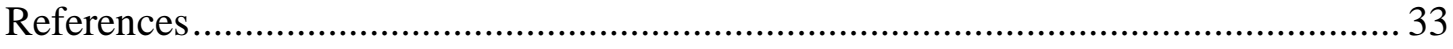

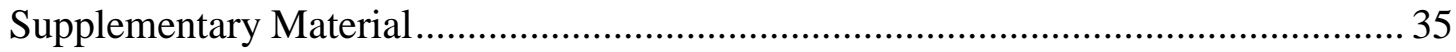

Chapter 3: Season and Flower Composition affect Bumblebee Foraging Behaviour

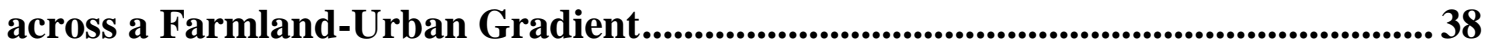

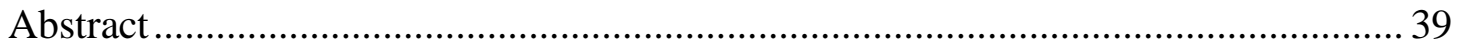

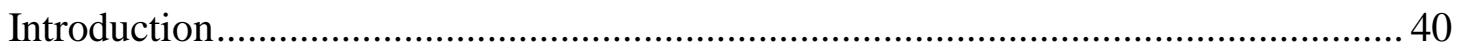

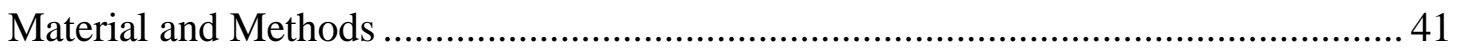

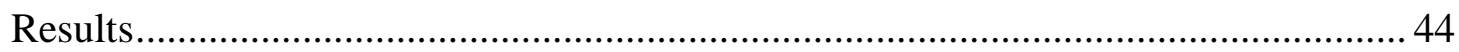

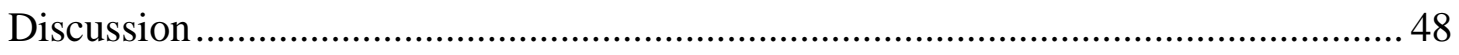

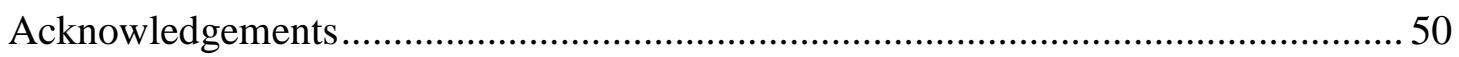

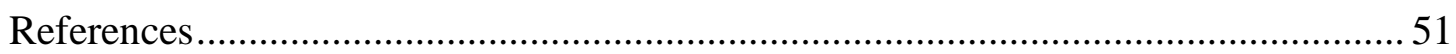

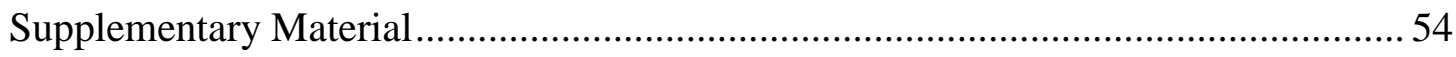


Chapter 4: Plant-Pollinator Interactions along an Urbanisation Gradient from

Cities and Villages to Farmland Landscapes ....................................................................558

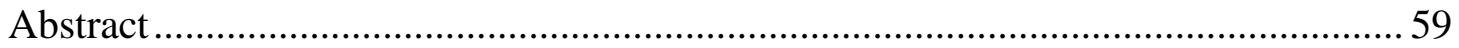

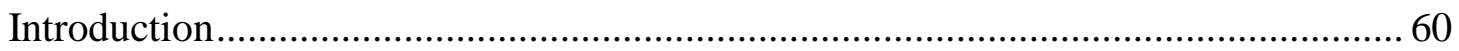

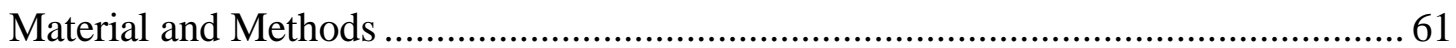

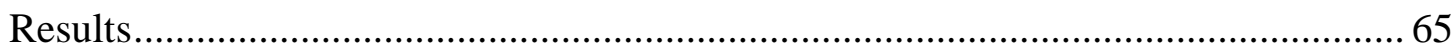

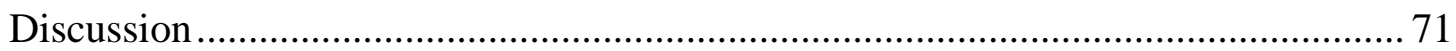

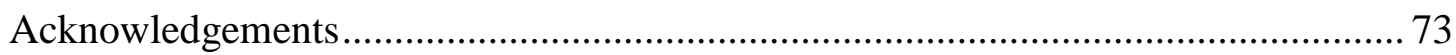

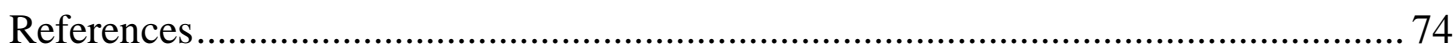

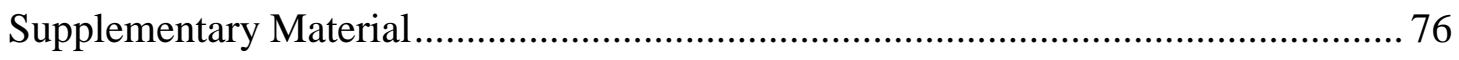

Chapter 5: Arthropod Diversity across an Urbanisation Gradient of City Size .... 78

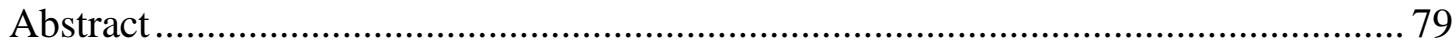

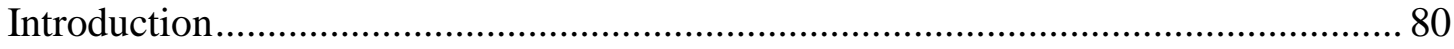

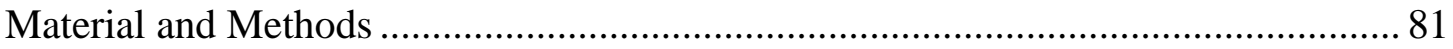

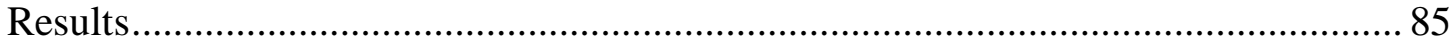

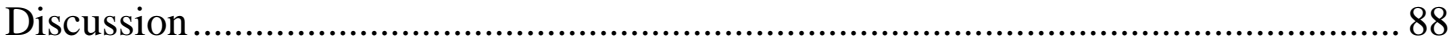

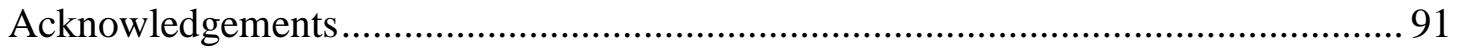

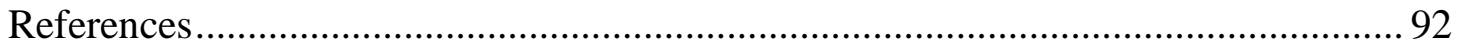

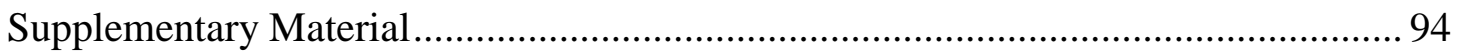

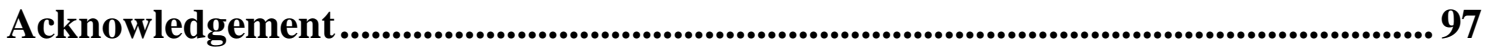

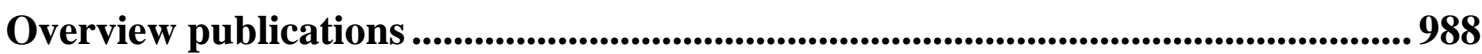




\section{Summary}

The increase and expansion of urbanisation and agriculture intensification has led to a decrease of natural habitats worldwide. Natural habitats offer resources such as food or nesting sites for different arthropod groups. Decline of these habitats could cause a loss of arthropod biodiversity. Semi-natural habitats in farmland, but also green spaces (e.g. parks and gardens) in cities that have high plant richness and flower cover, can potentially maintain this biodiversity and the associated ecosystem services.

Pollinators provide vital ecosystem services and are highly dependent on flowering resources in natural habitats. Bumblebees (Bombus) are a particularly important pollinator group in Europe. In study 1, I examined how floral resources at the local and landscape scale affect bumblebee foraging behaviour and colony performance. I conducted an experiment with 32 Bombus terrestris colonies along a farmland to urban gradient. I analysed local and long-range movement patterns of bumblebees to assess where pollinators forage in urban areas. I measured if $B$. terrestris colony growth depended on resource availability in the direct surroundings of the colonies or on landscape scale. The colony performance was the same along the gradient and workers visited plants providing floral resources in the direct surroundings and foraged at greater distances to their colonies. My results indicate that resources at the local and landscape scale affect bumblebee behaviour and performance. It is important to provide sufficient amounts of vegetated area for pollinators in farmland and urban areas as they benefit from plant rich environments.

Additionally, in study 2 I collected pollen from 48 bumblebee colonies in May and July 2015 and analysed which plant families were collected most frequently from bumblebee workers and if these plant families occurred in the surroundings of the colonies. Bumblebee workers showed high preferences for specific plant families with high flower cover and a high amount of nectar and pollen resources. Bumblebees foraged in greater distance to their colonies when these plant families were not present in the direct surroundings of the colonies. My results suggest that in bumblebee conservation and green space management these plant families should be taken into account. These plant families could help with the maintenance and restoration of good quality habitat for pollinators. 
In study 3, I conducted a pollinator observation experiment along a farmland to urban gradient. I planted phytometer plants along grassy margins in farmland sites, in village gardens and city gardens and observed plant-pollinator interactions. Plant-pollinator networks were more robust with higher interaction strength in farmland sites than networks in village and city gardens. Pollinator community composition changed with increasing urbanisation. In farmland sites, syrphid flies visited the phytometer plants more often, whereas wild-bees were more often present in gardens. In village gardens intermediate amounts of syrphid flies and bees visited the phytometer plants. My results suggest that farmland and urban landscapes support different pollinator communities and that the interface between the two extremes is of particular importance for the maintenance and restoration of a complementary pollinator community.

In study 4, I sampled three arthropod taxa (Coleoptera, Araneae and Hymenoptera) along an urbanisation gradient from small villages to cities. Sampling was conducted in gardens and public green spaces in the edge or centre of settlements to investigate if the direct surroundings or the amount of urban area in the landscape affected arthropod community composition. Coleoptera community structure and composition changed depending on the local surroundings (position in the settlement and green space type) and the amount of urban area (landscape effect). Hymenoptera and Araneae were influenced predominantly by the local surroundings. Our study deepens our understanding of how arthropod communities respond to urbanisation, as it is the first to investigate the influence of both urban area size and position in an urban area.

In conclusion, the results of my thesis show that arthropod groups respond to local habitat type and resource availability such as flower cover and plant richness in urban green spaces. Arthropod community composition and structure are influenced by landscape factors, such as degree of urbanisation or the amount of a mass flowering crop. Vegetated areas and urban green spaces have biodiversity value and my results suggest that landscape and the type of local habitat are intricately linked and therefore they should be evaluated together when designing landscapes to maintain and conserve biodiversity. 


\section{Chapter 1}

\section{General Introduction}

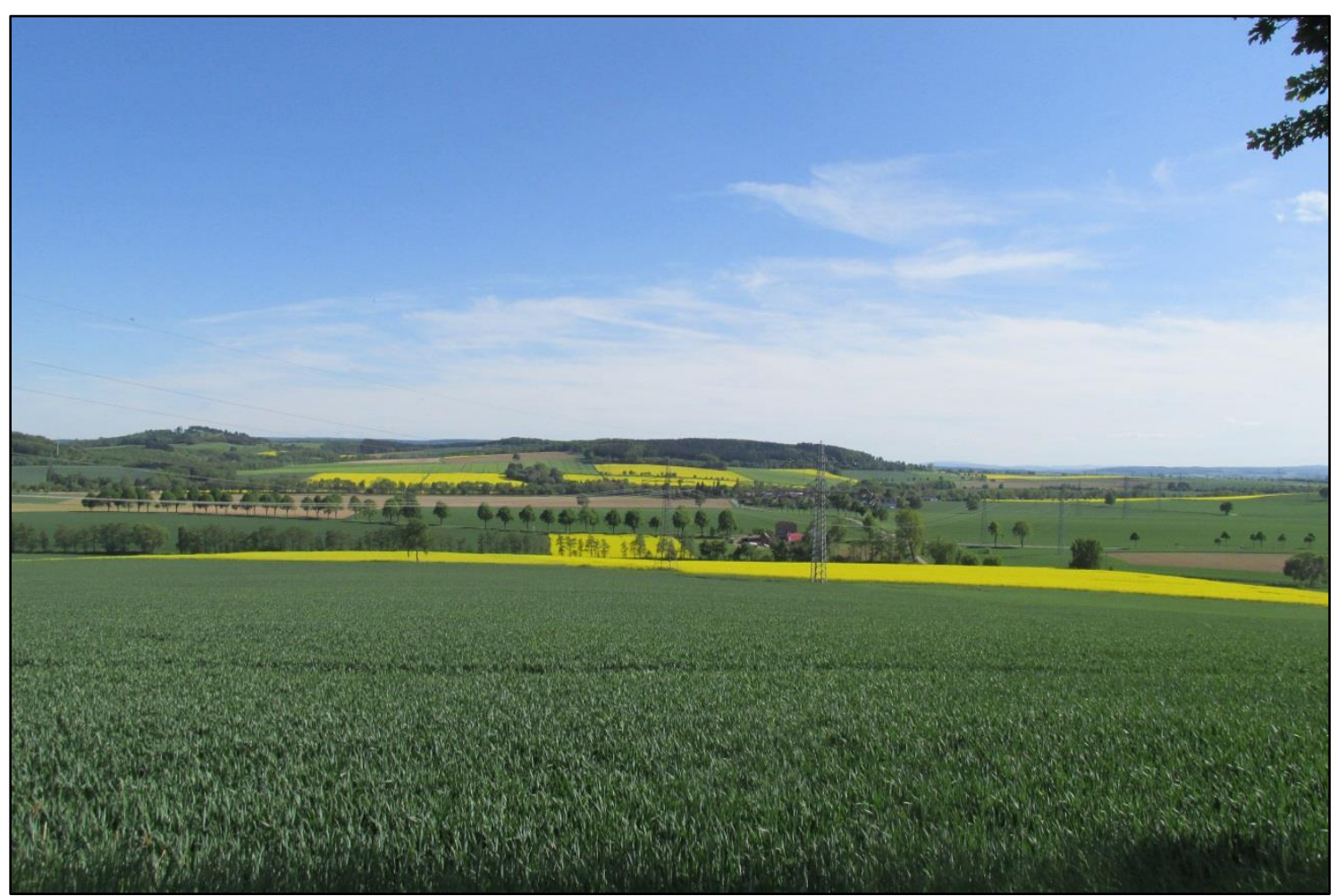

Landscape near Göttingen (May 2015, (C) Hannah Reininghaus) 


\section{Introduction}

Landscape change through agriculture intensification and increasing urbanisation causes widespread loss of biodiversity in anthropogenic landscapes (Goulson et al. 2005, Biesmeijer et al. 2006, Potts et al. 2010). The growth of the human population causes a demand for agricultural products and corresponding expansion of cropland (Godfray et al. 2010). These modified environments have been found to support lower insect diversity compared to natural areas (Bates et al. 2011).

A major cause of landscape modification is urbanisation. Over the last decades urban areas increased rapidly in size and density. Urban areas are defined as areas with human population density exceeding 620 individuals $/ \mathrm{km}^{2}$ (Bourne and Simmons 1982, United Nations 2014). The increase of urban areas results in a modification of the landscape through the conversion of cropland, pastures and natural habitats into built-up areas and urban and suburban environments (Grimm et al. 2008).

Gardens and semi-natural areas within urban areas provide resources for pollinator insects and other arthropod groups in urban areas (Fig. 1; McKinney 2008, Ahrne et al. 2009, Pereira-Peixoto et al. 2014). Cities can harbour higher abundance of arthropods than managed farmland (Turrini and Knop 2015), but different taxa show a heterogeneous response to urbanisation (Gleason 1926, McDonnell and Hahs 2008). Differences in species composition are due to the local resources, as plant richness is generally higher in urban areas due to the presence of many non-native plants in gardens (Fig. 2; Pyšek 1998, McKinney 2008). Pollinators can be positively affected by plant richness in urban green spaces (Baldock et al. 2015, Sirohi et al. 2015), but forest specialized ground beetle abundance decreases in gardens when compared with farmland (McKinney 2008, Vergnes et al. 2012). Besides plant species richness, the vegetation type is important. Some arthropod species, such as spiders, may thrive in habitats with larger extents of woody areas (Vergnes et al. 2012) that are more extensive in parks. Studies that examine an urbanisation gradient from rural to urban across the boundary of a city found differences in pollinator communities, with lower diversity of insects in the centre of an urban area (Ahrne et al. 2009, Bates et al. 2011, PereiraPeixoto et al. 2014). These differences were strongly related to local habitat quality and to isolation of the study site. For example, green spaces on the edge of urban areas were influenced by the adjacent habitat and could support higher species richness than green spaces in the centre of an urban area. 

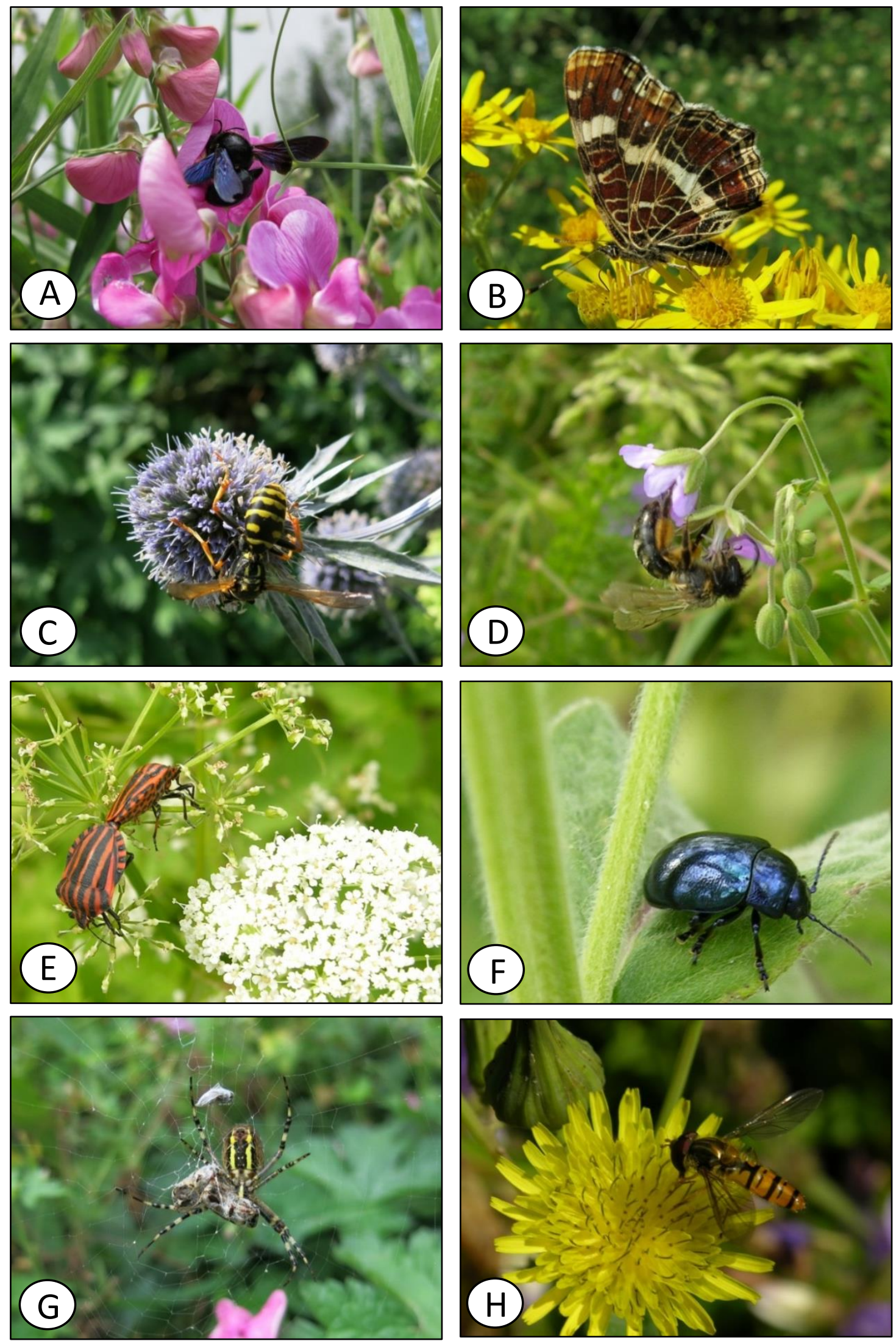

Fig. 1: Insect diversity in urban green spaces, A: Xylocopa spec. on Lathyrus latifolius (L.), B: Araschnia levana (L.) on Senecio jacobeae (L.), C: Vespula spec. on Echinops spec., D: Andrena spec. on Geranium spec., E: Graphosoma lineatum (L.) on Anthriscus cerefolium (L. Hoffm.), F: Chrysolina spec., G: Argiope bruennichi (Scopoli) H: Episyrphus balteatus (Degeer) on Hieracium spec. (C) Kristy Udy. 
Pollinators can benefit from floral resources and nesting sites in urban green spaces (Westrich 1996, Ebeling et al. 2008), thus green spaces in urban areas where plant diversity and floral resources are abundant can help reduce widespread declines in pollinator communities. A major benefit of urban areas is that floral resources are abundant in private gardens and parks with high plant richness and temporal stability (Fetridge et al. 2008). In contrast, the flowering period of mass-flowering crops as oilseed rape in farmland areas is limited. Yet, mass flowering crops may still positively affect pollinators as they provide additional foraging habitat and resources (Westphal et al. 2003, 2009) but could have negative impact on pollinator abundance (Holzschuh et al. 2016).

Farmland homogenization and intensification can shorten crop flowering time and therefore limit resource availability for arthropods, especially pollinators (Corbet et al. 1991, Ollerton et al. 2014). Consequently, both nesting sites and food resources are currently declining at alarming rates due to anthropogenic pressures, such as habitat conversion to farmland or urbanisation (Kremen et al. 2002, McKinney 2002, Tscharntke et al. 2005). Such loss of habitat and flowering plant resources may contribute to overall pollinator declines across Europe (Potts et al. 2010, Winfree 2010), with potentially negative impacts on pollination services (Allen-Wardell and Others 1998, Biesmeijer et al. 2006, Klein et al. 2007). However, enhancing the amount of natural habitats in farmland and urban areas can positively influence arthropod diversity (Fussell and Corbet 1992, Carvell et al. 2007, Öckinger and Smith 2007).

Pollinators need floral resources and nesting sites to survive (Westrich 1996, Ebeling et al. 2008) and these are available in green spaces in urban areas, where plant diversity and floral resources are abundant. Gardens have a diverse structure with lawns, flowers, shrubs and trees within a small area, whereas parks are dominated by short grass with few wild herbs and trees and with an occasional flower bed (Mata et al. 2017). Differences in habitat type could also be characterized by the local plant species richness, as gardens have a higher number of plant species present and higher flower cover, which could positively influence flower-visiting insects (Pyšek 1998, Baldock et al. 2015). Bumblebees respond to local and landscape resource availability as they are mobile species and can forage in the surroundings of their colony or at distances up to $2.8 \mathrm{~km}$ (Chapman et al. 2003, Westphal et al. 2006a, 2006b, Redhead et al. 2016). 

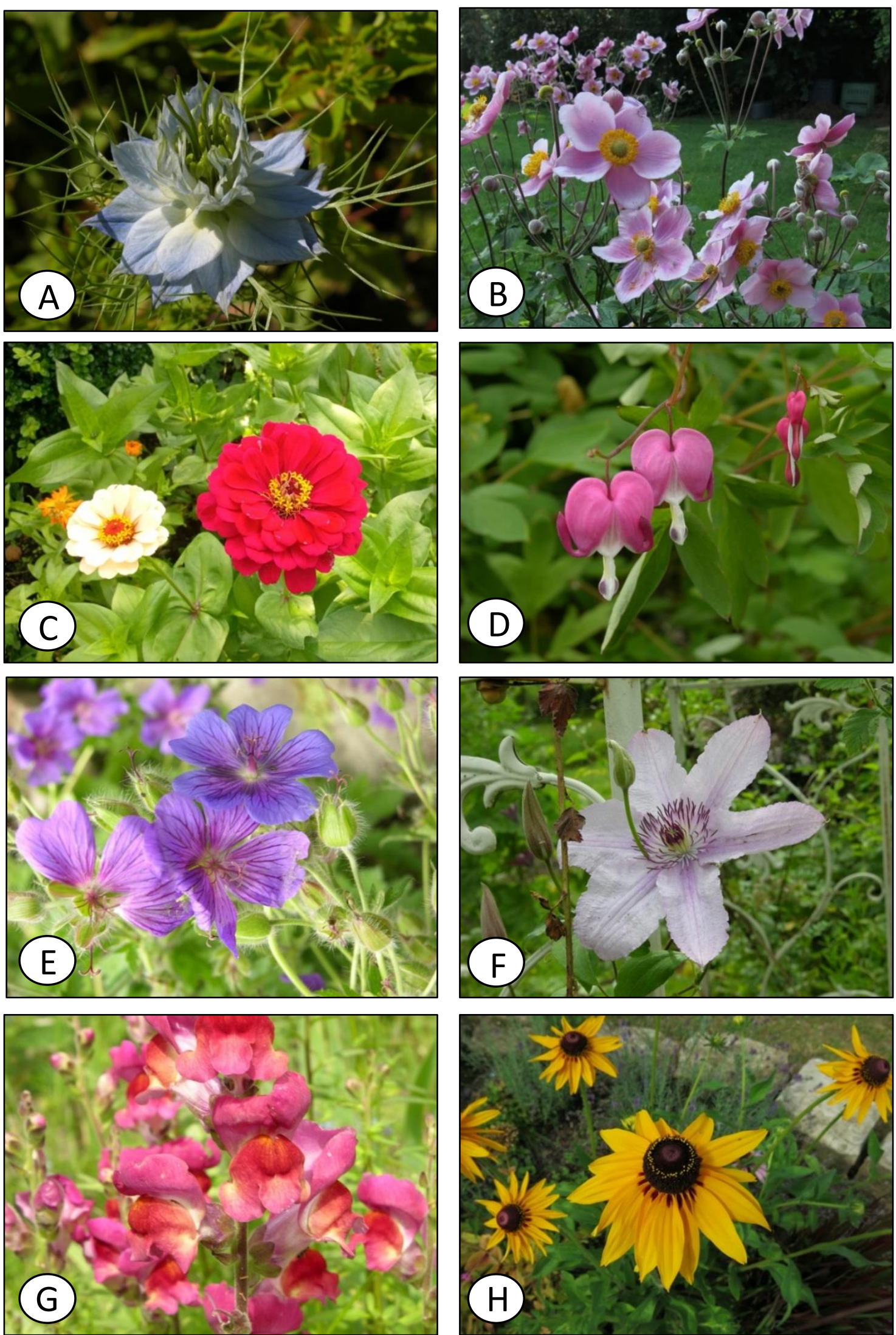

Fig. 2: Diversity of flowering plants in urban gardens, A: Nigella damascena (L.), B: Anemone hupehensis (É.Lemoine), C: Zinnia elegans (Jacq.), D: Lamprocapnos spectabilis (L.), E: Geranium spec., F: Clematis spec., G: Antirrhinum majus (L.), H: Rudbeckia spec. (C) Hannah Reininghaus. 
Plant richness and flower cover can positively influence colony performance but their movement may be restricted due to fragmented farmland areas or anthropogenic barriers in urban environments (Bhattacharya et al. 2002). In heterogeneous landscapes, urban areas can support at least as much pollinator diversity as the surrounding farmland (Fig. 1; Baldock et al. 2015, Sirohi et al. 2015). In farmland areas more syrphid flies can be found as their larvae feed on aphids in managed fields. Syrphid flies are therefore not linked to semi-natural habitat availability (Jauker et al. 2009) and are an important pollinator in areas unsuitable for wild bees. In contrast, wild bees need floral resources and semi-natural habitats and are therefore present in flower rich urban green spaces (Baldock et al. 2015). Both pollinator groups may act as important pollinators in different landscapes (Orford et al. 2015).

\section{Study region}

The studies presented in this thesis were conducted from April to October in two consecutive years, 2014 and 2015, in central Europe. The study area consists mainly of farmland, pastures, forest patches and scattered urban areas (Fig. 3). The study area was placed around Göttingen, within approximately a $30 \mathrm{~km}$ radius, and sites used were private gardens, parks or pastures in urban areas or grassy margins along field borders in farmland areas. Garden sites consisted of diverse structures, such as lawn, trees, flower beds and vegetable patches (Loram et al. 2008). Parks contained lawn, a few hedges and trees but pastures were dominated by grass. Sites were selected based on the amount of urban area and farmland within a $500 \mathrm{~m}$ buffer in the surroundings. I sampled and observed arthropod communities in a total of over 60 sites around Göttingen (Fig. 4; central Germany). In 2014 I conducted experiments in gardens and pastures in settlements with increasing size and compared arthropod communities at the edge and the centre of each settlement. Pollinator abundance and movement was examined along an farmland to urban gradient 


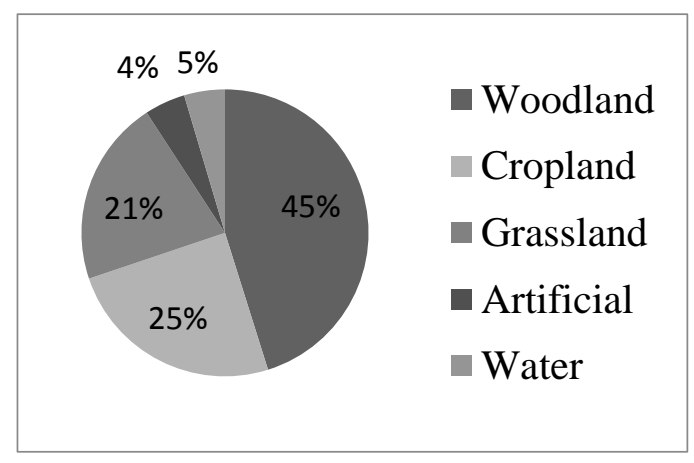

Fig. 3: Land cover of Europe altered by Eurostat-Statistics (2012).

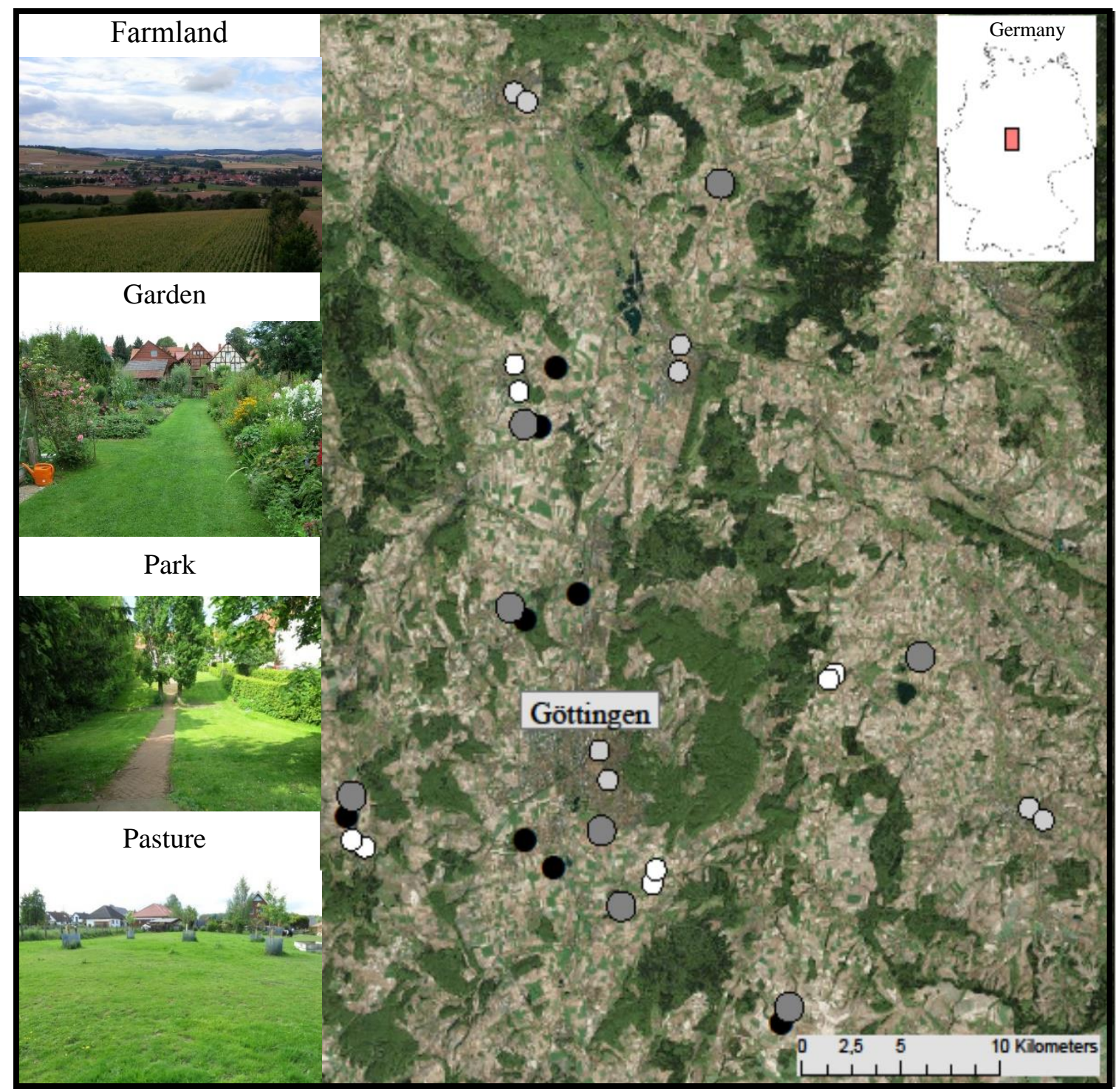

Fig. 4: Study system in Germany in the surroundings of Göttingen (30 km radius). The landscape consists of farmland, pastures and forest patches scattered by urban area. I studied arthropod communities in gardens, parks and pastures of cities (light grey), villages (white), farmhouses (dark grey) and farmland sites (black).

(C) Hannah Reininghaus. 


\section{Hypotheses}

Different patterns influence arthropod community composition, arthropod diversity and movement on the local and landscape scales. Most studies on urban arthropod diversity so far have been conducted along farmland-urban gradients in only a single urban area (Egerer et al. 2017). By contrast, the studies presented in this thesis focused on farmland to urban gradients replicated at the landscape scale to gain general insights in arthropod diversity and movement within an urbanised landscape.

It is hypothesised that increasing urbanisation negatively affects the foraging distance of bumblebees due to the high cover of human structures, such as roads and railroads in urban areas, and that these may restrict foraging behaviour of bumblebees (Bhattacharya et al. 2002). Furthermore, local plant species richness and flower cover in urban gardens may provide habitat for bumblebees, therefore bumblebee movement will be concentrated in urban gardens with high resource availability (Fig. 5).

I further hypothesise that the arthropod diversity in urban green spaces increases with increasing plant diversity as different arthropod groups benefit from high plant flower cover and richness.

I expect that urbanisation will affect arthropod species composition in green spaces in different sized urban areas. Arthropod species identity may change between small and large settlements. This could be due to the isolation of green spaces in the centre of large settlements, whereas green spaces in small settlements could be more affected by spill over from adjacent farmland.
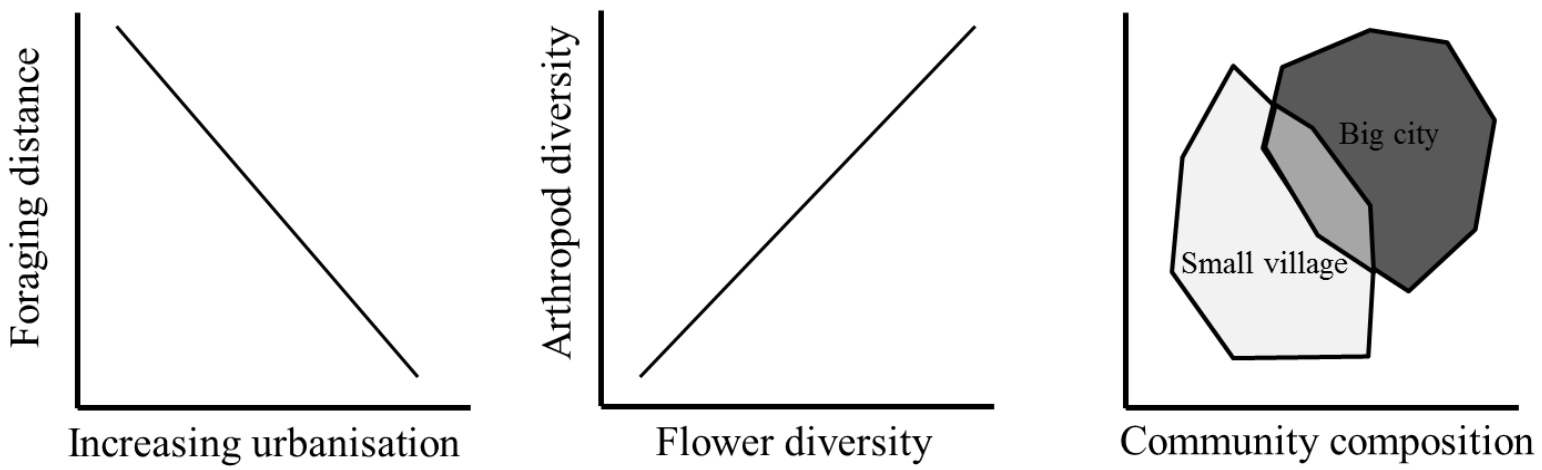

Fig. 5: Hypotheses graphs. Increasing urbanisation has a negative effect on arthropod forage distance. Flower diversity in urban green spaces has a positive effect on arthropod diversity. The arthropod community composition between small and large settlements is different. 


\section{Chapter Outline}

Chapter 2: Reversed Importance of Local vs. Landscape Flower Resources for Bumblebee Foraging and Colony Performance along Farmland-Urban Gradients

I studied whether local floral resources in gardens and resources throughout the landscape affect bumblebee foraging behaviour and colony performance along a farmland-urban gradient. I conducted a marking and tracking experiment using fluorescent dye with bumblebee colonies to assess their short-range movement and I employed pollen analysis to study long-distance movement. Bumblebee colonies were setup along a contrasting farmland to urban gradient in settlements of increasing size. Bumblebee colony performance was measured by calculating weight gain. B. terrestris workers visited plants providing floral resources in the direct surroundings of the colonies. Furthermore, the workers foraged in greater distances to their colonies, if the mass flowering crop oilseed rape was flowering. My results suggest that bumblebee colonies benefit from flower resources at the local and landscape scale. It indicates that urban green spaces can serve as reservoirs for bumblebees and it is crucial in the time of biodiversity loss to raise the attention of urban planners for the importance of flower rich areas for pollinators in urban areas.

\section{Chapter 3: Season and Flower Composition affect Bumblebee Foraging Behaviour across a Farmland-Urban Gradient}

I investigated whether local flower resources or landscape resources affect bumblebee foraging behaviour and resource preference along a farmland-urban gradient. I tested if local plant richness and plant identity affects forage distance of bumblebee workers. I compared pollen collected from bumblebee workers to examine which plant families are usually collected. Plant family richness was much higher in gardens and differed compositionally from farmland sites. Bumblebee workers collected preferentially the same plant families in farmland sites and urban areas. These plant families had high flower cover and high amounts of nectar and pollen resources. In contrast, plant families bred as ornamental plants for gardens with low nectar and pollen resources were not visited by bumblebees. Bumblebees showed no differences in plant family preference along the urbanisation gradient. This study shows that gardeners, who want to plant wildlife friendly gardens, should be encouraged to grow these specific plant families. Furthermore, for the maintenance and restoration of good quality habitats in farmland, 
my results indicate, which plant families are utilised by bumblebees and should be taken into account when planting flower strips.

\section{Chapter 4: Plant-Pollinator Interactions along an Urbanisation Gradient from Cities and Villages to Farmland Landscapes}

My aim was to test how pollinator communities change across an urbanisation gradient comparing farmland with village and city gardens, and how plant-pollinator network structure is altered in these different landscapes. I disentangled the influence of local plant communities and landscape context on pollinator communities by conducting pollinator observations on experimental plant patches along the urbanisation gradient. With increasing urbanisation the richness of pollinators and the plant-pollinator network stability decreased, although local plant richness simultaneously increased. The high plant species richness in urban gardens supported number of flower visits of pollinators, whereas plants in farmland sites had the lowest visitation rate and plants in village gardens being intermediate. My research found that urban and farmland landscapes support different pollinator communities and that the interface between the two extremes is of particular importance as it supports a complementary pollinator community.

\section{Chapter 5: Arthropod Diversity across an Urbanisation Gradient of City Size}

I investigated how local or landscape scale variables affected structure and diversity of arthropod communities in urban areas. The influence on arthropod communities of the urban landscape was tested for the first time along an urbanisation gradient of city size from small villages to a mid-size city as well as the position in a city (edge or centre). I also investigated the influence of local scale variables, green area type and plant species richness, on arthropod communities. The arthropods sampled were Coleoptera, Araneae and Hymenoptera. I found that Coleoptera community structure and composition changed depending on the local surrounding (position in the settlement and green space type) and the amount of urban area (landscape effect). Hymenoptera and Araneae were influenced predominantly by the local surroundings. The results show different responses of arthropod communities to urbanisation on local and landscape scales. This study is the first that investigates the importance of urban size and position within an urban area and may support appropriate urban planning to promote biodiversity in urban areas. 


\section{References}

Ahrne, K., J. Bengtsson, and T. Elmqvist. 2009. Bumble Bees ( Bombus spp ) along a Gradient of Increasing Urbanization. PloS ONE 4.

Allen-Wardell, G., and Others. 1998. The potential consequences of pollinator declines on the conservation of biodiversity and stability of fruit crop yields. The Forgotten Pollinators Campaign 12:8-17.

Baldock, K. C. R., M. A. Goddard, D. M. Hicks, E. Kunin, N. Mitschunas, L. M. Osgathorpe, S. G. Potts, K. M. Robertson, A. V Scott, G. N. Stone, I. P. Vaughan, and J. Memmott. 2015. Where is the UK's pollinator biodiversity? The importance of urban areas for flower- visiting insects. Proceedings of the Royal Society of Britain 282:20141849

Bates, A. J., J. P. Sadler, A. J. Fairbrass, S. J. Falk, J. D. Hale, and T. J. Matthews. 2011. Changing bee and hoverfly pollinator assemblages along an urban-rural gradient. PloS ONE 6:e23459.

Bhattacharya, M., R. B. Primack, and J. Gerwein. 2002. Are roads and railroads barriers to bumblebee movement in a temperate suburban conservation area ? Biological Conservation 109:37-45.

Biesmeijer, J. C., S. P. M. Roberts, M. Reemer, R. Ohlemüller, M. Edwards, T. Peeters, A. P. Schaffers, S. G. Potts, R. Kleukers, C. D. Thomas, J. Settele, and W. E. Kunin. 2006. Parallel Declines in Pollinators and Insect-Pollinated Plants in Britain and the Netherlands. Science 313:351-354.

Bourne, L. S., and J. W. Simmons. 1982. Defining the area of interest: definition of the city, metropolitan areas and extended urban regions. In Internal structure of the city. (L. S. Bourne, ed.)Oxford University Press, New York 57-72.

Carvell, C., W. R. Meek, R. F. Pywell, D. Goulson, and M. Nowakowski. 2007. Comparing the efficacy of agri-environment schemes to enhance bumble bee abundance and diversity on arable field margins. Journal of Applied Ecology 44:29-40.

Chapman, R. E., J. Wang, and A. F. G. Bourke. 2003. Genetic analysis of spatial foraging patterns and resource sharing in bumble bee pollinators. Molecular ecology 12:2801-2808.

Corbet, S., I. Williams, and J. Osborne. 1991. Bees and the pollination of crops and wild flowers in the European Community. Bee World 72:47-59.

Ebeling, A., A. M. Klein, J. Schumacher, W. W. Weisser, and T. Tscharntke. 2008. How does plant richness affect pollinator richness and temporal stability of flower visits? Oikos 117:1808-1815.

Egerer, M. H., C. Arel, M. D. Otoshi, R. D. Quistberg, P. Bichier, and S. M. Philpott. 2017. Urban arthropods respond variably to changes in landscape context and spatial scale. Journal of Urban Ecology:1-10.

Fetridge, E. D., J. S. Ascher, and G. A. Langellotto. 2008. The Bee Fauna of Residential Gardens in a Suburb of New York City (Hymenoptera: Apoidea). Annals of the Entomological Society of America 101:1067-1077.

Fussell, M., and S. A. Corbet. 1992. Flower usage by bumble-bees: a basis for forage plant management. Journal of Applied Entomology 29:451-465.

Gleason, H. A. 1926. The Individual Concept of Plant Assosciation. Bulletin of the Torry Botanical Club 53:7-26.

Godfray, H. C. J., J. R. Beddington, I. R. Crute, L. Haddad, D. Lawrence, J. F. Muir, J. Pretty, S. Robinson, S. M. Thomas, and C. Toulmin. 2010. Food Security: The Challenge of Feeding 9 Billion People. Science 327:812-818. 
Goulson, D., M. E. Hanley, B. Darvill, J. S. Ellis, and M. E. Knight. 2005. Causes of rarity in bumblebees. Biological Conservation 122:1-8.

Grimm, N. B., S. H. Faeth, N. E. Golubiewski, C. L. Redman, J. Wu, X. Bai, and J. M. Briggs. 2008. Global Change and the Ecology of Cities. Science 319:756-760.

Holzschuh, A., M. Dainese, J. P. González-Varo, S. Mudri-Stojnić, V. Riedinger, M. Rundlöf, J. Scheper, J. B. Wickens, R. Bommarco, D. Kleijn, S. G. Potts, S. P. M. Roberts, H. G. Smith, M. Vilá, A. Vujić, and I. Steffen-Dewenter. 2016. Massflowering crops dilute pollinator abundance in agricultural landscapes across Europe. Ecology letters 19:1228-1236.

Jauker, F., T. Diekötter, F. Schwarzbach, and V. Wolters. 2009. Pollinator dispersal in an agricultural matrix: Opposing responses of wild bees and hoverflies to landscape structure and distance from main habitat. Landscape Ecology 24:547555.

Klein, A.-M., B. E. Vaissiere, J. H. Cane, I. Steffan-Dewenter, S. A. Cunningham, C. Kremen, and T. Tscharntke. 2007. Importance of pollinators in changing landscapes for world crops. Proceedings of the Royal Society B: Biological Sciences 274:303-313.

Kremen, C., N. M. Williams, and R. W. Thorp. 2002. Crop pollination from native bees at risk from agricultural intensification. PNAS 99:16812-16816.

Loram, A., K. Thompson, P. H. Warren, and K. J. Gaston. 2008. Urban domestic gardens ( XII ): The richness and composition of the flora in five UK cities 321330.

Mata, L., C. G. Threlfall, N. S. G. Williams, A. K. Hahs, M. Malipatil, N. E. Stork, and S. J. Livesley. 2017. Conserving herbivorous and predatory insects in urban green spaces. Scientific Reports 7:40970.

McDonnell, M. J., and A. K. Hahs. 2008. The use of gradient analysis studies in advancing our understanding of the ecology of urbanizing landscapes: Current status and future directions. Landscape Ecology 23:1143-1155.

McKinney, M. L. 2002. Urbanization, Biodiversity, and Conservation. BioScience 52.

McKinney, M. L. 2008. Effects of urbanization on species richness: A review of plants and animals. Urban Ecosystems 11:161-176.

Öckinger, E., and H. E. Smith. 2007. Semi-natural grasslands as population sources for pollinating insects in agricultural landscapes. Journal of Applied Ecology 44:5059.

Ollerton, J., H. Erenler, M. Edwards, and R. Crockett. 2014. Pollinator declines. Extinctions of aculeate pollinators in Britain and the role of large-scale agricultural changes. Science 346:1360-2.

Orford, K. A., I. P. Vaughan, and J. Memmott. 2015. The forgotten flies: the importance of non-syrphid Diptera as pollinators. Proceedings. Biological sciences / The Royal Society 282:20142934.

Pereira-Peixoto, M. H., G. Pufal, C. F. Martins, and A.-M. Klein. 2014. Spillover of trap-nesting bees and wasps in an urban-rural interface. Journal of Insect Conservation.

Potts, S. G., J. C. Biesmeijer, C. Kremen, P. Neumann, O. Schweiger, and W. E. Kunin. 2010. Global pollinator declines: Trends, impacts and drivers. Trends in Ecology and Evolution 25:345-353.

Pyšek, P. 1998. Alien and native species in Central European urban floras: a quantitative comparison. Journal of Biogeography 25:155-163.

Redhead, J. W., S. Dreier, A. F. G. Bourke, M. S. Heard, W. C. Jordan, S. Sumner, J. Wang, and C. Carvell. 2016. Effects of habitat composition and landscape structure 
on worker foraging distances of five bumble bee species. Ecological Applications 26:726-739.

Sirohi, M. H., J. Jackson, M. Edwards, and J. Ollerton. 2015. Diversity and abundance of solitary and primitively eusocial bees in an urban centre: a case study from Northampton (England). Journal of Insect Conservation 19:487-500.

Tscharntke, T., A. M. Klein, A. Kruess, I. Steffan-Dewenter, and C. Thies. 2005. Landscape perspectives on agricultural intensification and biodiversity - ecosystem service management. Ecology Letters 8:857-874.

Turrini, T., and E. Knop. 2015. A landscape ecology approach identifies important drivers of urban biodiversity. Global change biology.

United Nations. 2014. World Urbanisation Prospects: The 2014 Revision: Highlights. United Nations Department of Economic and Social Affairs, Population Division, New York, United Nations.

Vergnes, A., I. Le Viol, and P. Clergeau. 2012. Green corridors in urban landscapes affect the arthropod communities of domestic gardens. Biological Conservation 145:171-178.

Westphal, C., I. Steffan-Dewenter, and T. Tscharntke. 2003. Mass flowering crops enhance pollinator densities at a landscape scale. Ecology Letters 6:961-965.

Westphal, C., I. Steffan-Dewenter, and T. Tscharntke. 2006a. Foraging trip duration of bumblebees in relation to landscape-wide resource availability. Ecological Entomology 31:389-394.

Westphal, C., I. Steffan-Dewenter, and T. Tscharntke. 2006b. Bumblebees experience landscapes at different spatial scales: Possible implications for coexistence. Oecologia 149:289-300.

Westphal, C., I. Steffan-Dewenter, and T. Tscharntke. 2009. Mass flowering oilseed rape improves early colony growth but not sexual reproduction of bumblebees. Journal of Applied Ecology 46:187-193.

Westrich, P. 1996. Habitat requirements of central European bees and the problems of partial habitats. Pages 2-15 The Conservation of Bees. Academic Press, London.

Winfree, R. 2010. The conservation and restoration of wild bees. Annals of the New York Academy of Sciences 1195:169-97. 


\section{Chapter 2}

\section{Reversed Importance of Local vs. Landscape Flower Resources for Bumblebee Foraging and Colony Performance along Farmland- Urban Gradients}

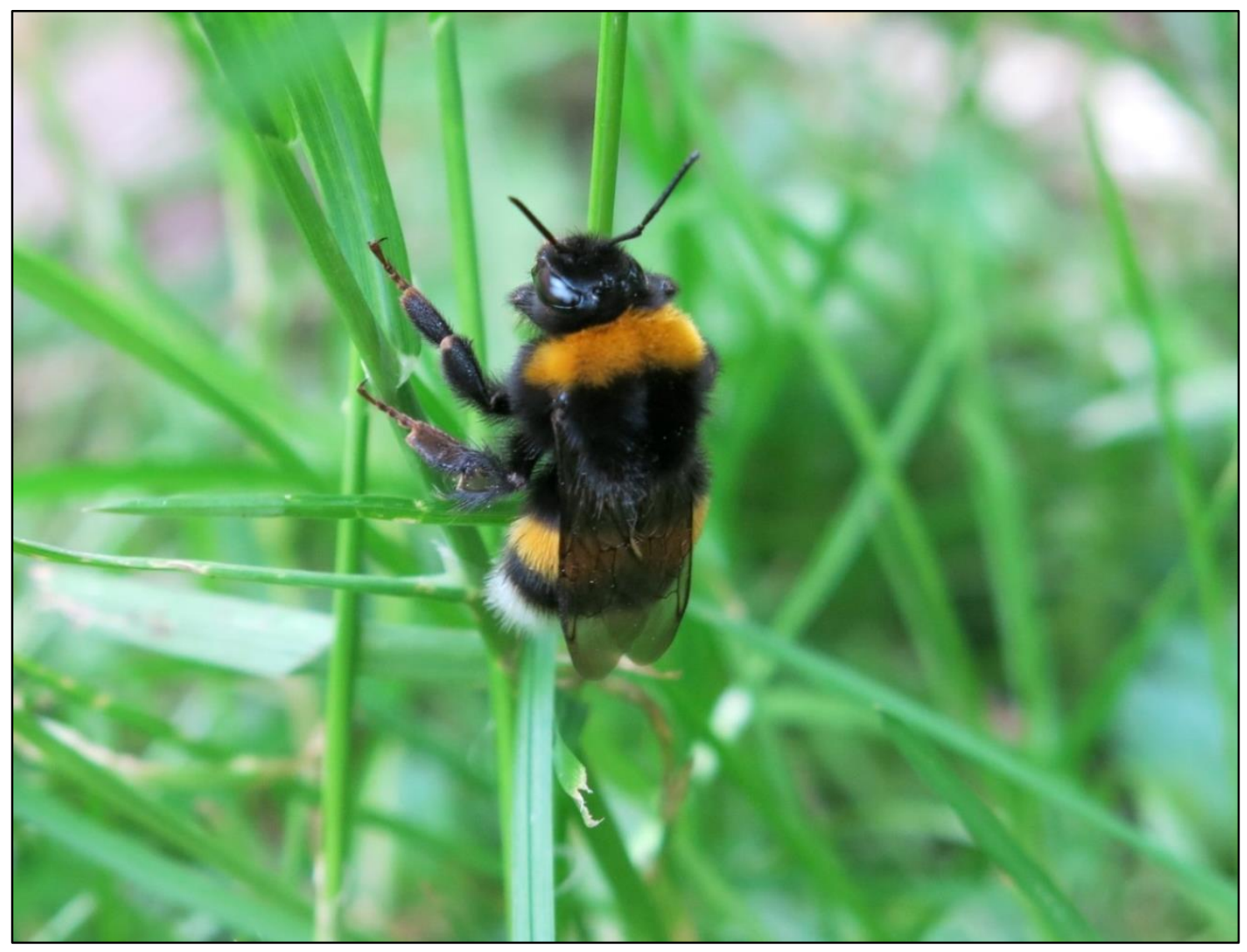

Bombus terrestris (L.) (May 2015, (C Kristy Udy)

Authors:

Hannah Reininghaus, Kristy Leah Udy, Erin Treanore, 


\begin{abstract}
Increasing urbanisation may lead to declines in pollinator biodiversity and associated pollination services. Here, we study how floral resources at local and landscape scales affect bumblebee foraging and colony performance along a farmland-urban gradient. Bumblebee colonies were setup along a contrasting farmland to urban gradient in settlements of increasing size. We conducted a marking tracking experiment with fluorescent dye to determine how bumblebees forage in the local surroundings of their colonies and took pollen samples to investigate bumblebee long-range foraging behaviour. From farmland to farmhouses, village gardens and city gardens, distance to mass-flowering crops (i.e. oilseed rape) increased and oilseed rape pollen sampled by bumblebees decreased, from $19 \%$ to just $2 \%$. Instead, bumblebees in village and city gardens sampled more pollen, exploiting the high local plant diversity. This counterbalancing resource use may explain why weight of bumblebee colonies did not differ from farmland to cities. In conclusion, the relative importance of garden resources and landscape resources for bumblebee performance reversed along the farmland-urban gradient, which needs to be taken into account for pollinator management. It is crucial in the time of biodiversity loss to raise the attention for the importance of flower rich areas for pollinators in urban and farmland areas.
\end{abstract}

Keywords: Apidae; Bombus terrestris; urbanisation; city size; resources; bee decline; pollinator; gradient; fluorescent dye; movement. 


\section{Introduction}

Urbanisation is a major threat to natural habitats and associated biodiversity in anthropogenic landscapes (Goulson et al. 2005, Biesmeijer et al. 2006, Potts et al. 2010). The increase of urban areas results in landscape modification through the conversion of crop lands, pastures and natural habitats into built-up areas and urban and suburban environments (Grimm et al. 2008). However, urban areas may serve as refuges for pollinator communities, when agricultural landscapes are dominated by farmland, as long as sufficient green areas are available that can support high pollinator species richness (Goddard et al. 2010, Williams et al. 2015, Hall et al. 2016).

Most urban ecology studies sample along a farmland to urban gradient in a single city where they focus on natural habitats within the farmland landscape or on biodiversity conservation (Egerer et al. 2017). To increase our understanding of how urbanisation affects biodiversity services, broad-scale, highly replicated studies of resource use in different settlements with increasing amount of urbanisation will be beneficial. As little is known about resource use of pollinators in response to contrasting amounts of farmland and urban area, we focus here on bumblebees and how they are influenced by landscape-wide mass flowering crop or local garden flower resources. Although the flowering period of mass-flowering crops is limited, they may positively affect bumblebee colony growth as they provide additional foraging habitat and resources (Westphal et al. 2003, 2009).

Bumblebees (Bombus spp.) are important pollinators of wild plants and provide pollination services to crop plants (Velthuis and van Doorn 2006). Yet, both their nesting sites and food resources currently decline at alarming rates in response to anthropogenic pressures, such as habitat conversion to farmland or urbanisation. Such loss of habitat and flowering plant resources may contribute to overall pollinator declines across Europe (Potts et al. 2010, Winfree 2010), with potentially negative impacts on pollination services (Allen-Wardell and Others 1998, Biesmeijer et al. 2006, Klein et al. 2007)

Bumblebees are highly mobile pollinators and forage both in the direct surroundings of their colony and at the landscape scale (Chapman et al. 2003, Westphal et al. 2006a, 2006b). The foraging distance of Bombus terrestris workers is highly variable and ranges from a few meters around the colony to $2.8 \mathrm{~km}$ (Walther-Hellwig and Frankl 2000, Redhead et al. 2016), but fragmented green spaces and barriers in 
cities can restrict bumblebee movement through the landscape (Bhattacharya et al. 2002). Collecting pollen loads is an established method to test bumblebee flight distance and resource preference (Beil et al. 2008, Kleijn and Raemakers 2008). Another way to study bumblebee flight distance and short-distance forage behaviour is by marking individuals with fluorescent dye (Osborne et al. 2008).

In this study, we assessed whether bumblebees in urban areas forage only locally in gardens or search for major floral resources throughout the landscape. Additionally, we tested whether this foraging behaviour depends on distance to farmland areas. Bumblebee colonies were setup along a contrasting gradient of farmland to urban in settlements of increasing size. This gradient included farmland, farmhouse gardens, village gardens and city gardens. To test whether bumblebees forage in their local surroundings, we experimentally marked bumblebees with fluorescent dye. Long-range movement was studied by analysing the proportion of oilseed rape (OSR) pollen in pollen samples and this was tested against the distance to local mass-flowering crop fields. Bumblebee colony performance was measured by calculating weight gain (Westphal et al. 2009).

\section{Material and Methods}

\section{Study sites}

The study was conducted in May 2015 in 32 sites within a radius of approximately $30 \mathrm{~km}$ from the city of Göttingen (central Germany). The study area consisted mainly of crop fields, permanent pastures and interspersed by forest patches and urban areas. The study sites were selected based on the amount of urban area and farmland area within a radius of $500 \mathrm{~m}$. We used ArcGIS 10.4.1 (ESRI) to calculate the size of each settlement in the surroundings of Göttingen (within $30 \mathrm{~km}$ ). We selected randomly four small villages (around $0.7 \mathrm{~km}^{2}$ size, Diemarden, Dransfeld, Moringen and Ebergötzen) and four cites (up to $16 \mathrm{~km}^{2}$, Duderstadt, Einbeck, Göttingen and Northeim; Table S1). The farmhouse gardens and farmland sites were selected by not more than $10 \%$ urban area in a radius of $500 \mathrm{~m}$ (Fig. 1). Within the cities and villages we selected gardens with a size of at least $1000 \mathrm{~m}^{2}$. In cities, gardens had just urban area within a radius of $500 \mathrm{~m}$, whereas village gardens contained 50\% urban area and 50\% farmland in a radius of $500 \mathrm{~m}$. The selected sites were separated by at least $500 \mathrm{~m}$. In total we selected eight city gardens, eight village gardens, eight farmhouse gardens and eight farmland sites. 


\section{Bumblebee colonies}

Bombus terrestris colonies were purchased from Biobest (Westerlo, Belgium). Bumblebee colonies were placed at field sites for three weeks from May $6^{\text {th }}$ to May $28^{\text {th }}$, 2015. The colonies were setup in semi shady areas and were sheltered from the sun and rain by a wooden roof and secured to the ground with nails. One colony from the farmland landscape was vandalised, therefore it was excluded from analysis. Before colonies were collected, we closed the exit for $24 \mathrm{~h}$ to prevent bumblebees from exiting the hive but left the entrance open so that foraging bumblebees could enter the hive. When we collected the colonies, we closed them completely and froze them in a cool chamber. We weighed the bumblebee colonies before and after they had been setup at the field sites to calculate weight gain as a measure of bumblebee colony performance. We setup eight bumblebee colonies in farmland sites, farmhouse gardens, villages and cities. 


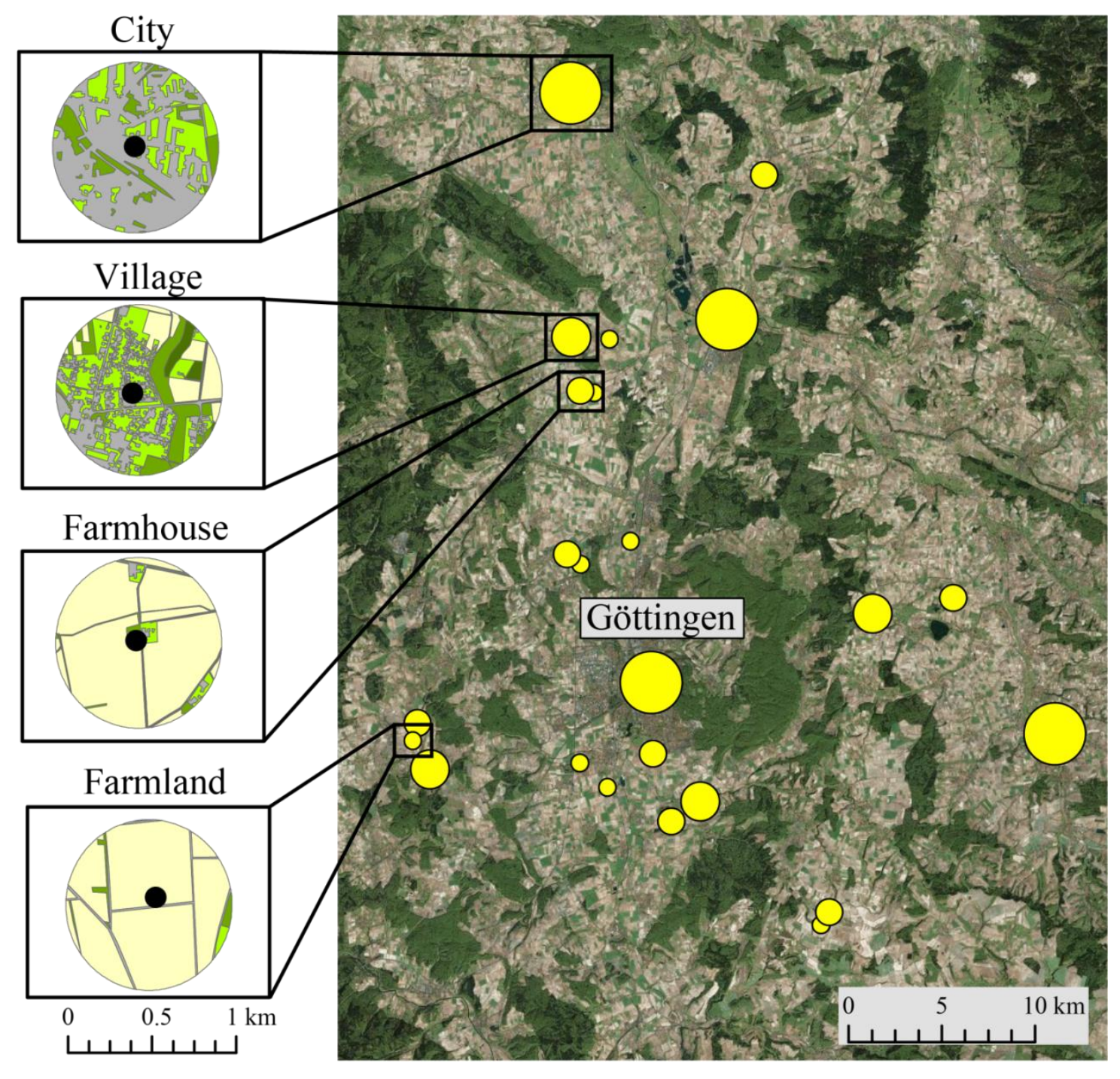

$\square$ Farmland $\square$ Forest $\square$ Garden $\square$ Green space $\square$ Urban

Fig. 1: Map of 32 different sized urban areas, size of circle indicates the different landscape type from farmland to farmhouse and village to city. Insets show examples of amount of urban area and farmland in a $500 \mathrm{~m}$ radius.

\section{Movement Experiment}

To measure bumblebees' short-range movement, we marked individuals using fluorescent dye. We placed a teaspoon of fluorescent dye powder (Dane Colour UK Ltd: Swada brand) in the exit of each colony in the early morning between 6 and $7 \mathrm{am}$. Bumblebees exiting the colony were thereby coated with dye. We visited sites again the same night to remove the dye from the colonies and to check for fluorescent dye on flowers within a radius of approximately $20 \mathrm{~m}$ from the colonies. We searched for fluorescent dye using UV-torches (Solarforce L2P HighEnd) and mapped every plant that was visited and covered with dye powder. The experiment was conducted once per 
colony. All flowering plant species per site were mapped within a radius of $20 \mathrm{~m}$ around each colony and we estimated the flower cover per site and calculated the species richness of flowering plants.

We used ArcGIS (v10.4.1, ESRI) to calculate the amount of urban area (streets, buildings), green area (pastures, grassland, parks and hedges), gardens, forest, water bodies and farmland within a $500 \mathrm{~m}$ radius around the bumblebee colonies. We also measured the distance from each colony to the next OSR field and calculated the amount of OSR fields in the bumblebee colonies surroundings.

To measure long-range movement of the bumblebees, we collected pollen samples from the colony. We used the Acetolysis method to prepare pollen samples from wax and honey (Table S2) and counted 100 pollen grains per colony and calculated the proportion of oilseed rape pollen per colony.

\section{Statistics}

All analyses and data visualization was performed in R 3.3.0 (R Core Team 2016). To test which local and landscape variables affected bumblebee colony growth and long and short-range foraging, we used mixed effects models with location of the bumblebee colonies (if possible) as a random effect to control for spatial non-independence. All proportion and percentage variables (percentage flower cover, percentage urban area, proportion of OSR, proportion of OSR pollen) were transformed using the logit transformation (Fox and Weisberg 2011) and then tested against influence of increasing urbanisation using linear mixed-effects models fit by penalized quasi-likelihood (Pinheiro et al. 2016). The influence of increasing urbanisation on plant richness and the number of visited plants (fluorescent dye experiment) was investigated using generalized linear mixed-effects models with negative binomial errors (Bates et al. 2015, Venables and Ripley 2002) and distance to the next OSR field was investigated using a linear mixed effects model. Generalized linear mixed-effects models with Gamma errors were used to analyse colony weight gain in response to different landscape types and local and landscape variables. All models were simplified using AICc. 


\section{Results}

There were significant differences in the proportion of urban area between the experimental sites in the surroundings $(500 \mathrm{~m}$ ) of the colonies (Chi-square $=370.91$, d.f. $=3, \mathrm{p}<0.001)$. Farmland contained the lowest proportion of urban area $(\mathrm{n}=8$, mean $\pm \mathrm{SD}, \quad 3.85 \pm 2.14 \%$; Fig. S1), farmhouse and village gardens comprised intermediate amounts of urban area (villages: $\mathrm{n}=8$, mean $\pm \mathrm{SD}, 29.27 \pm 12.81 \%$, farmhouses: $n=8$, mean $\pm S D, 4.64 \pm 2.38 \%$ ) and cities had the highest amount of urban area (Fig. S1, $\mathrm{n}=8$, mean $\pm \mathrm{SD}, 59.50 \pm 0.86 \%$ ). The amount of crops in the surroundings showed the opposite gradient (high amount of arable in farmland sites compared to city sites with very little crop land in the surroundings; within a $500 \mathrm{~m}$ radius).

The distance to the next OSR field increased from farmland sites to city sites (Chi-square $=18.078$, d.f. $=3, \mathrm{p}<0.001)$. The largest distance was more than $2 \mathrm{~km}$ from a city garden to the next OSR field. Additionally, the amount of OSR fields in the surrounding landscape decreased significantly from farmland sites to city sites (Chisquare $=15.334$, d.f. $=3, p=0.002$, Fig. 2 C, D).

Local plant richness was higher in urban sites compared to farmland sites and flowering plant cover increased with amount of urban area (Chi-square $=2.757$, d.f. $=3$, p = 0.431; Fig. 2 A and B). 

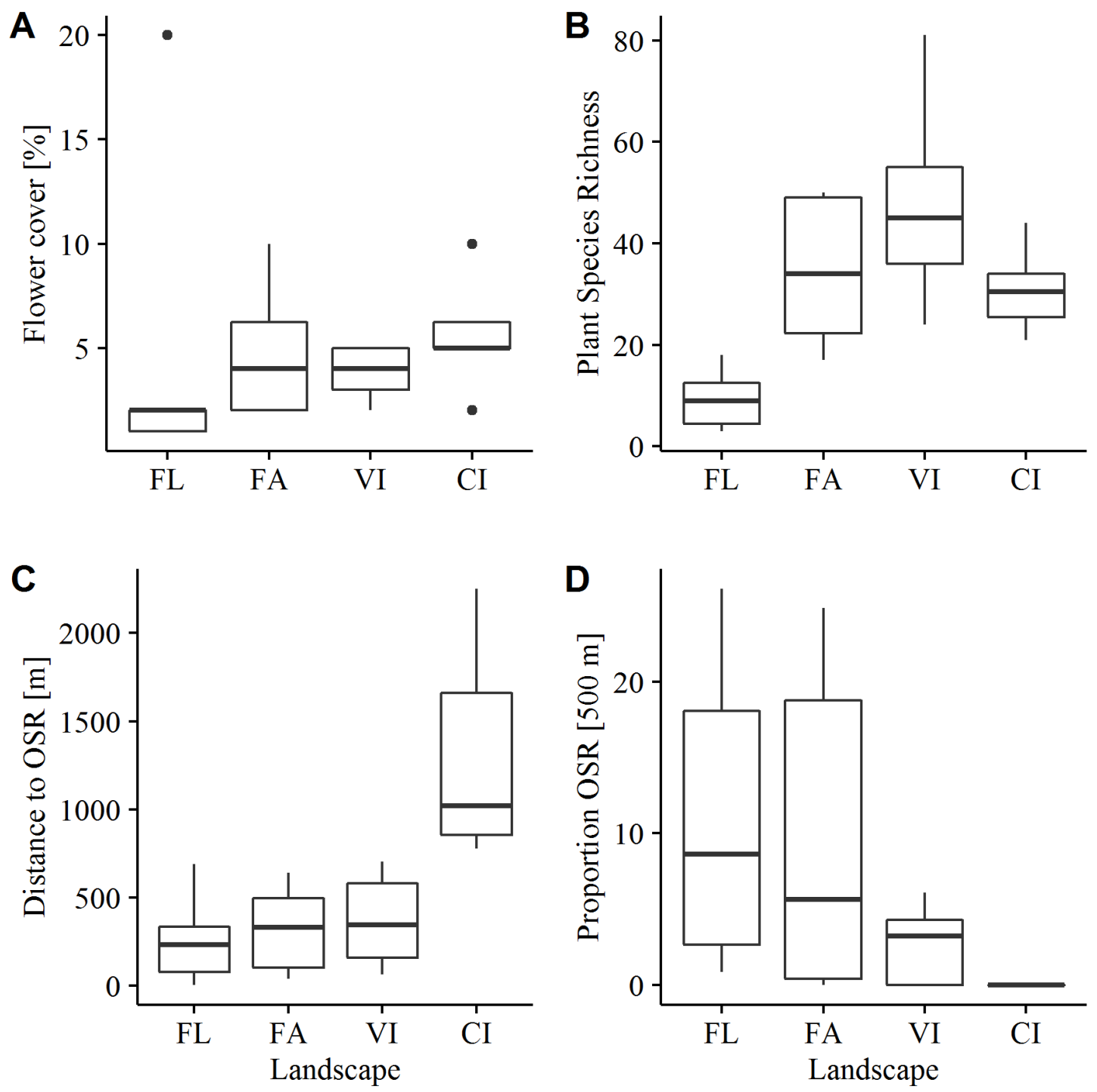

Fig. 2: Landscape type in relation to floral resources. A and B: local plant communities, $\mathrm{C}$ : distance to the next OSR field, D: amount of OSR in the landscape (within a radius of $500 \mathrm{~m}) . \mathrm{FL}=$ Farmland, $\mathrm{n}=7 ; \mathrm{FA}=$ Farmhouse, $\mathrm{n}=8$; VI $=$ Village $\mathrm{n}=8 ; \mathrm{CI}=$ City, $\mathrm{n}=8$.

During our short-range movement experiment we found fluorescent dye on a total of 65 flowering plant species. The number of plant species visited in the different sites increased with the number of flowering plant species in the local surroundings (Chisquare $=10.335$, d.f. $=1, p=0.001$; Fig. 3 ). In farmland sites the richness of flowering plants was much lower compared to the other study systems (Chi-square $=63.744$, d.f. $=3, \mathrm{p}<0.001)$. 


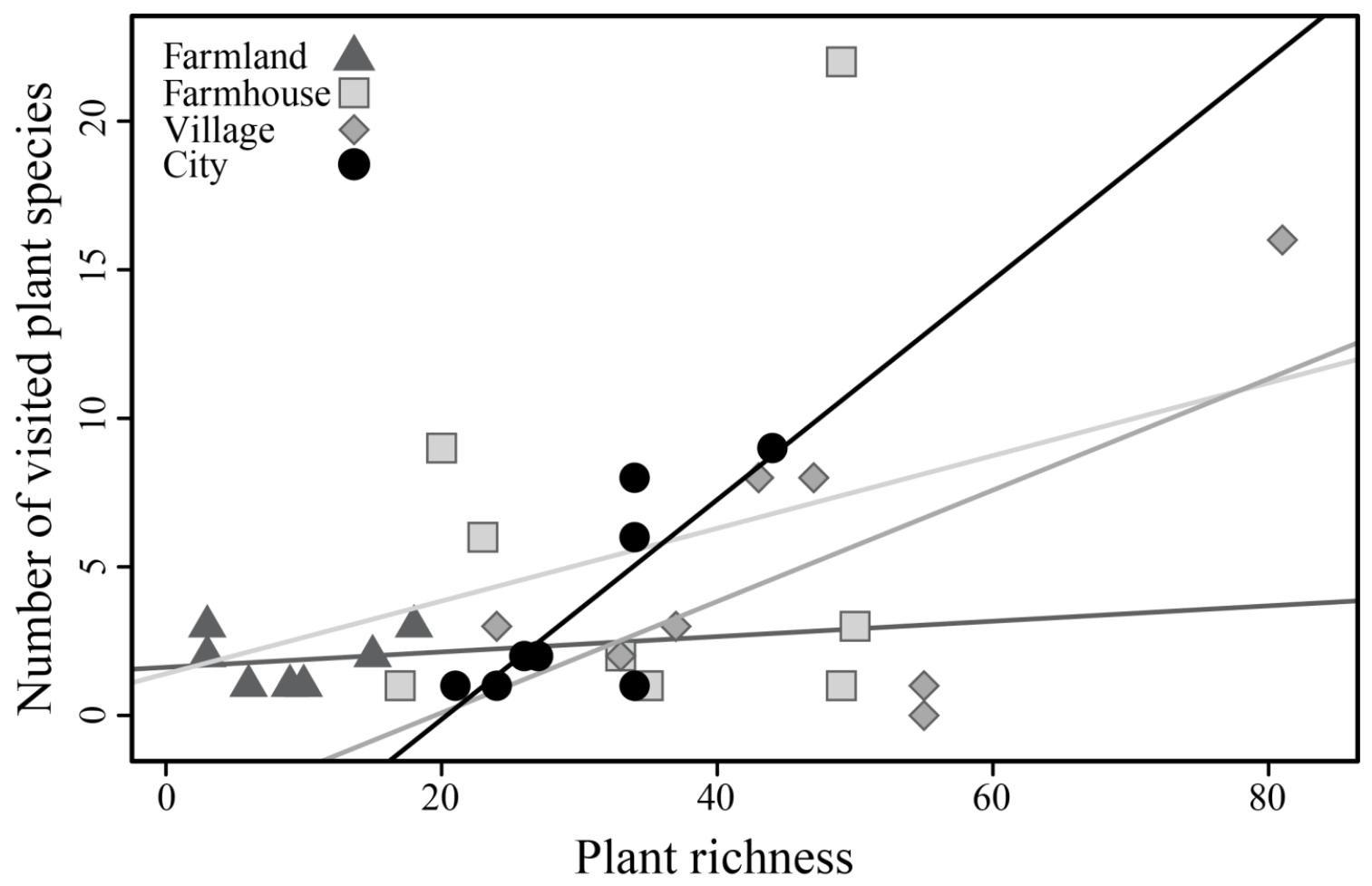

Fig. 3: Fluorescent dye experiment and number of visited plant species per site against plant richness per site.

Bumblebee colonies collected less OSR pollen with increasing distance to the next OSR field (Chi-square $=11.846$, d.f. $=1, \mathrm{p}<0.001$ ) and decreasing amount of OSR fields (Chi-square $=4.779$, d.f. $=1, p=0.029$ ). Bumblebee colonies from farmland sites collected around $19 \% \pm 8 \mathrm{SE}$ of OSR pollen, whereas urban colonies collected only 2\% 20.4 SE (Fig. 4, Table S3). Distance to the next OSR field increased with increasing urbanisation. Additionally, the proportion of OSR fields decreased in the surroundings $(500 \mathrm{~m})$ with increasing urbanisation and the proportion of OSR pollen collected decreased, too. In village gardens, distance to the next OSR field is the same as in farmland (Fig. 2 C), but the colonies in village gardens collected less OSR pollen than the colonies in farmland (Farmland $=19 \% \pm 8$ SE, Village $=5 \% \pm 2$ SE; Fig. 4). Colonies in farmhouse gardens collected $12 \% \pm 3$ SE of OSR pollen. 


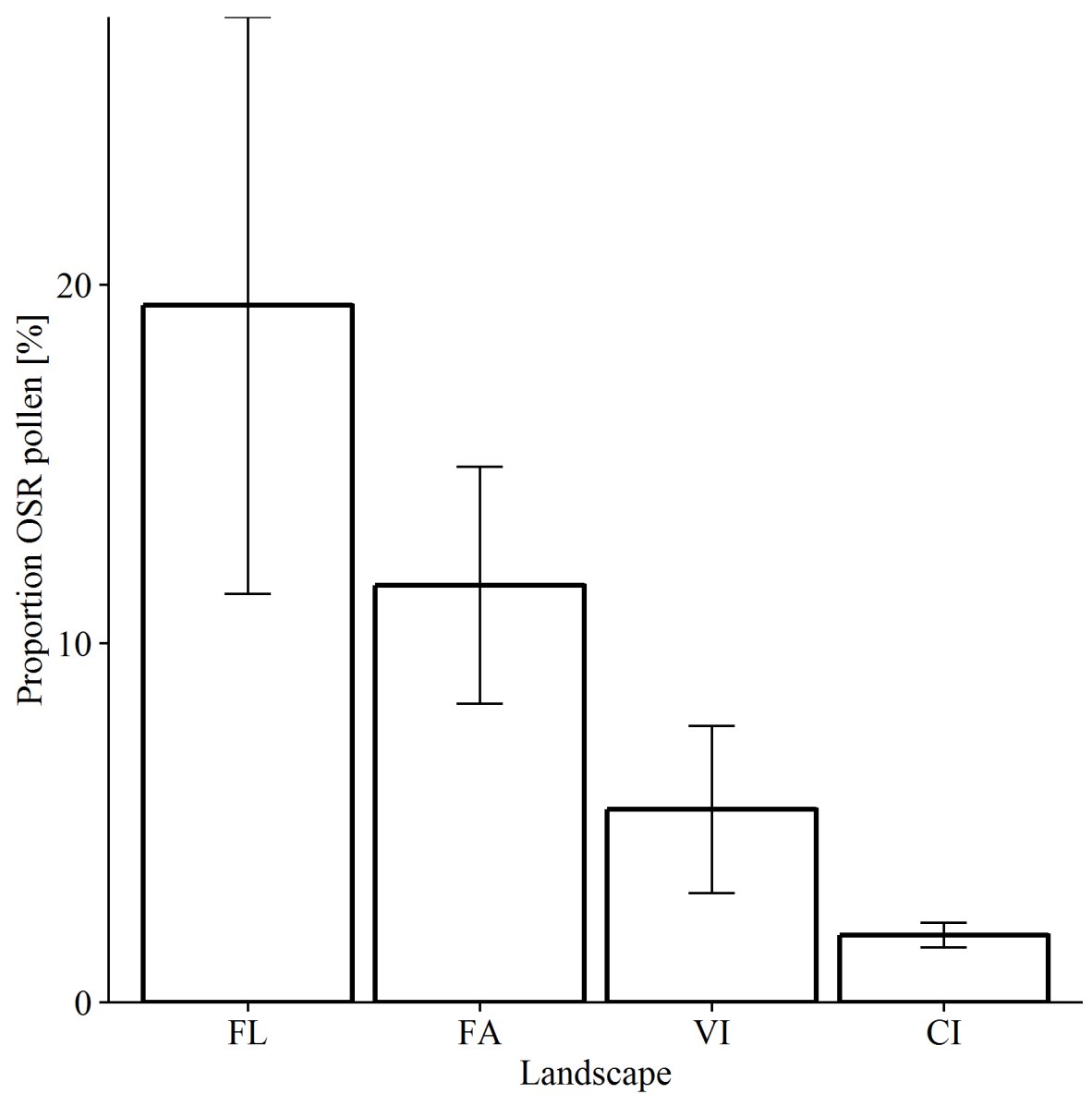

Fig. 4: Proportion of OSR pollen collected in different landscapes. Mean $\pm \mathrm{SE}$. $\mathrm{FL}=$ Farmland, $\mathrm{n}=7 ; \mathrm{FA}=$ Farmhouse, $\mathrm{n}=8 ; \mathrm{VI}=$ Village $\mathrm{n}=8 ; \mathrm{CI}=$ City, $\mathrm{n}=8$.

The starting weight of all 31 bumblebee colonies was $781.13 \pm 21.66 \mathrm{~g}$ (mean $\pm \mathrm{SD}$ ). All colonies gained weight during the experiment (weight gain: mean \pm SD $585.19 \pm 171.69 \mathrm{~g}$ ), but there were no differences in weight gain in the different landscape types along the urbanisation gradient (Chi-square $=0.778$, d.f. $=3$, $\mathrm{p}=0.855)$.

Bumblebee colony weight slightly increased with increasing proportion of OSR fields in the surroundings (Chi-square $=1.243$, d.f. $=1, p=0.265$; Fig. 5) and decreased slightly with increasing distance to the next OSR field (Chi-square $=0.596$, d.f. $=1$, $p=0.440)$. The amount of plant species (Chi-square $=2.274$, d.f. $=1, p=0.132)$ and the cover of flowering plants (Chi-square $=0.122$, d.f. $=1, p=0.726$ ) had no impact on the weight gain of bumblebee colonies along the gradient. 

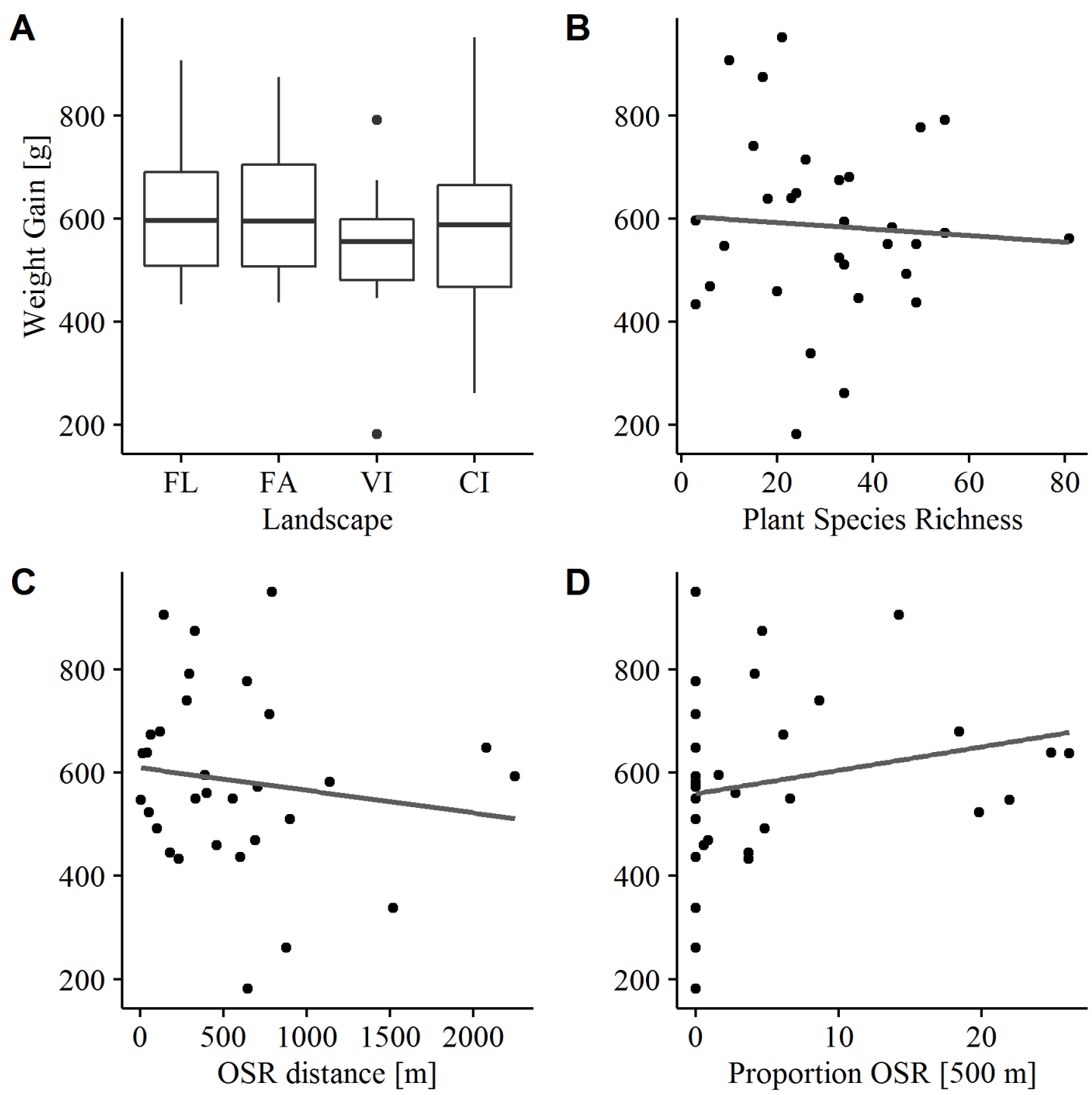

Fig. 5: Bumblebee colony weight gain in the four landscapes and influenced through local and landscape factors. $\mathrm{FL}=$ Farmland, $\mathrm{n}=7$; $\mathrm{FA}=$ Farmhouse, $\mathrm{n}=8$; VI $=$ Village $\mathrm{n}=8 ; \mathrm{CI}=$ City, $\mathrm{n}=8$.

\section{Discussion}

Our results show that bumblebee foraging changed along a farmland-urban gradient with settlements of different sizes. We found that bumblebee workers in urban areas remained within the urban boundaries when the colony was setup at least $500 \mathrm{~m}$ from the city edge. This could be due to buildings, roads and railroads, which act as barriers for bumblebee foraging (Bhattacharya et al. 2002). However, urban areas consist not just of built-up area but also of home gardens and parks that may provide nectar and pollen resources. Bumblebee colonies can benefit from these urban green areas in the local surroundings (Baldock et al. 2015, Crone and Williams 2016). In our study the bumblebee colonies in urban areas and in farmland sites increased in weight. This could 
be due to the amount of flower resources in city gardens, as Goulson et al. (2002) show that gardens provide enough local resources for bumblebee colony growth. High flower cover and plant richness in urban areas mitigates the fact that resources in the surroundings are often missing (Gunnarsson and Federsel 2014).

In farmland sites, the amount of OSR fields in the surrounding landscape was highest and the distance to the next OSR field was lowest. The bumblebee colonies from the farmland sites collected the highest amount of OSR pollen suggesting that OSR is an important resource for bumblebees in farmland. Other studies show that bumblebee colonies profit highly from mass flowering crops and develop better close to OSR fields (Westphal et al. 2009), which reinforces our findings.

Hence, bumblebee colonies in urban areas benefited from the nectar and pollen resources provided by plants in the gardens, whereas colonies in farmland benefited from the short distance to and high amount of oilseed rape fields. This could explain why all bumblebee colonies gained the same amount of weight, regardless of the surrounding landscape type.

We showed in this replicated study that bumblebees in farmland foraged throughout the landscape and collected OSR pollen, while bumblebees from urban gardens benefited from flowering plants in the gardens. This finding supports the idea that the landscape scale, as well as local resource availability in gardens, influences bumblebee colony health depending on where colonies are along the farmland-urban gradient. Due to these switches in resource use, bumblebee colony growth remained the same regardless of city size and landscape type. In conclusion, the relative importance of local garden resources and OSR resources for bumblebee performance reversed along the farmland-city gradient, which needs to be taken into account for pollinator management.

\section{Acknowledgements}

We thank Siria Biagioni from the Department of Palynology and Climate Dynamics of the University of Goettingen for help with pollen preparation and identification. We are grateful to all student helpers and gardens owners. We thank the RTG 1644 "Scaling Problems in Statistics" and the German research foundation (DFG) for funding. 


\section{References}

Allen-Wardell, G., P. Bernhardt, R. Bitner, A. Burquez, S. Buchmann, J. Canes, P. A. Cox, V. Dalton, P. Feinsinger, M. Ingram, D. Inouye, C. E. Jones, K. Kenney, P. Kevan, H. Koopowitz, R. Medellin, S. Medellin-Morales, G. P. Nabhan, B. Pavlik, V. Tepedino, P. Torchio, and S. Walker. 1998. The potential consequences of pollinator declines on the conservation of biodiversity and stability of fruit crop yields. The Forgotten Pollinators Campaign 12:8-17.

Baldock, K. C. R., M. A. Goddard, D. M. Hicks, E. Kunin, N. Mitschunas, L. M. Osgathorpe, S. G. Potts, K. M. Robertson, A. V Scott, G. N. Stone, I. P. Vaughan, and J. Memmott. 2015. Where is the UK' s pollinator biodiversity? The importance of urban areas for flower- visiting insects.

Bates, D., M. Maechler, B. Bolker, and S. Walker. 2015. Fitting Linear Fixed-Effects Models Using lme4. Journal of Statistical Software 67(1):1-48. doi:10.18637/jss.v067.i01.

Beil, M., H. Horn, and A. Schwabe. 2008. Analysis of pollen loads in a wild bee community (Hymenoptera: Apidae) - a method for elucidating habitat use and foraging distances. Apidologie 39:456-467.

Bhattacharya, M., R. B. Primack, and J. Gerwein. 2002. Are roads and railroads barriers to bumblebee movement in a temperate suburban conservation area? Biological Conservation 109:37-45.

Biesmeijer, J. C., S. P. M. Roberts, M. Reemer, R. Ohlemüller, M. Edwards, T. Peeters, A. P. Schaffers, S. G. Potts, R. Kleukers, C. D. Thomas, J. Settele, and W. E. Kunin. 2006. Parallel Declines in Pollinators and Insect-Pollinated Plants in Britain and the Netherlands. Science 313:351-354.

Chapman, R. E., J. Wang, and A. F. G. Bourke. 2003. Genetic analysis of spatial foraging patterns and resource sharing in bumble bee pollinators. Molecular ecology 12:2801-2808.

Crone, E. E., and N. M. Williams. 2016. Bumble bee colony dynamics: Quantifying the importance of land use and floral resources for colony growth and queen production. Ecology Letters 19:460-468.

Egerer, M. H., C. Arel, M. D. Otoshi, R. D. Quistberg, P. Bichier, and S. M. Philpott. 2017. Urban arthropods respond variably to changes in landscape context and spatial scale. Journal of Urban Ecology:1-10.

Fox, J., and S. Weisberg. 2011. An R Companion to Applied Regression, Second Edition. Thousand Oaks CA: Sage.

URL:http://socserv.socsci.mcmaster.ca/jfox/Books/Companion.

Goddard, M. A., A. J. Dougill, and T. G. Benton. 2010. Scaling up from gardens: biodiversity conservation in urban environments. Trends in Ecology \& Evolution 25:90-98.

Goulson, D., M. E. Hanley, B. Darvill, J. S. Ellis, and M. E. Knight. 2005. Causes of rarity in bumblebees. Biological Conservation 122:1-8.

Goulson, D., W. O. H. Hughes, L. C. Derwent, and J. C. Stout. 2002. Colony growth of the bumblebee, Bombus terrestris, in improved and conventional agricultural and suburban habitats. Oecologia 130:267-273.

Grimm, N. B., S. H. Faeth, N. E. Golubiewski, C. L. Redman, J. Wu, X. Bai, and J. M. Briggs. 2008. Global Change and the Ecology of Cities. Science 319:756-760.

Gunnarsson, B., and L. M. Federsel. 2014. Bumblebees in the city: abundance, species richness and diversity in two urban habitats. Journal of Insect Conservation 18:1185-1191.

Hall, D. M., G. R. Camilo, R. K. Tonietto, J. Ollerton, K. Ahrné, M. Arduser, J. S. Ascher, 
K. C. R. Baldock, R. Fowler, G. Frankie, D. Goulson, B. Gunnarson, M. E. Hanley, J. I. Jackson, G. Langellotto, D. Lowenstein, E. S. Minor, S. M. Philpott, S. G. Potts, M. H. Sirohi, E. M. Spevak, G. N. Stone, and C. G. Threlfall. 2016. The city as a refuge for insect pollinators. Conservation Biology 31(1):24-29.

Kleijn, D., and I. Raemakers. 2008. A Retrospective Analysis of Pollen Host Plant Use by Stable and Declining Bumble Bee Species. Ecology 89:1811-1823.

Klein, A.-M., B. E. Vaissiere, J. H. Cane, I. Steffan-Dewenter, S. A. Cunningham, C. Kremen, and T. Tscharntke. 2007. Importance of pollinators in changing landscapes for world crops. Proceedings of the Royal Society B: Biological Sciences 274:303313.

Osborne, J. L., A. P. Martin, N. L. Carreck, J. L. Swain, M. E. Knight, D. Goulson, R. J. Hale, and R. A. Sanderson. 2008. Bumblebee flight distances in relation to the forage landscape. Journal of Animal Ecology 77:406-415.

Pinheiro, J., D. Bates, S. DebRoy, D. Sarkar, and R Core Team. 2016. _nlme: Linear and Nonlinear Mixed Effects Models_. R package version 3.1-128, <URL: http://CRAN.R-project.org/package=nlme>.

Potts, S. G., J. C. Biesmeijer, C. Kremen, P. Neumann, O. Schweiger, and W. E. Kunin. 2010. Global pollinator declines: Trends, impacts and drivers. Trends in Ecology and Evolution 25:345-353.

R Core Team. 2016. R: a language and environment for sta- tistical computing. Vienna. http://www.R-project.org Regali.

Redhead, J. W., S. Dreier, A. F. G. Bourke, M. S. Heard, W. C. Jordan, S. Sumner, J. Wang, and C. Carvell. 2016. Effects of habitat composition and landscape structure on worker foraging distances of five bumble bee species. Ecological Applications 26:726-739.

Velthuis, H. H. W., and A. van Doorn. 2006. A century of advances in bumblebee domestication and the economic and environmental aspects of its commercialization for pollination. Apidologie 37:421-451.

Venables, W. N., and B. D. Ripley. 2002. Modern Applied Statistics with S. Fourth edition. Springer.

Walther-Hellwig, K., and R. Frankl. 2000. Foraging habitats and foraging distances of bumblebees, Bombus spp. (Hym., Apidae), in an agricultural landscape. Journal of Applied Entomology 124:299-306.

Westphal, C., I. Steffan-Dewenter, and T. Tscharntke. 2003. Mass flowering crops enhance pollinator densities at a landscape scale. Ecology Letters 6:961-965.

Westphal, C., I. Steffan-Dewenter, and T. Tscharntke. 2006a. Foraging trip duration of bumblebees in relation to landscape-wide resource availability. Ecological Entomology 31:389-394.

Westphal, C., I. Steffan-Dewenter, and T. Tscharntke. 2006b. Bumblebees experience landscapes at different spatial scales: Possible implications for coexistence. Oecologia 149:289-300.

Westphal, C., I. Steffan-Dewenter, and T. Tscharntke. 2009. Mass flowering oilseed rape improves early colony growth but not sexual reproduction of bumblebees. Journal of Applied Ecology 46:187-193.

Williams, N. M., J. Regetz, and C. Kremen. 2015. Landscape-scale resources promote colony growth but not reproductive performance of bumble bees promote reproductive performance growth of bumble and. Ecology 93:1049-1058.

Winfree, R. 2010. The conservation and restoration of wild bees. Annals of the New York Academy of Sciences 1195:169-97. 


\section{Supplementary Material}

Table S1: Coordinates of 32 different sites.

\begin{tabular}{|c|c|c|c|c|c|c|c|}
\hline Site & $\begin{array}{l}\text { Land } \\
\text { scape }\end{array}$ & Lat. & Long & Site & $\begin{array}{l}\text { Land } \\
\text { scape }\end{array}$ & Lat. & Long \\
\hline Bremke & FL & 51.424 & 10.073 & Diemarden & VI & 51.483 & 9.978 \\
\hline Dransfeld & FL & 51.512 & 9.753 & Diemarden & VI & 51.489 & 9.981 \\
\hline Göttingen & FL & 51.501 & 9.884 & Dransfeld & VI & 51.498 & 9.766 \\
\hline Göttingen & FL & 51.490 & 9.905 & Dransfeld & VI & 51.501 & 9.757 \\
\hline Lenglern & FL & 51.596 & 9.884 & Ebergötzen & VI & 51.572 & 10.113 \\
\hline Moringen & FL & 51.677 & 9.895 & Ebergötzen & VI & 51.570 & 10.108 \\
\hline Moringen & FL & 51.703 & 9.907 & Moringen & VI & 51.704 & 9.876 \\
\hline $\begin{array}{l}\text { Nörten- } \\
\text { Hardenberg }\end{array}$ & FL & 51.607 & 9.923 & Moringen & VI & 51.692 & 9.880 \\
\hline Bremke & FA & 51.430 & 10.079 & Duderstadt & CI & 51.515 & 10.256 \\
\hline Dransfeld & FA & 51.520 & 9.756 & Duderstadt & CI & 51.510 & 10.266 \\
\hline Friedland & FA & 51.473 & 9.955 & Einbeck & CI & 51.820 & 9.876 \\
\hline Göttingen & FA & 51.506 & 9.941 & Einbeck & $\mathrm{CI}$ & 51.816 & 9.885 \\
\hline Kalefeld & FA & 51.781 & 10.028 & Göttingen & CI & 51.527 & 9.946 \\
\hline Lenglern & FA & 51.601 & 9.873 & Göttingen & CI & 51.540 & 9.939 \\
\hline Moringen & FA & 51.678 & 9.883 & Northeim & $\mathrm{CI}$ & 51.712 & 9.999 \\
\hline $\begin{array}{l}\text { Wollbrands- } \\
\text { hausen }\end{array}$ & FA & 51.580 & 10.176 & Northeim & CI & 51.701 & 9.998 \\
\hline
\end{tabular}


Table S2: Preparation of pollen samples from honey and wax.

University of Jambi, Department of Palynology and Climate Dynamics

Suggested number of samples per time: 10

Always wear gloves and lab coat when working in the lab.

1) Switch on the water bath; check if there is enough water in it (it takes more than 30 minutes to heat up to $\left.90^{\circ} \mathrm{C}\right)$.

2) Transfer the honey and or wax in a conical test tube. Make sure to wash all the tools to avoid contamination between samples.

3) Only for the honey (for the wax move to step 5): add $4 \mathrm{ml}$ of concentrated acetic acid $(\mathrm{CH} 3 \mathrm{COOH})$ to the sample (for dehydration) and mix the content.

4) Centrifuge the tubes for $5 \mathrm{~min}$ at $3500 \mathrm{RPM}$ and pour of the supernatant in a beaker and then in the acetic acid waste container).

5) Acetolysis: make sure all the tools are dry including the gloves! Use the measuring cylinder to prepare a mixture of 9 parts acetic anhydride $((\mathrm{CH} 3 \mathrm{CO}) 2 \mathrm{O})$ and 1 part concentrated sulphuric acid (H2SO4). Fill in first the acetic anhydride then the sulphuric acid. Add the one part of sulphuric acid into the measuring cylinder using a plastic pipette very slowly (exothermic reaction, might get warm). Be careful $\mathrm{H} 2 \mathrm{SO} 4$ reacts with water!

e.g. of calculation $-4 \mathrm{ml}$ per sample:

For 1 sample à $3.6 \mathrm{ml}(\mathrm{CH} 3 \mathrm{CO}) 2 \mathrm{O}+0,4 \mathrm{ml} \mathrm{H} 2 \mathrm{SO} 4$

For 10 samples à $36 \mathrm{ml}(\mathrm{CH} 3 \mathrm{CO}) 2 \mathrm{O}+4 \mathrm{ml} \mathrm{H} 2 \mathrm{SO} 4$

It is recommended to prepare a bit more, e.g. per 10 samples ca. $39.6 \mathrm{ml}(\mathrm{CH} 3 \mathrm{CO}) 2 \mathrm{O}+4.4 \mathrm{ml} \mathrm{H} 2 \mathrm{SO} 4$

6) Add ca. $4 \mathrm{ml}$ of the Acetolysis mixture to each sample (first $2 \mathrm{ml}$ and then the other $2 \mathrm{ml}$ ) using the plastic pipette. Mix, if necessary, thoroughly with a plastic stick, one for each sample (be careful not to use wet tools). Remove the plastic sticks.

7) Put the tubes into the water bath for 10 minutes at $90^{\circ} \mathrm{C}$. Leave the water bath open! You will see the colour turning dark yellow. Centrifuge the tubes for $5 \mathrm{~min}$. at $3500 \mathrm{RPM}$ and pour off the supernatant in a beaker.

8) Wash the samples with distilled water one or more times (until the water is clear): fill them up equally with water mix with clean plastic sticks if necessary, centrifuge for $5 \mathrm{~min}$. at $3500 \mathrm{RPM}$, pour off the supernatant in the beaker. If the sample is solid add acetic acid to the top and centrifuge.

At the end empty the beaker into the Acetolysis waste container.

9) If necessary sieve the sample with a $150 \mu \mathrm{m}$ filter and then back sieve in the original tubes

10) Transfer the residues into labelled Eppendorf-tubes.

11) Centrifuge the Eppendorf tubes for 3 minutes at 12000 RPM and pour off the water supernatant.

12) Create pollen slides using glycerine gel as fixer. 
Table S3: Proportion of OSR in pollen samples collected from the bumblebee colonies with standard deviation (sd), standard error (se) and confidence interval (ci).

\begin{tabular}{|l|l|l|l|l|l|}
\hline Landscape & $\mathrm{N}$ & $\begin{array}{l}\text { OSR } \\
\text { pollen }\end{array}$ & sd & se & ci \\
\hline FL & 7 & 19.42857 & 21.26701 & 8.0381742 & 19.6687038 \\
\hline FA & 8 & 11.625 & 9.3493697 & 3.3055014 & 7.8162687 \\
\hline VI & 8 & 5.375 & 6.5669628 & 2.321772 & 5.4901183 \\
\hline CI & 8 & 1.875 & 0.9910312 & 0.3503824 & 0.8285228 \\
\hline
\end{tabular}
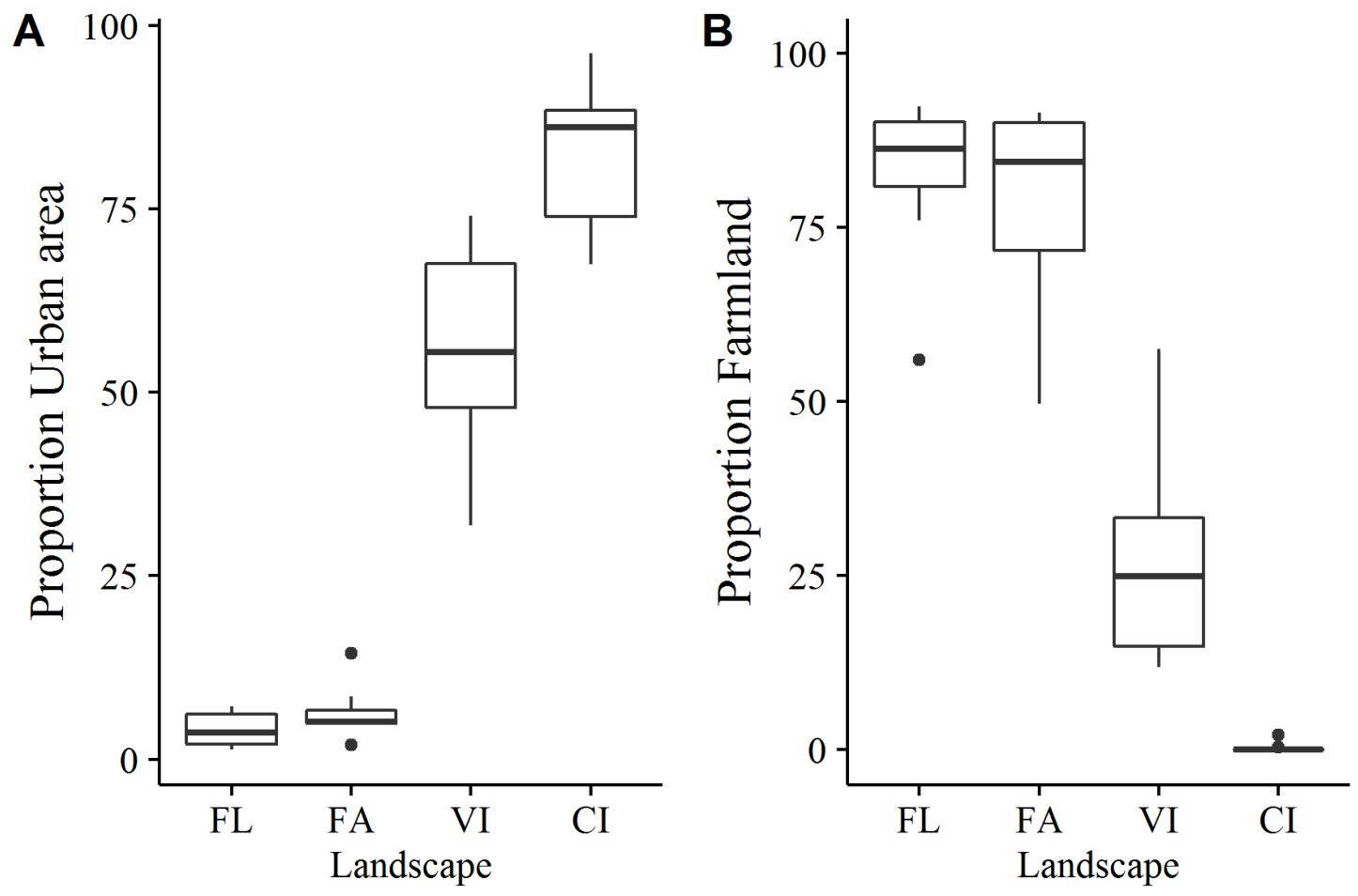

Fig. S1: Proportion urban area and farmland in $500 \mathrm{~m}$ around the sites. FL $=$ Farmland, $\mathrm{n}=7 ; \mathrm{FA}=$ Farmhouse, $\mathrm{n}=8 ; \mathrm{VI}=$ Village $\mathrm{n}=8 ; \mathrm{CI}=$ City, $\mathrm{n}=8$. 


\section{Chapter 3}

\section{Season and Flower Composition affect Bumblebee Foraging Behaviour across a Farmland-Urban Gradient}

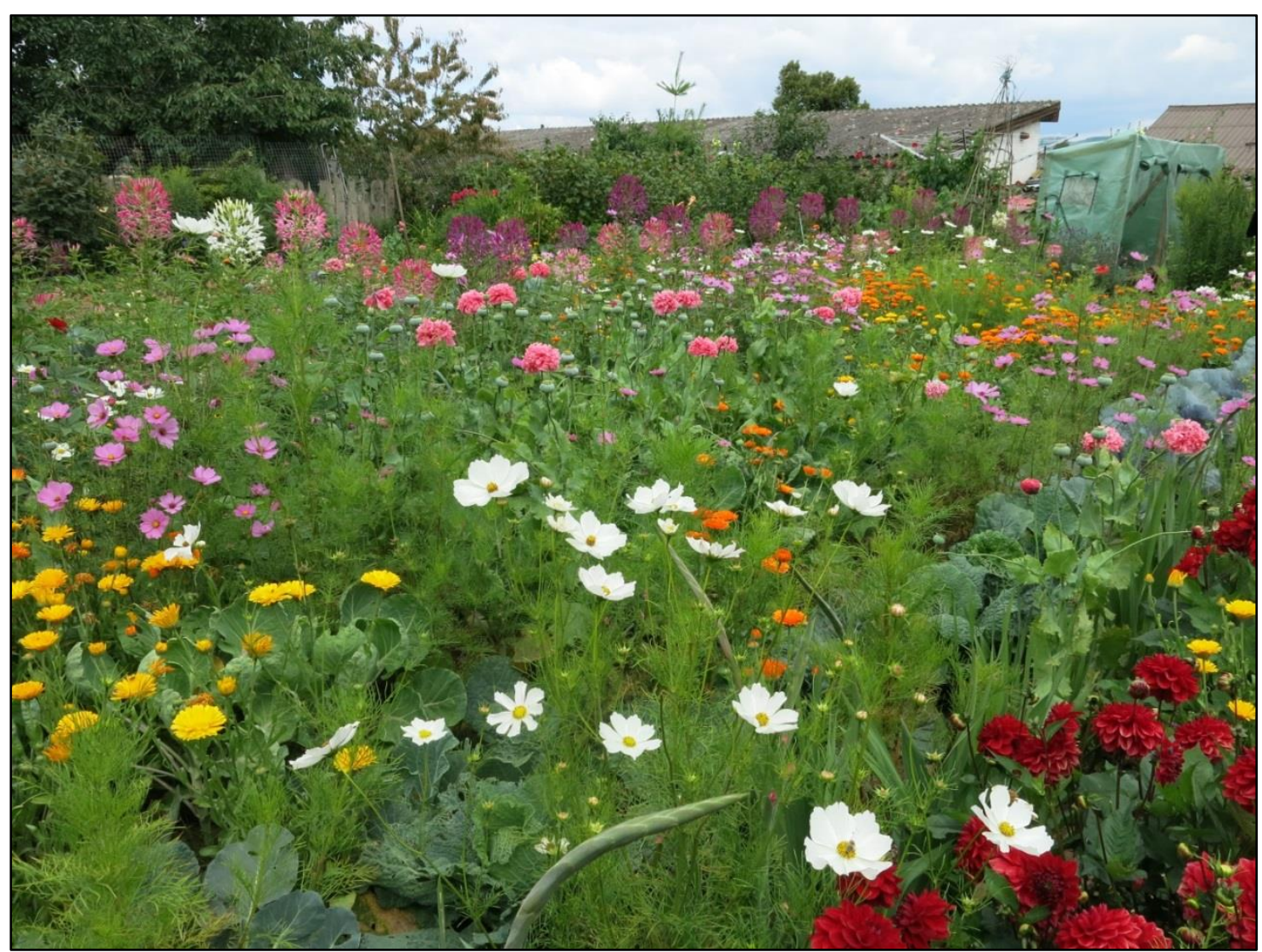

Farmhouse garden near Göttingen (August 2015, ( Hannah Reininghaus)

Authors:

Hannah Reininghaus, Kristy Leah Udy, Teja Tscharntke and Christoph Scherber 


\begin{abstract}
Bumblebees are important pollinators for a wide range of wild and crop plants. Bumblebee populations are in severe decline across the Northern Hemisphere, largely in response to declines in semi-natural habitats through expansion of farmland and urban landscape. Yet, in farmland, negative effects may be mitigated by mass-flowering crops, and, in urban areas, a high diversity of different plants in gardens and parks may provide resources for bumblebees.

Here, we tested if local flower resources or landscape resources affect bumblebee foraging behaviour and resource preference along a farmland-urban gradient. We conducted an experiment with Bombus terrestris colonies exposed along a gradient of urbanisation from farmland sites (low urbanisation), to farmhouses, village gardens and city gardens, the latter surrounded by high level of urbanisation. Plant family richness was much higher in gardens and differed compositionally from farmland sites. Bumblebee workers collected preferentially the same plant families in farmland sites and urban areas. These plant families included Asteraceae, Brassicaceae, Fabaceae and Rosaceae that have high flower cover and high amounts of nectar and pollen resources. In contrast, plant families such as Caryophyllaceae and Geraniaceae are bred as ornamental plants for gardens and do not provide sufficient resources and were therefore not visited by the bumblebees. Along the urbanisation gradient bumblebees showed the same plant family preferences and forage behaviour. For the maintenance and restoration of good quality habitats in farmland, my results indicate, which plant families are utilised by bumblebees and should be taken into account when planting flower strips.
\end{abstract}

Keywords: urbanisation gradient; bumblebee; foraging behaviour; Bombus terrestris; pollen; floral resource. 


\section{Introduction}

Bumblebees are a major pollinator group as they forage across the entire flowering season and pollinate a huge variety of wild and crop plants (Chittka et al. 1999, Cussans et al. 2010). The destruction and fragmentation of natural habitats by increasing urbanisation and agricultural intensification has led to a decline in bumblebees and other pollinator groups over the last decades (Kremen et al. 2002, Goulson et al. 2005, Biesmeijer et al. 2006, Potts et al. 2010).

Studies in urban areas show that negative effects of urbanisation may at least partially be mitigated by urban green spaces, as gardens and parks contain a high richness of flowering plant species and plentiful nesting resources (McFrederick and LeBuhn 2006, Samnegård et al. 2011, Hall et al. 2016). Bumblebee abundance is positively correlated with plant species richness and the presence of specific plant families (Goulson et al. 2015, Hülsmann et al. 2015, Kämper et al. 2016). Gardens have a high variety of different plant species with a high diversity of non-native plants (Smith et al. 2005). However, a high diversity of garden plants in itself is not necessarily beneficial for bumblebees as garden plants are often purely ornamental and are bred for colour or number of petals, providing only a reduced amount of nectar or inaccessible pollen (Garbuzov and Ratnieks 2014).

In contrast to high plant species richness in urban green spaces, plant species richness generally decreases with increasing amount of farmland (McKinney 2008). Important plant resources for bumblebees in farmland areas are mass flowering crops (e.g. oilseed rape, Brassica napus L.) that provide nectar and pollen resources for a short time during the year (Westphal et al. 2003). Landscape studies showed that Bombus terrestris workers can fly several kilometres from their colonies to find suitable resources (Walther-Hellwig and Frankl 2000, Osborne et al. 2008). Previous studies on bumblebee foraging behaviour in urban areas only sampled along rural-urban gradients in a single city and did not replicate their experiments in different urban areas (Egerer et al. 2017).

Here, we setup 48 bumblebee colonies in gardens along a gradient of urbanisation. We replicated our study in different sized urban settlements and during the year. All flowering plant families at the study sites were mapped and pollen samples from each bumblebee colony were analysed. The aim of our study was to examine differences in plant species composition between farmland and gardens and if these 
differences affect bumblebee foraging behaviour. We tested if bumblebee workers are attracted by different plant families at the landscape scale and if their foraging behaviour is affected by local plant family richness.

\section{Material and Methods}

This study was conducted in May 2015 in 32 sites around Göttingen (central Germany) and was repeated in July 2015 at 16 sites (Table S1). The study area within a radius of $30 \mathrm{~km}$ around Göttingen consists mainly of farmland, pastures and forest patches and scattered urban areas. Sites used were grassy field margins or private gardens and were selected based on the amount of urban area and farmland within a $500 \mathrm{~m}$ radius. We used ArcGIS (version 10.4.1, ESRI) to calculate the size of each settlement in the surroundings of Göttingen. We overlaid each settlement with a polygon where urban boundary was defined as the edge of built-up area to farmland and calculated the size of the polygon. We randomly chose four intermediate sized villages (around $0.7 \mathrm{~km}^{2}$ size, Diemarden, Dransfeld, Moringen and Ebergötzen) and the four biggest cities (up to 16 $\mathrm{km}^{2}$, Duderstadt, Einbeck, Göttingen and Northeim, Table S1). Farmhouses and farmland sites were selected when nearly no forest and built-up area were present in a radius of $500 \mathrm{~m}$ (Fig. S1). Eight farmhouses with a garden and eight farmland sites with grassy field margin were randomly chosen for our study. Within the four villages and four cities all gardens were mapped with ArcGIS and gardens with at least $1000 \mathrm{~m}^{2}$ area were selected. In each village two gardens at the edge with 50\% urban area and 50\% farmland within a radius of $500 \mathrm{~m}$ were randomly selected. Within the four cities, two gardens with just urban area within a radius of $500 \mathrm{~m}$ were randomly selected. The gardens were separated by at least $500 \mathrm{~m}$. In May, we conducted the study at 32 sites and repeated the experiment in July in 16 sites (Fig. 1), with four farmland sites, four farmhouse gardens and two villages (Diemarden and Dransfeld) and two cities (Göttingen and Einbeck). 


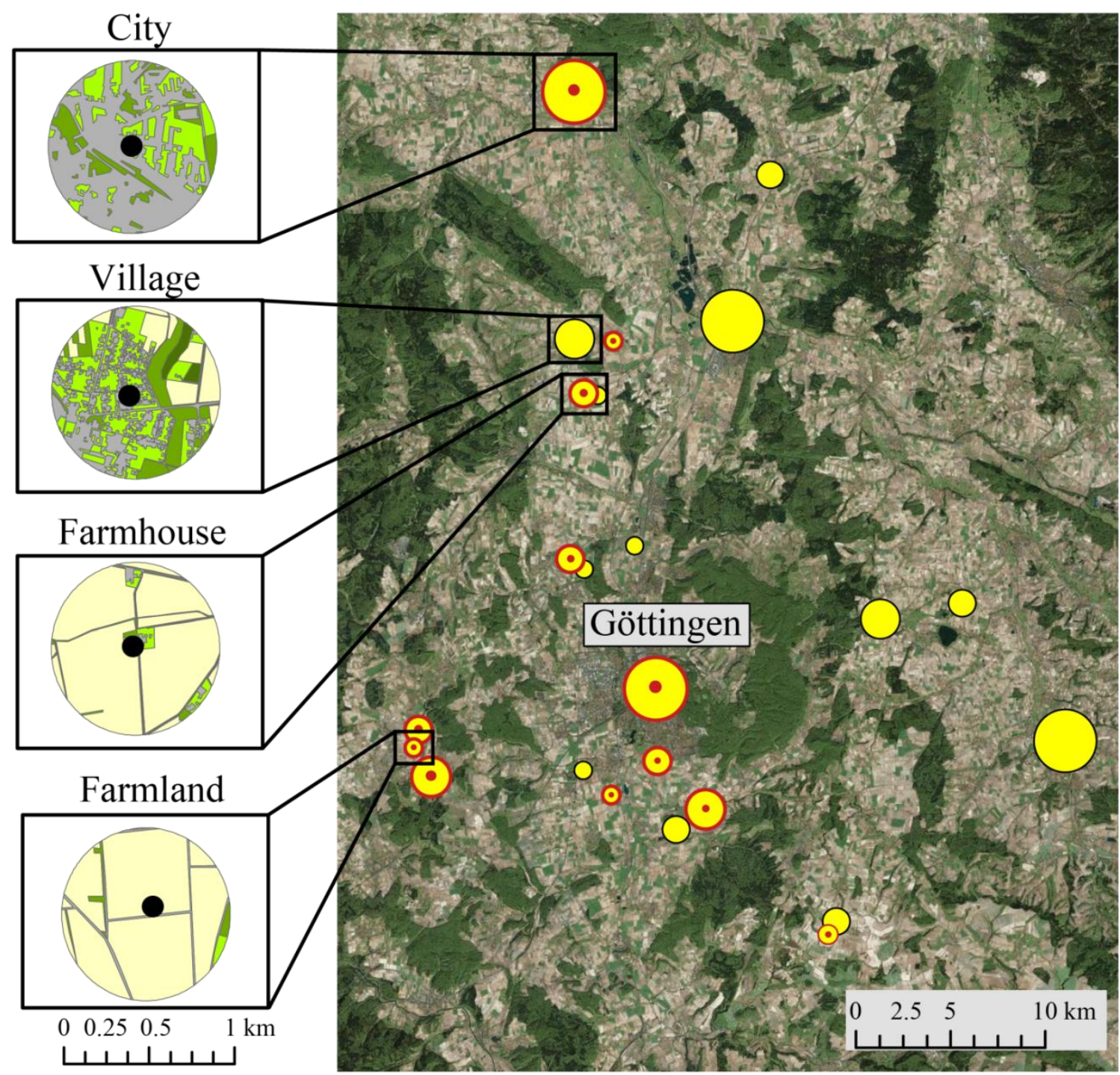

$\square$ Farmland $\square$ Forest $\square$ Garden $\square$ Green space $\square$ Urban

Fig. 1: Study area around Göttingen. Yellow circles represent 32 sites in May and red circles represent 16 sites in July. Size of circle indicates the different landscape types from farmland to farmhouse and village to city. Insets show examples of amount of urban area and farmland in a $500 \mathrm{~m}$ radius.

\section{Bumblebee colonies}

We purchased Bombus terrestris colonies from Biobest (Westerlo, Belgium) in May and in July 2015. The colony boxes consisted of an outer paper box, which contained an inner ventilated plastic box with the colony and a container with sugar water. The sugar water was opened at the day of the delivery and closed at the first day in the field. During the first round the bumblebee colonies were setup in the experimental sites for three weeks from May $6^{\text {th }}$ to May $28^{\text {th }}$ and during the second round from July $28^{\text {th }}$ to August $20^{\text {th }}$. The colonies were placed at partly shaded areas facing away from obstacles. They were sheltered from sun and rain by a wooden roof and were secured to 
the ground with nails. During the study period the colonies were visited frequently and checked for disturbances. One farmland colony was vandalised and removed from our analyses. Before we collected the colonies, we closed the exit of the colony boxes for $24 \mathrm{~h}$ to prevent bumblebees exiting the hive, the entrance was left open so that foraging bumblebees could return to the colony and enter the hive. When we collected the colonies, we closed them completely and froze them in a cool chamber at $-20^{\circ} \mathrm{C}$.

\section{Pollen samples}

The colonies were opened and pollen samples were collected from honey pots and brood cells. We cleaned the pollen samples following the Acetolysis method for wax and honey outlined in Table S2. Three pollen slides were made per colony and 100 pollen grains were counted per colony and identified to family level. In the farmhouse, village and city gardens we surveyed all flowering plants. We identified them when possible to species level and allocated them as either non-native or native species and ordered them according to family. At farmland sites we identified all flowering plants within a radius of $20 \mathrm{~m}$ around each colony in May and July.

\section{Statistics}

All analyses and data visualisation was performed in R 3.3.0 (R Core Team 2016). The pollen and the flowering plant data were combined from the different study sites and analysed per sampling round (May and July). To test difference in plant community composition between the farmland sites and gardens, we created plant family community matrices and pollen family community matrices for May and July.

We used a nonmetric multidimensional scaling method (metaMDS) to visualise community composition for the plant families and the pollen families in our different landscapes (along the urbanisation gradient). We calculated plant family community dissimilarities with the Bray-Curtis index ("vegdist" function, Oksanen et al. 2017). The significance of these ordinations was tested with a permutation test with pseudo F-ratios ("Permutational Multivariate Analysis of Variance Using Distance Matrices", "Adonis", Oksanen et al. 2017).

We calculated the average number of plant families in the gardens and the average number of plant families found in the pollen samples for the four different landscape types (farmland, farmhouse, village and city). Finally, we analysed plant family richness in the gardens and plant family richness from the pollen samples against 
landscape type with linear mixed-effect models fit using maximum likelihood (Pinheiro et al. 2016) and included site as the random effect. We calculated the presence of each plant family within each site and compared it with the presence of plant families found in the pollen samples.

\section{Results}

The total number of flowering plant families was 61 plant families in May and 52 plant families in July (Table S3). Village gardens had the highest plant family richness in May, whereas city gardens had the highest plant family richness in July. The number of plant families was always higher in gardens compared with farmland sites. Analyses of the pollen samples showed that bumblebees collected the same number of plant families in May and July (Table S3).

The flowering plants in the direct surroundings of each colony were identified to family level and compared to the results from the pollen samples. We found that bumblebees preferred plants from specific families (Fig. 2). For example, in May bumblebees collected Rosaceae pollen from all our sites. Rosaceae was the most abundant plant family at all sites. Furthermore, bumblebees preferred plants of the family Salicaceae and collected pollen from this family, although this family was not present in the direct surrounding of the colony. Bumblebee colonies did not collect pollen from the families Geraniaceae and Caryophyllaceae but these families were present in the surroundings of the colonies.

In July, Asteraceae and Rosaceae were most abundant and were collected from the bumblebee colonies (Fig. 3). Boraginaceae, Campanulaceae, Ranunculaceae and Oleaceae plant families were not present in the surroundings of the bumblebee colonies but pollen from these families was collected. 


\section{Farmland}

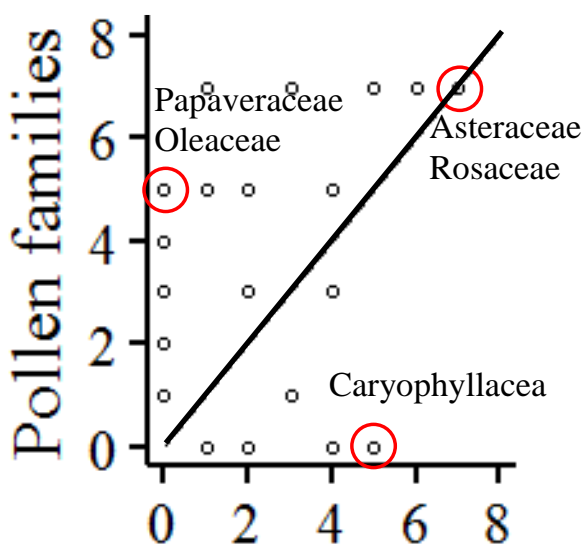

\section{Village}

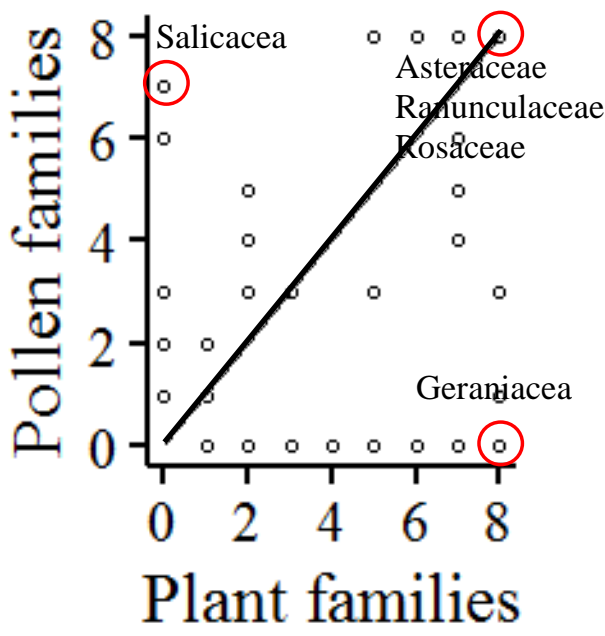

\section{Farmhouse}

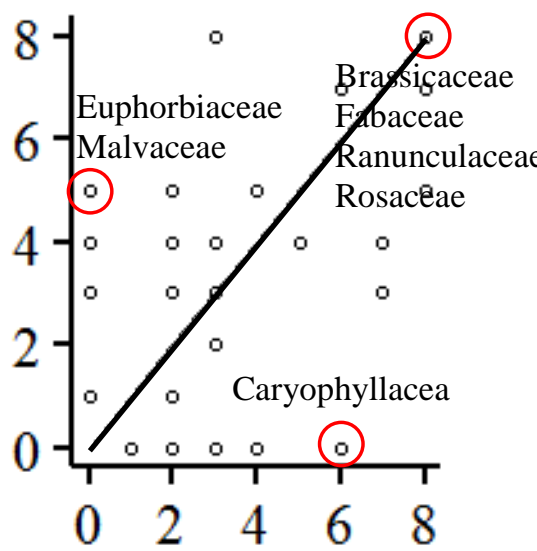

City

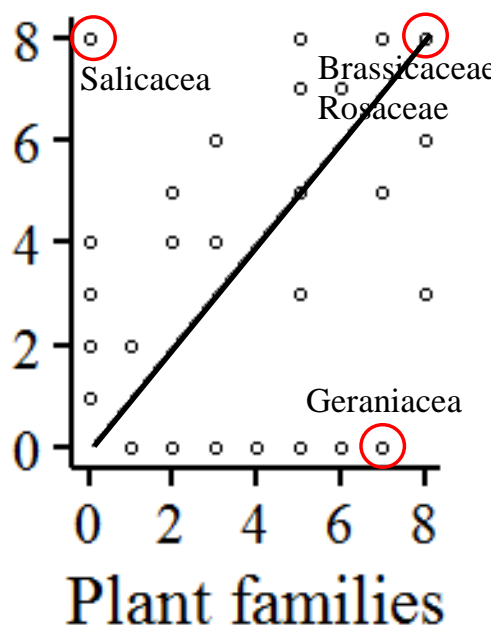

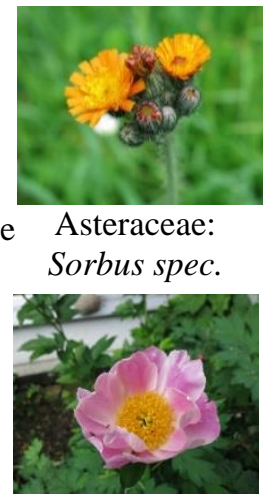

Rosaceae: Rosa canina (L.)

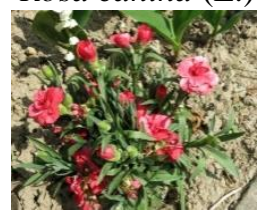

Caryophyllaceae

Dianthus

caryophyllus

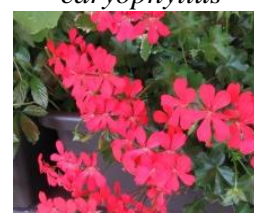

Geraniaceae:

Pelargonium spec.

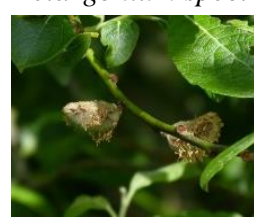

Salicaceae:

Salix spec.

Fig. 2: Abundance of plant families at different landscape types against visited plant families in May. Trend line shows a perfect fit for plant families that were present and always visited, points below the line indicate plant families that were present but not always visited and points above the line are plant families that were visited but not always present in the local surroundings. Example pictures of some plant species (C Kristy Udy). 

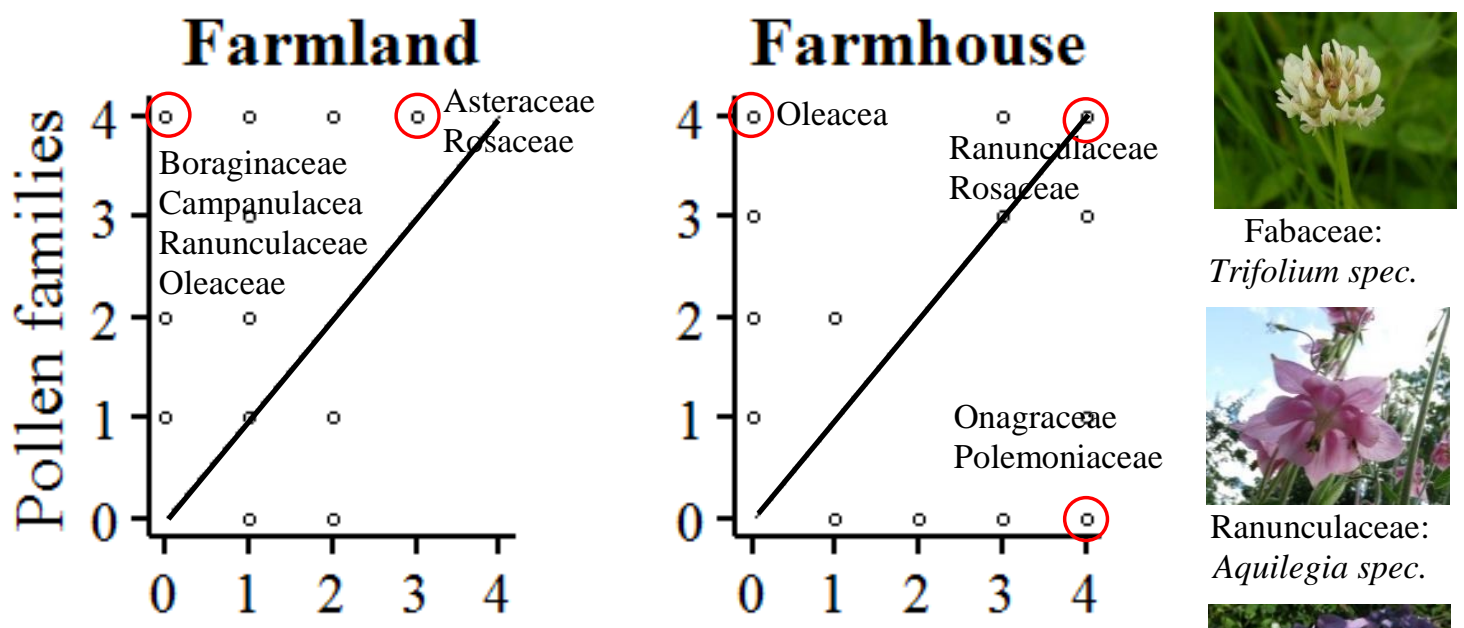

Fabaceae: Trifolium spec.

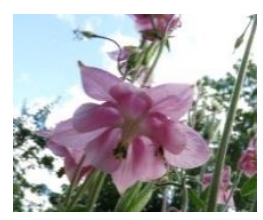

Ranunculaceae: Aquilegia spec.

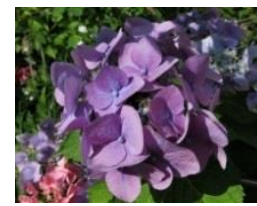

Hydrangeaceae: Hydrangea spec.

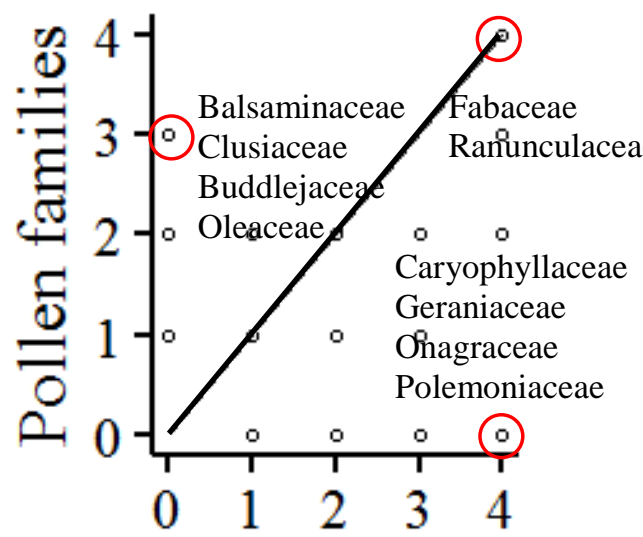
Plant families

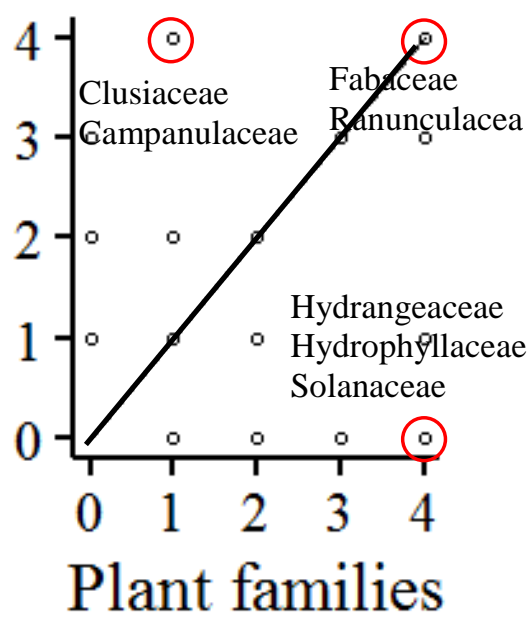

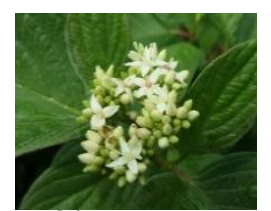

Oleaceae:

Ligustrum spec.

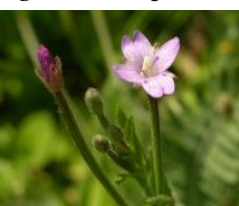

Onagraceae:

Epilobium parviflorum (Schreb.)

Fig. 3: Abundance of plant families at different landscape types against visited plant families in July. Trend line shows a perfect fit for plant families that were present and always visited, points below the line indicate plant families that were present but not always visited and points above the line are plant families that were visited but not always present in the local surroundings. Example pictures of some plant species (C) Hannah Reininghaus). 

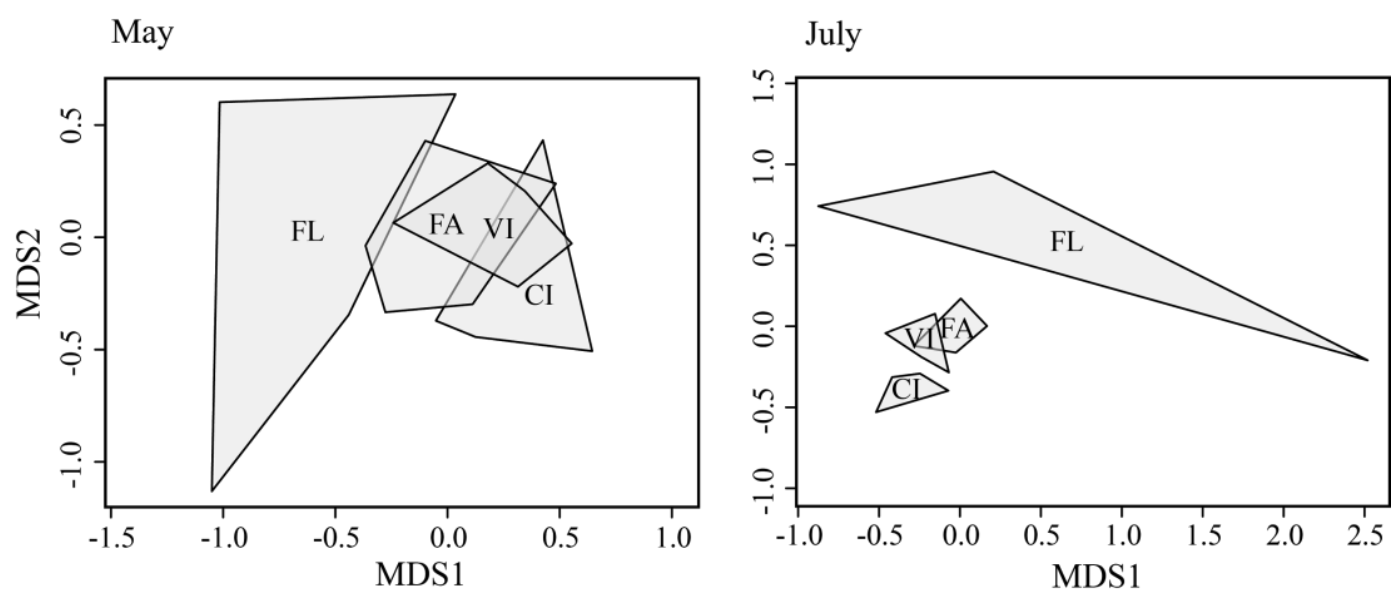

Fig. 4: Nonmetric multidimensional ordination plots of plant family community composition in May and July, based on Bray-Curtis dissimilarity index. FL = Farmland, $\mathrm{FA}=$ Farmhouse garden, $\mathrm{VI}=$ Village, $\mathrm{CI}=$ City

The overall plant family composition differed between farmland sites and farmhouse, village and city gardens in May and July (May: F-ratio ${ }_{3,27}=4.863$, p $<0.001$, July: F-ratio $3,12=2.485$, d.f. $=3, p<0.001$; Fig. 4). The plant family composition between the farmland, village and city gardens was more similar than plant family composition in the farmland sites (Table S4).
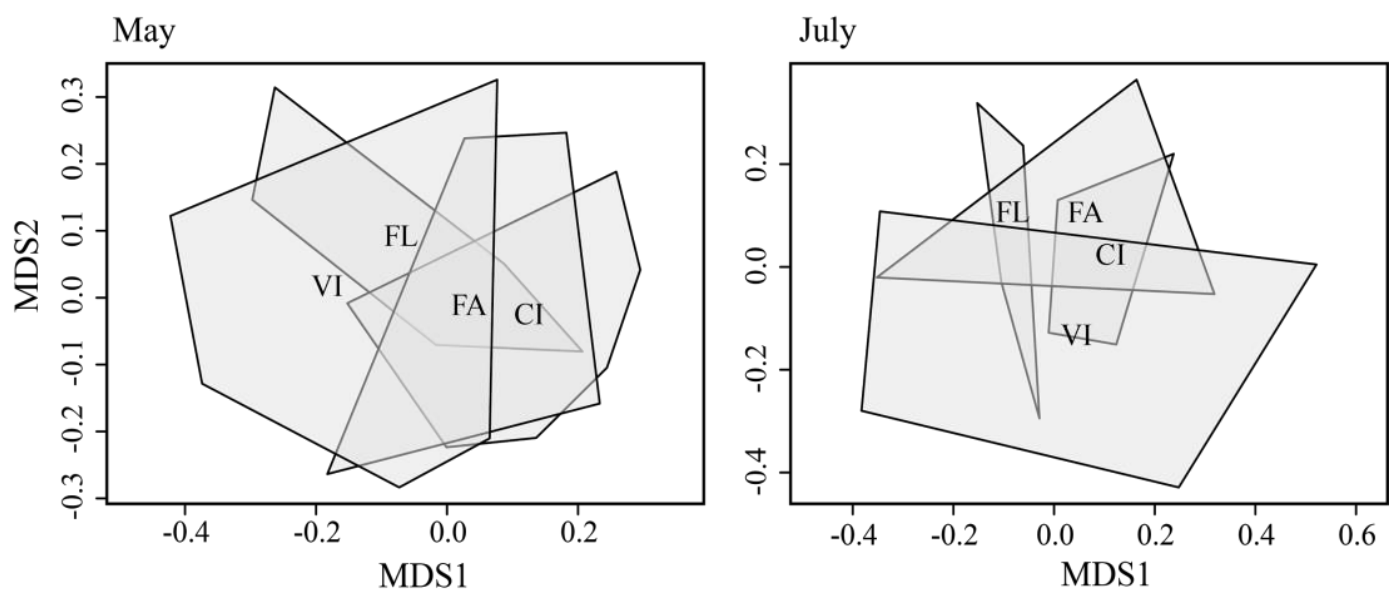

Fig. 5: Nonmetric multidimensional ordination plots of plant family community composition collected from bumblebee pollen in May and July, based on the BrayCurtis dissimilarity index. FL = Farmland, FA = Farmhouse garden, VI = Village, $\mathrm{CI}=$ City.

The plant family composition of the pollen samples did not differ between the sites (Fig. 5). Bumblebees collected the same plant families in farmland sites, farmhouse, village and city gardens in May and July (May: F-ratio ${ }_{3,27}=1.119, \mathrm{p}=0.325$, July: Fratio $_{3,12}=1.003 \mathrm{p}=0.483$, Table S4). 

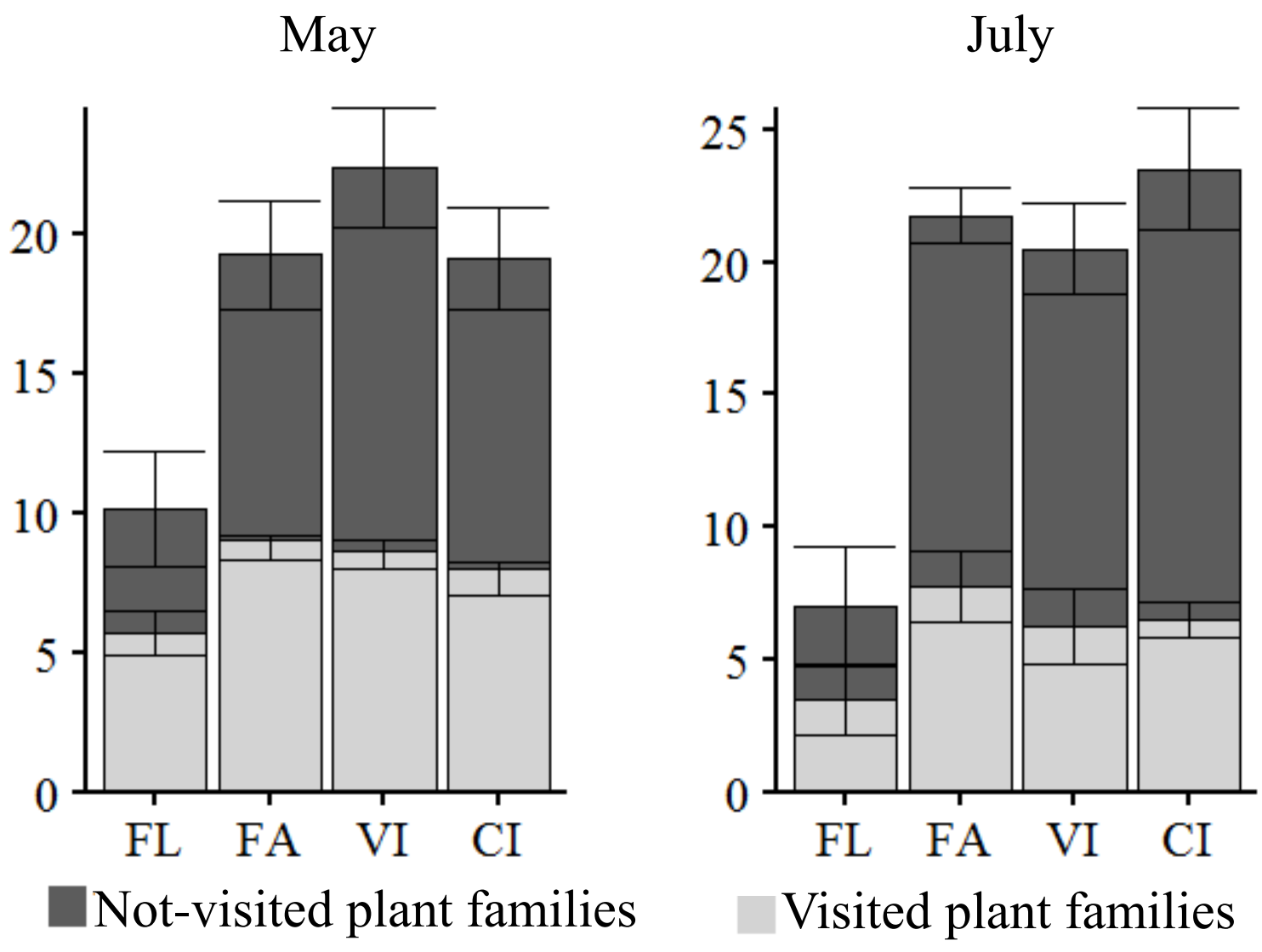

Fig. 6: Mean number (May: $\mathrm{n}=7$ farmland sites, $\mathrm{n}=8$ gardens, July: $\mathrm{n}=4$ all sites) of visited plant families (grey bar, mean \pm SE) and mean number of not visited plant families (dark grey bar, mean \pm SE) in the different landscape types. FL $=$ Farmland, $\mathrm{FA}=$ Farmhouse garden, $\mathrm{VI}=$ Village, $\mathrm{CI}=$ City .

The mean number of plant family richness in gardens of farmhouses, villages and cities in May was higher compared to farmland sites (Chi-square $=19.653$, d.f. $=3, p<0.001$; Fig. 6). In July, around 20 plant families were recorded in the gardens, whereas only 7 families were flowering at the farmland sites (Chi-square $=46.553$, d.f. $=3$, $\mathrm{p}<0.001$ ). In May and July in farmland sites around $50 \%$ of the plant families in the direct surroundings of the colonies were visited from bumblebee workers (Chisquare $=40.527$, d.f. $=3, \mathrm{p}<0.001$, whereas only $30 \%$ of the plant families in the gardens were visited by bumblebees (Chi-square $=13.59$, d.f. $=3, p=0.004)$.

\section{Discussion}

Differences in the composition of flowering plant families along the farmland-urban gradient are due to different management practises in farmland and private gardens. Agriculture intensification led to a decline in wild plants and overall plant richness 
(Robinson and Sutherland 2002), which correspond to our results that plant richness in farmland sites was much lower compared to gardens. Some mass flowering crops, such as oilseed rape or legumes, can mitigate somewhat the negative effects of low plant richness for pollinators (Hanley et al. 2011, Holzschuh et al. 2013). Mass flowering crops have a high flower cover and provide nectar and pollen resources, but their flowering time is limited (Westphal et al. 2003) and Holzschuh et al. (2016) showed a dilution effect of mass-flowering crops on pollinator abundance. Agri-environmental schemes try to improve flowering plant species richness and to provide stable flowering resources for pollinators in farmland landscapes (Carvell et al. 2007, Garibaldi et al. 2014).

Urban gardens provide a stable source of flower resources for pollinators throughout the year, as garden owners plant a large variety of native and non-native plant species (Pyšek 1998, Loram et al. 2008). This explains the high plant family richness in our study gardens. The number of flowering plant families was lowest in farmland sites with half of them visited by bumblebees. In gardens the number of plant families visited was much higher, but only $30 \%$ of the available plant families were visited by bumblebees. This suggests that bumblebees prefer specific plant families and will fly longer distances if these families are not flowering in the direct surroundings of their colony.

The high number of plants in gardens was not reflected by the foraging behaviour of the bumblebees. Along the farmland-urban gradient bumblebee workers did not visit all present plant families in the surroundings. Instead, we found evidence that bumblebees visit the same plant families at the farmland sites and in urban gardens. For example, Rosaceae were present in all our landscapes and were always visited by bumblebees. Parmentier et al. (2014) and Hülsmann et al. (2015) found that these families are most frequently visited by bumblebees. Additionally, they found that Malvaceae and Salicaceae are particularly attractive to bumblebees. This supports our findings as these plant families were not present at our farmland sites but bumblebees collected pollen from these families.

Bumblebee colonies collected pollen from other plant families that were not present in the direct surroundings of the colonies. The plant families Buddlejaceae and Oleaceae contain plant species that are small flowering bushes or trees with large flower heads, high abundance of flowers and high nectar and pollen quality (Anderson 1976, Denisow and Strzałkowska-Abramek 2013). This indicates that bumblebees are attracted 
by resource abundance and quality as they will fly longer distances if the preferred flowering plant is not in the direct surroundings of the colonies (Redhead et al. 2016).

Caryophyllaceae, Geraniaceae and Hydrangeaceae were highly abundant in gardens in May and July but were not visited by bumblebees. Plants from these families are often bred as ornamental plants for gardens but they provide no suitable nectar and pollen resources for bumblebees (Corbet et al. 2001, Garbuzov and Ratnieks 2014). Furthermore, a high number of plant families are not visited by bumblebees because some plants exist at low abundances through management by the garden owner and are therefore not attractive for bumblebees (Spiesman et al. 2016). Kämper et al. (2016) suggest that bumblebees prefer abundant plants more than less abundant plants with higher pollen and nectar quality.

It is interesting to note that bumblebee workers preferred the same plant families along the farmland-urban gradient regardless of whether they grew in the surroundings of the colony or not. High plant family richness in the gardens did not change plant family preference of the bumblebee workers, suggesting that high plant family richness does not necessarily improve bumblebee foraging efficiency. Our results suggest that specific plant families (e.g. Buddlejaceae, Oleaceae and Rosaceae) provide important resources for pollinators and are therefore preferred by the bumblebee colonies. For bumblebee conservation and urban green space management, these important plant families should be taken into account. Our results show that gardeners, who want to plant wildlife friendly gardens should be encouraged to grow these specific plant families. Furthermore, for the maintenance and restoration of good quality habitats in farmland, our results should be taken into account when planting flower strips.

\section{Acknowledgements}

We thank Siria Biagioni from the Department of Palynology and Climate Dynamics of the University of Goettingen for pollen preparation and identification. We are grateful to all student helpers and garden owners. We thank the RTG 1644 "Scaling Problems in Statistics" and the German research foundation (DFG) for funding. We also thank Erin Treanore for her assistance in the field. 


\section{References}

Anderson, G. J. 1976. The Pollination Biology of Tilia. American Journal of Botany 63:1203.

Biesmeijer, J. C., S. P. M. Roberts, M. Reemer, R. Ohlemüller, M. Edwards, T. Peeters, A. P. Schaffers, S. G. Potts, R. Kleukers, C. D. Thomas, J. Settele, and W. E. Kunin. 2006. Parallel Declines in Pollinators and Insect-Pollinated Plants in Britain and the Netherlands. Science 313:351-354.

Carvell, C., W. R. Meek, R. F. Pywell, D. Goulson, and M. Nowakowski. 2007. Comparing the efficacy of agri-environment schemes to enhance bumble bee abundance and diversity on arable field margins. Journal of Applied Ecology 44:29-40.

Chittka, L., J. D. Thomson, and N. M. Waser. 1999. Flower constancy, insect psychlogy, and plant evolution. Naturwissenschaften 86:361-377.

Corbet, S. A., J. Bee, K. Dasmahapatra, S. Gale, E. Gorringe, B. La Ferla, Y. Van Bergen, and M. Vorontsova. 2001. Native or Exotic? Double or Single? Evaluating Plants for Pollinator-friendly Gardens. Annals of Botany 87:219-232.

Cussans, J., D. Goulson, R. Sanderson, L. Goffe, B. Darvill, and J. L. Osborne. 2010. Two bee-pollinated plant species show higher seed production when grown in gardens compared to arable farmland. PLoS ONE 5.

Denisow, B., and M. Strzałkowska-Abramek. 2013. Characteristics of blooming and pollen in flowers of two Syringa species (f. Oleaceae). Acta Agrobotanica 66:6572.

Egerer, M. H., C. Arel, M. D. Otoshi, R. D. Quistberg, P. Bichier, and S. M. Philpott. 2017. Urban arthropods respond variably to changes in landscape context and spatial scale. Journal of Urban Ecology 1-10.

Garbuzov, M., and F. L. W. Ratnieks. 2014. Quantifying variation among garden plants in attractiveness to bees and other flower-visiting insects. Functional Ecology 28:364-374.

Garibaldi, L. A., L. G. Carvalheiro, S. D. Leonhardt, M. A. Aizen, B. R. Blaauw, R. Isaacs, M. Kuhlmann, D. Kleijn, A. M. Klein, C. Kremen, L. Morandin, J. Scheper, and R. Winfree. 2014. From research to action: enhancing crop yield through wild pollinators. Frontiers in Ecology and the Environment:140923061035000.

Goulson, D., M. E. Hanley, B. Darvill, J. S. Ellis, and M. E. Knight. 2005. Causes of rarity in bumblebees. Biological Conservation 122:1-8.

Goulson, D., E. Nicholls, C. Botías, and E. L. Rotheray. 2015. Bee declines driven by combined stress from parasites, pesticides, and lack of flowers. Science 347:1255957.

Hall, D. M., G. R. Camilo, R. K. Tonietto, J. Ollerton, K. Ahrné, M. Arduser, J. S. Ascher, K. C. R. Baldock, R. Fowler, G. Frankie, D. Goulson, B. Gunnarson, M. E. Hanley, J. I. Jackson, G. Langellotto, D. Lowenstein, E. S. Minor, S. M. Philpott, S. G. Potts, M. H. Sirohi, E. M. Spevak, G. N. Stone, and C. G. Threlfall. 2016. The city as a refuge for insect pollinators. Conservation Biology 31:24-29.

Hanley, M. E., M. Franco, C. E. Dean, E. L. Franklin, H. R. Harris, A. G. Haynes, S. R. Rapson, G. Rowse, K. C. Thomas, B. R. Waterhouse, and M. E. Knight. 2011. Increased bumblebee abundance along the margins of a mass flowering crop: Evidence for pollinator spill-over. Oikos 120:1618-1624.

Holzschuh, A., M. Dainese, J. P. González-Varo, S. Mudri-Stojnić, V. Riedinger, M. Rundlöf, J. Scheper, J. B. Wickens, R. Bommarco, D. Kleijn, S. G. Potts, S. P. M. Roberts, H. G. Smith, M. Vilá, A. Vujić, and I. Steffen-Dewenter. 2016. Mass- 
flowering crops dilute pollinator abundance in agricultural landscapes across Europe. Ecology letters 19:1228-1236.

Holzschuh, A., C. F. Dormann, T. Tscharntke, and I. Steffan-Dewenter. 2013. Massflowering crops enhance wild bee abundance. Oecologia 172:477-484.

Hülsmann, M., H. von Wehrden, A.-M. Klein, and S. D. Leonhardt. 2015. Plant diversity and composition compensate for negative effects of urbanization on foraging bumble bees. Apidologie 46:760-770.

Kämper, W., P. K. Werner, A. Hilpert, C. Westphal, N. Blüthgen, T. Eltz, and S. D. Leonhardt. 2016. How landscape, pollen intake and pollen quality affect colony growth in Bombus terrestris. Landscape Ecology 31:2245-2258.

Kremen, C., N. M. Williams, and R. W. Thorp. 2002. Crop pollination from native bees at risk from agricultural intensification. PNAS 99:16812-16816.

Loram, A., K. Thompson, P. H. Warren, and K. J. Gaston. 2008. Urban domestic gardens ( XII ): The richness and composition of the flora in five UK cities 321330.

McFrederick, Q. S., and G. LeBuhn. 2006. Are urban parks refuges for bumble bees Bombus spp. (Hymenoptera: Apidae)? Biological Conservation 129:372-382.

McKinney, M. L. 2008. Effects of urbanization on species richness: A review of plants and animals. Urban Ecosystems 11:161-176.

Oksanen J., F. G. Blanchet, M. Friendly, R. Kindt, P. Legendre, D. McGlinn, P. R. Minchin, R. B. O'Hara, G. L. Simpson, P. Solymos, M. Henry, H. Stevens, E. Szoecs, and H. Wagner. 2017. vegan: Community Ecology Package. R package version 2.4-3. https://CRAN.R-project.org/package=vegan.

Osborne, J. L., A. P. Martin, N. L. Carreck, J. L. Swain, M. E. Knight, D. Goulson, R. J. Hale, and R. A. Sanderson. 2008. Bumblebee flight distances in relation to the forage landscape. Journal of Animal Ecology 77:406-415.

Parmentier, L., I. Meeus, L. Cheroutre, V. Mommaerts, S. Louwye, and G. Smagghe. 2014. Commercial bumblebee hives to assess an anthropogenic environment for pollinator support: A case study in the region of Ghent (Belgium). Environmental Monitoring and Assessment 186:2357-2367.

Pinheiro, J., D. Bates, S. DebRoy, D. Sarkar, and R Core Team. 2016. _nlme: Linear and Nonlinear Mixed Effects Models_. R package version 3.1-128, <URL: http://CRAN.R-project.org/package=nlme>.

Potts, S. G., J. C. Biesmeijer, C. Kremen, P. Neumann, O. Schweiger, and W. E. Kunin. 2010. Global pollinator declines: Trends, impacts and drivers. Trends in Ecology and Evolution 25:345-353.

Pyšek, P. 1998. Alien and native species in Central European urban floras: a quantitative comparison. Journal of Biogeography 25:155-163.

R Core Team. 2016. R: a language and environment for sta- tistical computing. Vienna. http://www.R-project.org Regali.

Redhead, J. W., S. Dreier, A. F. G. Bourke, M. S. Heard, W. C. Jordan, S. Sumner, J. Wang, and C. Carvell. 2016. Effects of habitat composition and landscape structure on worker foraging distances of five bumble bee species. Ecological Applications 26.

Robinson, R. A., and W. J. Sutherland. 2002. Post-war changes in arable farming and biodiversity in Great Britain . Journal of applied ecology 39:157-176.

Samnegård, U., A. S. Persson, and H. G. Smith. 2011. Gardens benefit bees and enhance pollination in intensively managed farmland. Biological Conservation 144:2602-2606.

Smith, R. M., K. J. Gaston, P. H. Warren, and K. Thompson. 2005. Urban domestic 
gardens (V): relationships between landcover composition, housing and landscape. Landscape Ecology 20:235-253.

Spiesman, B. J., A. Bennett, R. Isaacs, and C. Gratton. 2016. Bumble bee colony growth and reproduction depend on local flower dominance and natural habitat area in the surrounding landscape. Biological Conservation:6-12.

Walther-Hellwig, K., and R. Frankl. 2000. Foraging habitats and foraging distances of bumblebees, Bombus spp. (Hym., Apidae), in an agricultural landscape. Journal of Applied Entomology 124:299-306.

Westphal, C., I. Steffan-Dewenter, and T. Tscharntke. 2003. Mass flowering crops enhance pollinator densities at a landscape scale. Ecology Letters 6:961-965. 


\section{Supplementary Material}

Table S1: Coordinates of 32 different sites from May, bold format indicates the 16 sites used in July

\begin{tabular}{|c|c|c|c|}
\hline Site & $\begin{array}{l}\text { Lands } \\
\text { cape }\end{array}$ & Lat. & Long. \\
\hline Bremke & $\mathbf{A G}$ & 51.424 & 10.073 \\
\hline Dransfeld & $\mathbf{A G}$ & 51.512 & 9.753 \\
\hline Göttingen & $\mathrm{AG}$ & 51.501 & 9.884 \\
\hline Göttingen & AG & 51.490 & 9.905 \\
\hline Lenglern & $\mathrm{AG}$ & 51.596 & 9.884 \\
\hline Moringen & $\mathrm{AG}$ & 51.677 & 9.895 \\
\hline Moringen & AG & 51.703 & 9.907 \\
\hline $\begin{array}{l}\text { Nörten- } \\
\text { Hardenberg }\end{array}$ & $\mathrm{AG}$ & 51.607 & 9.923 \\
\hline Bremke & FA & 51.430 & 10.079 \\
\hline Dransfeld & FA & 51.520 & 9.756 \\
\hline Friedland & FA & 51.473 & 9.955 \\
\hline Göttingen & FA & 51.506 & 9.941 \\
\hline Kalefeld & FA & 51.781 & 10.028 \\
\hline Lenglern & FA & 51.601 & 9.873 \\
\hline Moringen & FA & 51.678 & 9.883 \\
\hline $\begin{array}{l}\text { Wollbrands } \\
\text {-hausen }\end{array}$ & FA & 51.580 & 10.176 \\
\hline
\end{tabular}

\begin{tabular}{|c|c|c|c|}
\hline Site & $\begin{array}{l}\text { Lands } \\
\text { cape }\end{array}$ & Lat. & Long. \\
\hline Diemarden & VI & 51.483 & 9.978 \\
\hline Diemarden & VI & 51.489 & 9.981 \\
\hline Dransfeld & VI & 51.498 & 9.766 \\
\hline Dransfeld & VI & 51.501 & 9.757 \\
\hline Ebergötzen & VI & 51.572 & 10.113 \\
\hline Ebergötzen & VI & 51.570 & 10.108 \\
\hline Moringen & VI & 51.704 & 9.876 \\
\hline Moringen & VI & 51.692 & 9.880 \\
\hline Duderstadt & CI & 51.515 & 10.256 \\
\hline Duderstadt & CI & 51.510 & 10.266 \\
\hline Einbeck & CI & 51.820 & 9.876 \\
\hline Einbeck & CI & 51.816 & 9.885 \\
\hline Göttingen & CI & 51.527 & 9.946 \\
\hline Göttingen & CI & 51.540 & 9.939 \\
\hline Northeim & $\mathrm{CI}$ & 51.712 & 9.999 \\
\hline Northeim & CI & 51.701 & 9.998 \\
\hline
\end{tabular}



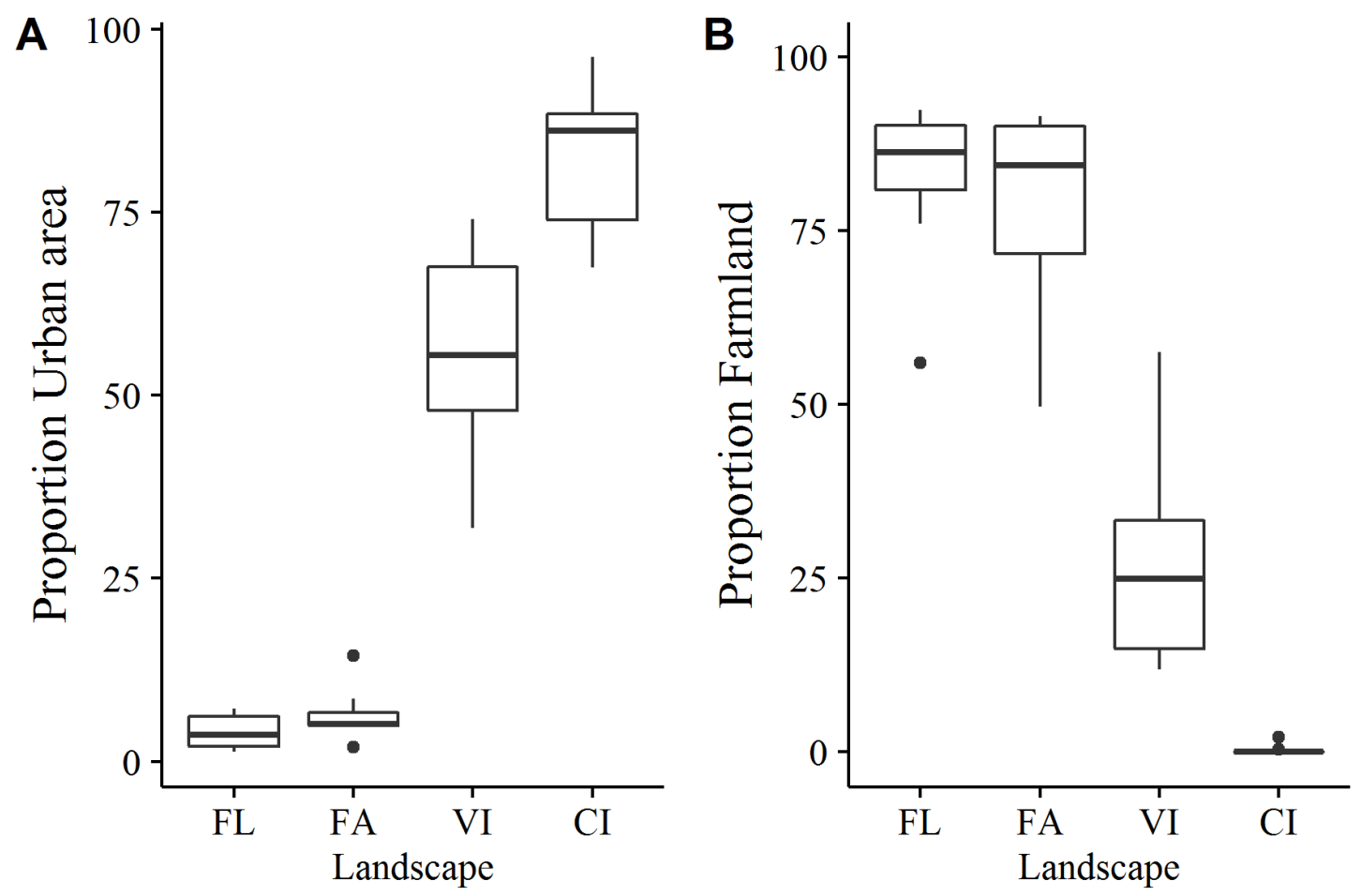

Fig. S1: Proportion of urban area and farmland within a radius of $500 \mathrm{~m}$. $\mathrm{FL}=$ Farmland, $\mathrm{n}=7 ; \mathrm{FA}=$ Farmhouse, $\mathrm{n}=8 ; \mathrm{VI}=$ Village $\mathrm{n}=8 ; \mathrm{CI}=$ City, $\mathrm{n}=8$. 
Table S2: Preparation of pollen samples from honey and wax.

University of Jambi, Department of Palynology and Climate Dynamics

Suggested number of samples per time: 10

Always wear gloves and lab coat when working in the lab.

1) Switch on the water bath; check if there is enough water in it (it takes more than 30 minutes to heat up to $90^{\circ} \mathrm{C}$ ).

2) Transfer the honey and or wax in a conical test tube. Make sure to wash all the tools to avoid contamination between samples.

3) Only for the honey (for the wax move to step 5): add $4 \mathrm{ml}$ of concentrated acetic acid (CH3COOH) to the sample (for dehydration) and mix the content.

4) Centrifuge the tubes for $5 \mathrm{~min}$. at $3500 \mathrm{RPM}$. and pour of the supernatant in a beaker and then in the acetic acid waste container).

5) Acetolysis: make sure all the tools are dry including the gloves! Use the measuring cylinder to prepare a mixture of 9 parts acetic anhydride $((\mathrm{CH} 3 \mathrm{CO}) 2 \mathrm{O})$ and 1 part concentrated sulphuric acid (H2SO4). Fill in first the acetic anhydride then the sulphuric acid. Add the one part of sulphuric acid into the measuring cylinder using a plastic pipette very slowly (exothermic reaction, might get warm).

Be careful $\mathrm{H} 2 \mathrm{SO} 4$ reacts with water!

e.g. of calculation $-4 \mathrm{ml}$ per sample:

For 1 sample à $3.6 \mathrm{ml}(\mathrm{CH} 3 \mathrm{CO}) 2 \mathrm{O}+0,4 \mathrm{ml} \mathrm{H} 2 \mathrm{SO} 4$

For 10 samples à $36 \mathrm{ml}(\mathrm{CH} 3 \mathrm{CO}) 2 \mathrm{O}+4 \mathrm{ml} \mathrm{H} 2 \mathrm{SO} 4$

It is recommended to prepare a bit more, e.g. per 10 samples ca. $39.6 \mathrm{ml}(\mathrm{CH} 3 \mathrm{CO}) 2 \mathrm{O}+4.4 \mathrm{ml}$ $\mathrm{H} 2 \mathrm{SO} 4$

6) Add ca. $4 \mathrm{ml}$ of the Acetolysis mixture to each sample (first $2 \mathrm{ml}$ and then the other $2 \mathrm{ml}$ ) using the plastic pipette. Mix, if necessary, thoroughly with a plastic stick, one for each sample (be careful not to use wet tools). Remove the plastic sticks.

7) Put the tubes into the water bath for 10 minutes at $90^{\circ} \mathrm{C}$. Leave the water bath open! You will see the colour turning dark yellow. Centrifuge the tubes for $5 \mathrm{~min}$. at $3500 \mathrm{RPM}$ and pour off the supernatant in a beaker.

8) Wash the samples with distilled water one or more times (until the water is clear): fill them up equally with water mix with clean plastic sticks if necessary, centrifuge for $5 \mathrm{~min}$. at $3500 \mathrm{RPM}$, pour off the supernatant in the beaker. If the sample is solid add acetic acid to the top and centrifuge.

At the end empty the beaker into the Acetolysis waste container.

9) If necessary sieve the sample with a $150 \mu \mathrm{m}$ filter and then back sieve in the original tubes

10) Transfer the residues into labelled Eppendorf-tubes.

11) Centrifuge the Eppendorf tubes for 3 minutes at 12000 RPM and pour off the water supernatant.

12) Create pollen slides using glycerine gel as fixer. 
Table S3: Flowering plant families at the sites and visited plant families.

\begin{tabular}{|l|l|l|}
\hline \multicolumn{3}{|c|}{ May } \\
\hline Site & $\begin{array}{l}\text { Number } \\
\text { Plant } \\
\text { Families }\end{array}$ & $\begin{array}{l}\text { Number } \\
\text { Pollen } \\
\text { Families }\end{array}$ \\
\hline Farmland & 28 & 29 \\
\hline Farmhouse & 41 & 34 \\
\hline Village & 48 & 40 \\
\hline City & 41 & 32 \\
\hline total & 61 & 49 \\
\hline
\end{tabular}

\begin{tabular}{|l|l|l|}
\hline \multicolumn{3}{|c|}{ July } \\
\hline Site & $\begin{array}{l}\text { Number } \\
\text { Plant } \\
\text { Families }\end{array}$ & $\begin{array}{l}\text { Number } \\
\text { Pollen } \\
\text { Families }\end{array}$ \\
\hline Farmland & 18 & 32 \\
\hline Farmhouse & 36 & 32 \\
\hline Village & 36 & 30 \\
\hline City & 41 & 33 \\
\hline total & 52 & 49 \\
\hline
\end{tabular}

Table S4: Dissimilarity indices calculated using Bray-Curtis index (“"vegdist"-function) that support Fig. 1 and 2. Numbers closer to 1 indicate dissimilar communities and numbers closer to 0 indicate similar communities.

\begin{tabular}{|l|l|l|l|l|}
\hline \multicolumn{5}{|c|}{ May } \\
\hline $\begin{array}{l}\text { Plant } \\
\text { Community } \\
\text { similarity }\end{array}$ & CI & $\mathbf{0 . 5 8}$ & & \\
\cline { 2 - 5 } & FA & $\mathbf{0 . 5 7}$ & $\mathbf{0 . 2 4}$ & \\
\cline { 2 - 5 } & VI & $\mathbf{0 . 6 6}$ & $\mathbf{0 . 2 8}$ & $\mathbf{0 . 2 3}$ \\
\hline
\end{tabular}

\begin{tabular}{|l|l|l|l|}
\hline \multicolumn{4}{|c|}{ July } \\
\hline & AG & CI & FA \\
\hline CI & $\mathbf{0 . 7 2}$ & & \\
\hline FA & $\mathbf{0 . 6 8}$ & $\mathbf{0 . 2 6}$ & \\
\hline VI & $\mathbf{0 . 7 0}$ & $\mathbf{0 . 2 2}$ & $\mathbf{0 . 2 1}$ \\
\hline
\end{tabular}

\begin{tabular}{|c|c|c|c|c|}
\hline \multirow{4}{*}{$\begin{array}{l}\text { Pollen } \\
\text { Community } \\
\text { similarity }\end{array}$} & & $\mathrm{AG}$ & CI & FA \\
\hline & CI & 0.30 & & \\
\hline & FA & 0.22 & 0.25 & \\
\hline & VI & 0.25 & 0.18 & 0.20 \\
\hline
\end{tabular}

\begin{tabular}{|l|l|l|l|}
\hline & AG & CI & FA \\
\hline CI & $\mathbf{0 . 4 2}$ & & \\
\hline FA & $\mathbf{0 . 4 0}$ & $\mathbf{0 . 3 4}$ & \\
\hline VI & $\mathbf{0 . 5 0}$ & $\mathbf{0 . 2 4}$ & $\mathbf{0 . 3 6}$ \\
\hline
\end{tabular}




\section{Chapter 4}

\section{Plant-Pollinator Interactions along an \\ Urbanisation Gradient from Cities and Villages to Farmland Landscapes}

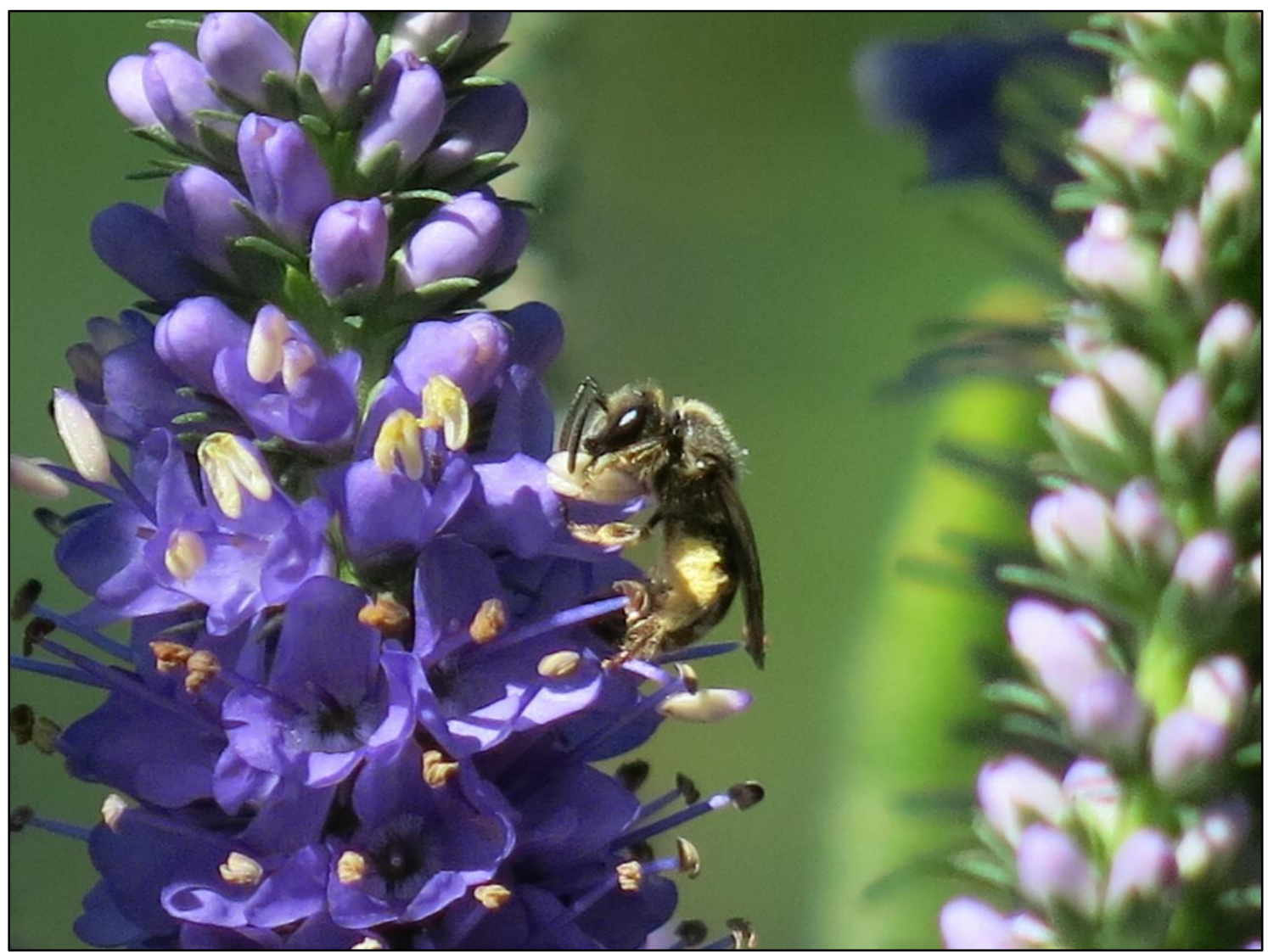

Heriades truncorum (L.) on Veronica spicata (L.) (June 2015, ( Hannah Reininghaus)

Authors:

Kristy Leah Udy, Hannah Reininghaus, Christoph Scherber and Teja Tscharntke 


\begin{abstract}
Urbanisation affects pollinator diversity and plant-pollinator networks by changing resource availability locally and in the surrounding landscape. To determine how plantpollinator communities change with increasing urbanisation, we experimentally established $\mathrm{N}=12$ standardised plant communities in farmland, villages and cities to identify the relative role of local and landscape effects along this urbanisation gradient. We found that species richness of pollinators and plant-pollinator network metrics such as robustness, interaction evenness and interaction diversity decreased with increasing urbanisation, although local plant richness increased in urban areas. Number of flower visits by solitary bees, but not bumblebees, syrphid flies and other flies, were highest in cities and lowest in farmland, with villages being intermediate. The high plant species richness in urban gardens appeared to support solitary bees more than other pollinator groups. In conclusion, urban and farmland landscapes support different pollinator communities. Enriching the interface between these two landscape types is of particular importance for a complementary pollinator community.
\end{abstract}

Keywords: plant-pollinator network; urbanisation; city size; plant richness; solitary bees; syrphid flies. 


\section{Introduction}

Worldwide, the predominant landscape type is farmland interspersed with urban areas, with rural areas generally supporting lower insect diversity than urban areas (Bates et al. 2011). This depends on local habitat quality, as natural areas do support highest insect diversity, but they are often small in size and patchily distributed throughout the landscape. Yet, plant richness in urban areas is often higher due to the presence of many non-native plants in gardens (Pyšek 1998), positively affecting flower-visiting taxa (Baldock et al. 2015, Sirohi et al. 2015). Urban gardens and other green areas play a particularly important role for pollinators as they provide pollen and nectar resources for pollinators (Ahrne et al. 2009).

The majority of studies comparing farmland with urban areas find that wild bees are more diverse and abundant in urban areas (Hall et al. 2016). However, Bates et al. (2011) found the opposite, and Ahrne et al. (2009) found that bumblebee richness shows a negative relationship with increasing urbanisation. These contrasting results illustrate that urbanisation effects on pollinators may be diverse. Additionally, urban ecology studies have so far mostly been conducted in a single city and did not compare a range of urban area size on pollinator community composition (Egerer et al. 2017). Here, we employ a novel approach using standardised plant communities along an urban-rural gradient to study a broad range of pollinator groups. This approach allows strong inference (due to its experimental nature) and generalisations extending beyond previous studies (Geslin et al. 2013, Theodorou et al. 2017). Our design also covers a broad gradient in city size, from small villages to mid-size cities.

The structure of plant-pollinator networks may change with community composition and richness of pollinators (higher richness correlates with higher network stability (McCann 2000, Dunne et al. 2002)). These networks are based on the local plant community (Memmott 1999), but are still influenced by the surrounding landscape. It is therefore difficult to disentangle the influences of local from landscape features on plant-pollinator networks. This can be achieved using an experimental approach where the same plant community is replicated in different urban landscapes (Geslin et al. 2013, Theodorou et al. 2017).

Pollinators need floral resources and nesting sites to survive (Westrich 1996, Ebeling et al. 2008), provided by green spaces in urban areas, where plant diversity and floral resources are abundant. Private gardens and parks provide many floral resources with 
high plant richness and high temporal stability (Fetridge et al. 2008). This resource stability is not the case in farmland, where mass flowering crops can support some pollinator species, but only for a limited time period per year (Westphal et al. 2003). Wild bee pollinators require semi-natural habitat as nesting resource, whereas syrphid flies are not linked to semi-natural habitat availability in the landscape (Jauker et al. 2009). Syrphid flies are present at much higher diversity and abundance in farmland landscapes with no semi-natural habitats than wild bees (Verboven et al. 2014, Baldock et al. 2015) and may also be effective pollinators (Orford et al. 2015). Hence, pollinator communities can be expected to show different responses to urbanisation depending on the pollinator group considered.

We test how pollinator communities change across an urbanisation gradient comparing farmland with villages and cities and how plant-pollinator network structure is altered in these different landscapes. We controlled for the potential influence of the local composition of floral resources by conducting pollinator observations on experimental plant patches where the same plant species were grown under the same conditions along our urbanisation gradient.

\section{Material and Methods}

\section{Study sites}

The study was conducted in North-Central Germany, in the Southern part of the federal state of Lower Saxony, within a $30 \mathrm{~km}$ radius of Göttingen (51³2’28.61'N, 954'56.89'E). We sampled along an urbanisation gradient from farmland and villages to cities, including grassy field margins in pure farmland, and gardens in villages and cities. Farmland sites were at least $500 \mathrm{~m}$ from the nearest house. Village sites were close to the village edge and were surrounded by a $500 \mathrm{~m}$ buffer comprising approximately $50 \%$ urban and $50 \%$ farmland. City sites were at least $500 \mathrm{~m}$ from the city edge and were completely surrounded by a buffer of $100 \%$ urban area (Fig. 1). Our urbanisation gradient was constructed in this way to test the influence of amount of farmland in the landscape and the urban area size. $\mathrm{N}=12$ sites were used: four farmland sites (maximum distance $30 \mathrm{~km}$ from Göttingen), two villages (two gardens each: Dransfeld $\quad\left(51^{\circ} 500^{\prime} 06.01^{\prime \prime N}, \quad 9^{\circ} 76^{\prime} 23.95^{\prime \prime} \mathrm{E}\right)$ and Diemarden $\left(51^{\circ} 48^{\prime} 72.82^{\prime \prime} \mathrm{N}\right.$, 9 98'05.67'E) and two cities (two gardens each: Göttingen and Einbeck $\left(51^{\circ} 49^{\prime} 13.29^{\prime \prime} \mathrm{N}, 9^{\circ} 52^{\prime} 6.14^{\prime \prime} \mathrm{E}\right)$, separated by a minimum of $500 \mathrm{~m}$ inside the city border). 

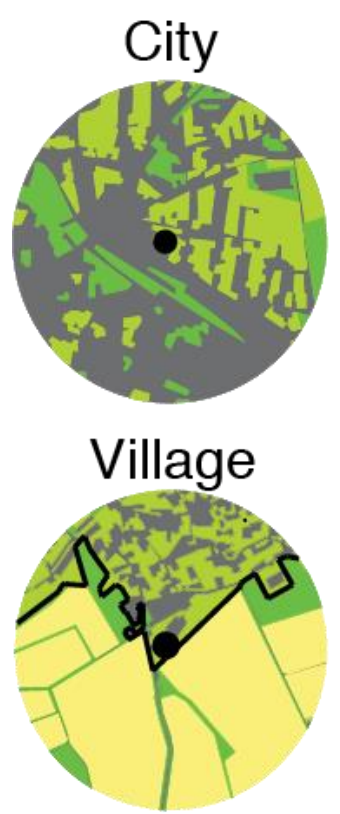

Farmland
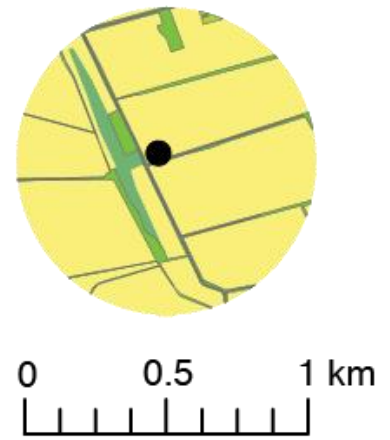

Farmland

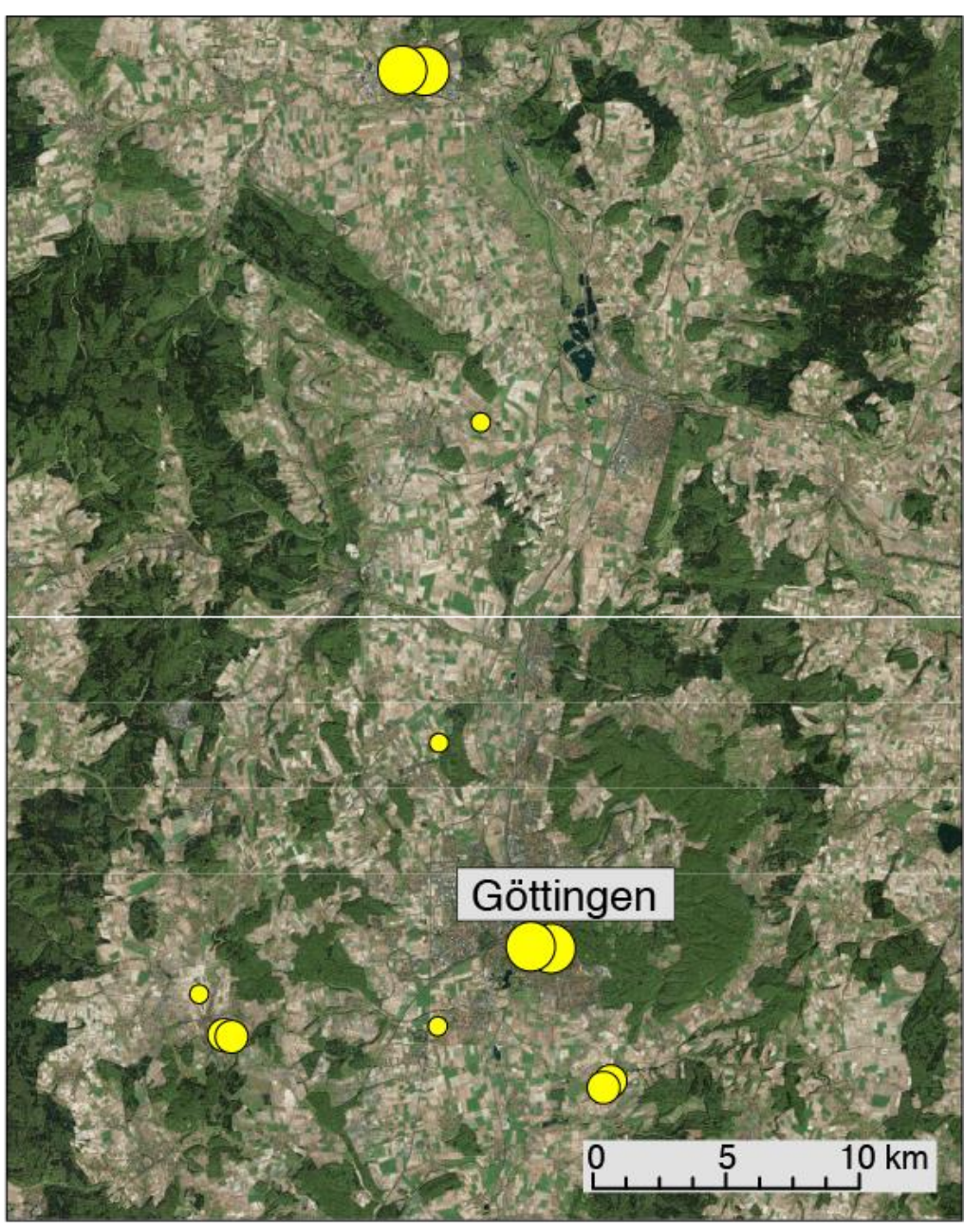

Garden

Green space Forest Urban

Fig. 1: GIS maps (ArcGIS, v. 10.4.1, ESRI) of the three different landscape types used. Yellow points indicate the sites used and point size denotes urban area type, small $=$ farmland, medium $=$ village and large $=$ city. Buffer is $500 \mathrm{~m}$ in radius with colours denoting land-use types in each landscape. The black point on each map denotes our site and the black line in the village landscape indicates the border of the urban area.

(C) Hannah Reininghaus. Basemap source: Esri basemap (Bing).

\section{Experimental plant plots}

Experimental plant patches were established in April 2015 (size 80 x 80cm) in the 12 sites (Fig. 2). We standardised soil conditions by using a soil mix at all sites (mix from volcanic clay, peat, lime carbonate and NPK fertiliser; $180 \mathrm{mg} / \mathrm{L} \mathrm{N}, 180 \mathrm{mg} / \mathrm{L} \mathrm{P}$; $260 \mathrm{mg} / \mathrm{L} \mathrm{K} ; 130 \mathrm{mg} / \mathrm{L} \mathrm{Mg}$ and $100 \mathrm{mg} / \mathrm{L}$ of $\mathrm{S}$ with a $\mathrm{pH}$ of 5.9). Approximately $30 \mathrm{~mL}$ of NPK fertiliser was added when the seeds were planted, which contained equal parts $\mathrm{N}(8 \%)$ and $\mathrm{P}(8 \%)$. The numbers of plant seeds used were standardised to approximately 20 seeds per plant species and were evenly scattered over the soil. The plant species used were: Phacelia tanacetifolia (Benth.) and Sinapis arvensis (L.). 
These annual plant species were chosen as they flower in the first year and have a variety of flower shape and colour so they would be attractive to a wide range of pollinators and functional groups. Plant patches were watered once a week with $10 \mathrm{~L}$ of water and fertilised once more after one month. The perennial plants Veronica spicata (L.) and Astilbe chinensis (Maxim.) were added to the plant plots in June. This mixture of four plant species included plants with high quality pollen and nectar that are attractive to pollinators and a mixture of flower types with open and tubular both represented and also a mixture of colours: yellow, white and purple (Pritsch 2007). All our plant species flowered simultaneously at the start of July for 2 weeks.

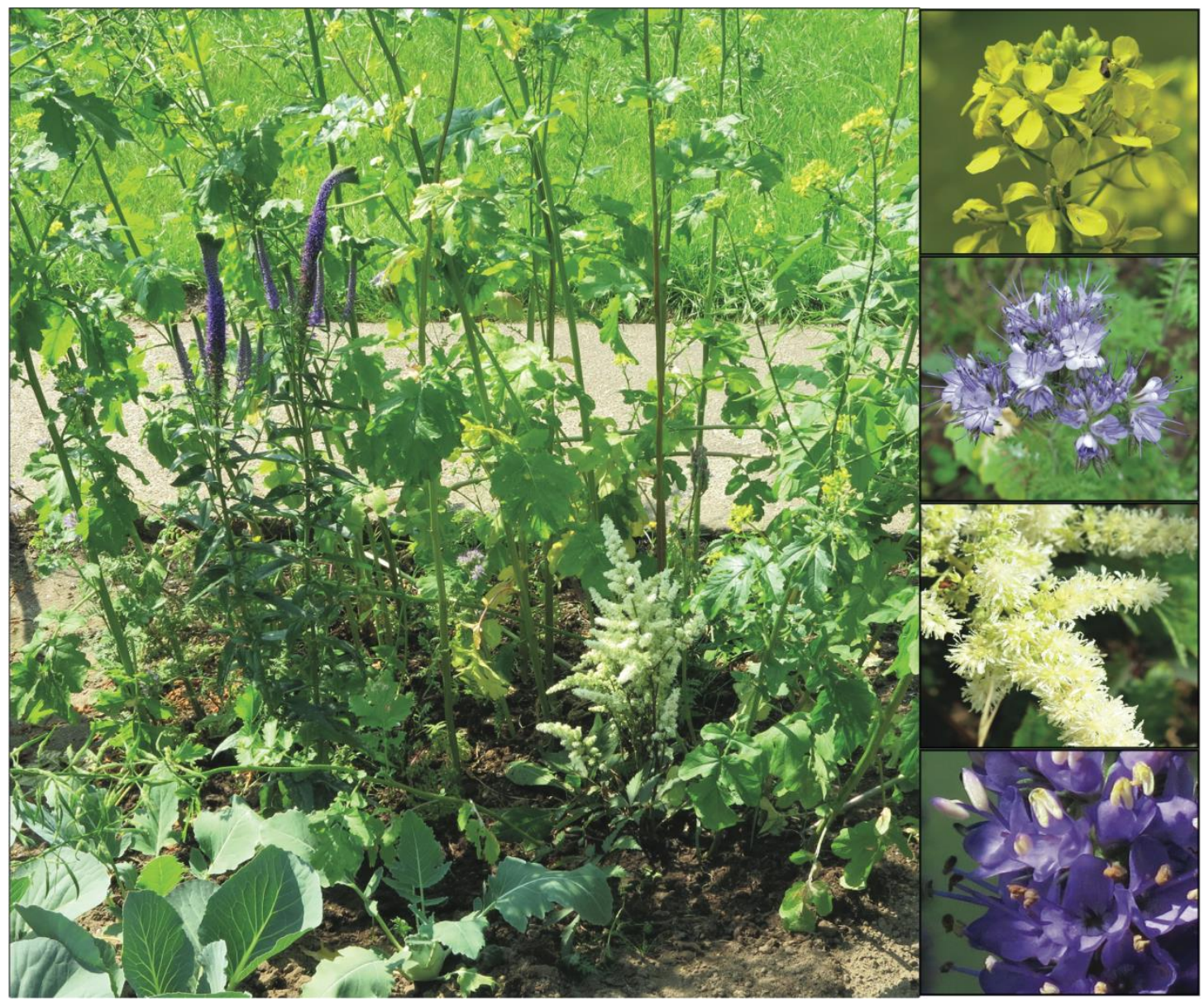

Fig. 2: Experimental plant plot. Plant species are from top to bottom: Sinapis arvensis, Phacelia tanacetifolia, Astilbe chinensis and Veronica spicata. (C) Kristy Udy. 


\section{Pollinator Observations}

Insect observations were run in early July (Leong et al. 2016) 2015 for 15-minute intervals at two different times of the day (total observation hours $=6)$ : morning $(10$ 11:30) and midday (12:45-14:30), these times were centred on midday (13:15), calculated as the midpoint between sunrise and sunset. Six plant plots were visited each day, three per time period, and the order they were visited was randomised. Observations were conducted on a corner of each plant plot $(50 \times 50 \mathrm{~cm})$. We observed all insect pollinators that visited a flower, identified them to genus or species level and counted the number of visits (landing on a single flower equals one visit) for each insect until it left the plant plot. We also recorded which plant species each insect pollinator was on. Insect pollinators included: solitary bees (i.e. non-bumblebees), bumblebees, butterflies, syrphid flies, non-syrphid flies and wasps. Honeybees (total $=79$ specimens) were observed but later excluded from analysis as their presence in the landscape depends on whether there are hives set up nearby. All flowering plants within a distance of $20 \mathrm{~m}$ were identified to species level and total flower cover was estimated.

\section{Statistics}

We found no differences in pollinator richness and their abundance between morning and mid-day observations; thus, abundances were summed for every observation day, resulting in a total of 363 data points. All analyses were performed using R (version 3.3.0; $\mathrm{R}$ core Team 2016). All response variables were tested against the landscape gradient and plant species richness (all plant species within $20 \mathrm{~m}$ of plant plot). These variables were always tested in separate models, as plant species richness was influenced by landscape type (Fig. 3). To test these influences on the pollinator richness and their number of visits, we used mixed-effects models (Bates et al. 2015) with site included as a random effect. We tested which distribution fitted each response variable using the fitdistrplus package (Delignette- Muller and Dutang 2015). Poisson models were used to test pollinator richness against the explanatory variables and negative binomial models (Bates et al. 2015) were used to test number of visits as the counts indicated overdispersion (Crawley 2013). Pollinator group was tested using multinomial models (Venables and Ripley 2002) against our explanatory variables. Wasps and butterflies were excluded from all analyses, as they were present in only two of the 12 sites. Bipartite networks (Fig. 7) were created from the plant-pollinator interactions for 
each site and their structure analysed with network level metrics using the bipartite package (Dormann et al. 2008). The network level metrics used were: robustness, interaction evenness and Shannon diversity of interactions (based on: Blüthgen et al. 2006). All models were simplified using a list of candidate models with all possible combinations of experimental variables and interactions; models were ranked based on AICc and the model with the lowest AICc value was used (Information Theoretic approach (Mazerolle 2016)).

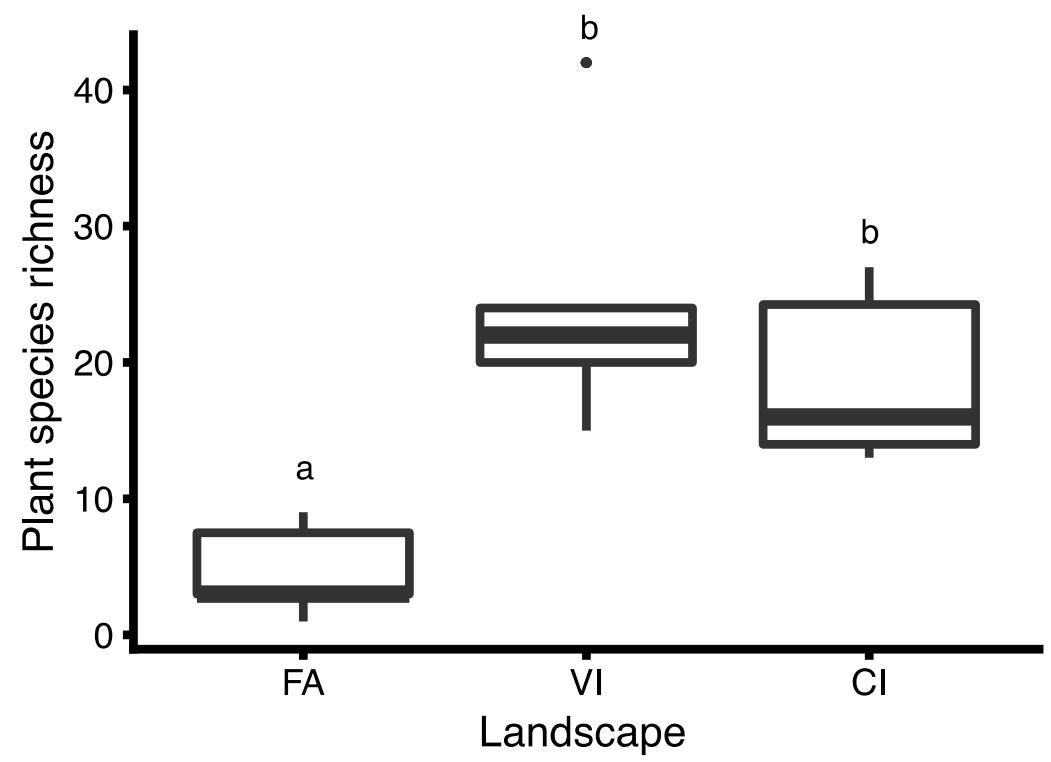

Fig. 3: Flowering plant species richness within $20 \mathrm{~m}$ of experimental plant patches in different landscapes along an urbanisation gradient. $\mathrm{N}_{\mathrm{FA}}=4, \mathrm{~N}_{\mathrm{VI}}=4, \mathrm{~N}_{\mathrm{CI}}=4$; $\mathrm{FA}=$ Farmland, $\mathrm{VI}=$ Village, $\mathrm{CI}=$ City. Bars that do not share the same letter show significant differences $(\mathrm{p}<0.05)$.

\section{Results}

We observed 18 pollinator morphospecies in farmland, and 15 morphospecies in both villages and cities. Of these, there were a total of 117 individuals in farmland, 115 in villages and 79 in cities and total number of flower visits by these individuals was 525 in farmland, 536 in villages and 293 in cities. Flower visitor taxonomic groups were classified into: solitary bees, bumblebees, syrphid flies and non-syrphid flies.

The pollinator group identity $($ Chi-square $=53.13$, d.f. $=3, \mathrm{p}<0.001)$ and an interaction between pollinator group identity and landscape type (Chi-square $=50.46$, d.f. $=5$, $\mathrm{p}<0.001)$ influenced the number of visits by pollinating insects with solitary bees and syrphid flies visiting flowers most often, but in different landscape types (Fig. 4; Table 1). The visits by syrphid flies were higher in farmlands and villages than in cities 
(Chi-square $=51.05$, d.f. $=2, \mathrm{p}<0.001)$ and visits by solitary bees were higher in urban areas than in farmland (Chi-square $=6.93$, d.f. $=2, p=0.031$ ). The other main pollinator groups, except for solitary bees, also showed a negative trend with increasing urbanisation (Fig. 4). The probability of occurrence of pollinator groups was significantly influenced by landscape type (LR Chi-square $=721.81$, d.f. $=2$, p < 0.001; Supplementary material Fig. S1) and was also influenced by plant richness in the direct surroundings $($ LR Chi-square $=185.59$, d.f. $=1, \mathrm{p}<0.001)$. With high plant richness, fewer pollinators per group were present. This pattern is most likely due to plant species richness being positively correlated with presence of urban area as plant richness was higher in villages and cities compared to farmland (urban area = impermeable sealed ground; Pearson correlation $=41 \%$; Fig. 3 ).

Pollinator richness was highest in farmland areas (Chi-square $=8.31$, d.f. $=1$, $\mathrm{p}=0.016$ ) where plant richness was lowest (Chi-square $=6.33$, d.f. $=1, p=0.012$; Fig. 5). Community composition also changed in the different landscapes, with solitary bees dominating in urban areas and syrphid flies dominating in farmland landscapes, but overlapping in the village landscapes (Fig. 4). Plant-pollinator networks (Fig. 7, Supplementary Table S1) were more robust in farmland and in villages compared with cities (F-ratio $=6.962,9, \mathrm{p}=0.015$; Fig. 6) and had the highest interaction evenness in farmland compared to urban areas $(\mathrm{F}-$ ratio $=8.992,9, \mathrm{p}=0.007)$. Shannon diversity of interactions was also highest in farmland and in villages compared with cities ( F-ratio $=$ $10.482,9, \mathrm{p}=0.005)$ 
Table 1: Chi-square values, degrees of freedom (as subscript) and level of significance for all variables and responses.

\section{Pollinators}

\begin{tabular}{|c|c|c|c|}
\hline & No. of visits ${ }^{* 1}$ & $\begin{array}{l}\text { No. of visits } \\
\text { Syrphid*1 }\end{array}$ & $\begin{array}{l}\text { No. of visits } \\
\text { solitary bee }{ }^{*} 1\end{array}$ \\
\hline Pollinator type & $53.133 * * *$ & NA & NA \\
\hline Landscape type $*^{5}$ & $50.46_{5} * * *$ & $51.05_{2} * * *$ & $6.93_{2} *$ \\
\hline \multirow[t]{2}{*}{ Plant richness } & $0.001_{3}$ & $0.04_{1}$ & $0.6_{1}$ \\
\hline & $\begin{array}{l}\text { Probability of } \\
\text { occurrence } *^{2,3}\end{array}$ & $\begin{array}{c}\text { Species } \\
\text { richness } *^{4}\end{array}$ & \\
\hline Pollinator type & NA & 0.069 & \\
\hline Landscape type & $721.81_{2} * * *$ & $8.31_{1} *$ & \\
\hline Plant richness & $185.599_{2} * * *$ & $6.33_{1} *$ & \\
\hline
\end{tabular}

Network structure (test $=$ linear mixed effects model $)$

\begin{tabular}{|l|ccc|}
\hline & Robustness & $\begin{array}{c}\text { Interaction } \\
\text { evenness }\end{array}$ & $\begin{array}{c}\text { Shannon } \\
\text { diversity of } \\
\text { interactions }\end{array}$ \\
\hline Landscape type & $6.96_{2,9} *$ & $8.99_{2,9} * *$ & $10.48_{2,9} * *$ \\
\hline
\end{tabular}

$*^{1}$ tested using mixed effects model with negative binomial family

$*^{2}$ tested using multinomial with pollinator type as response

$*^{3}$ tested with LR Chi-square

$*^{4}$ tested using mixed effects model with poisson family

$*^{5}$ for 'number of visits' this is an interaction: landscape type* pollinator type 


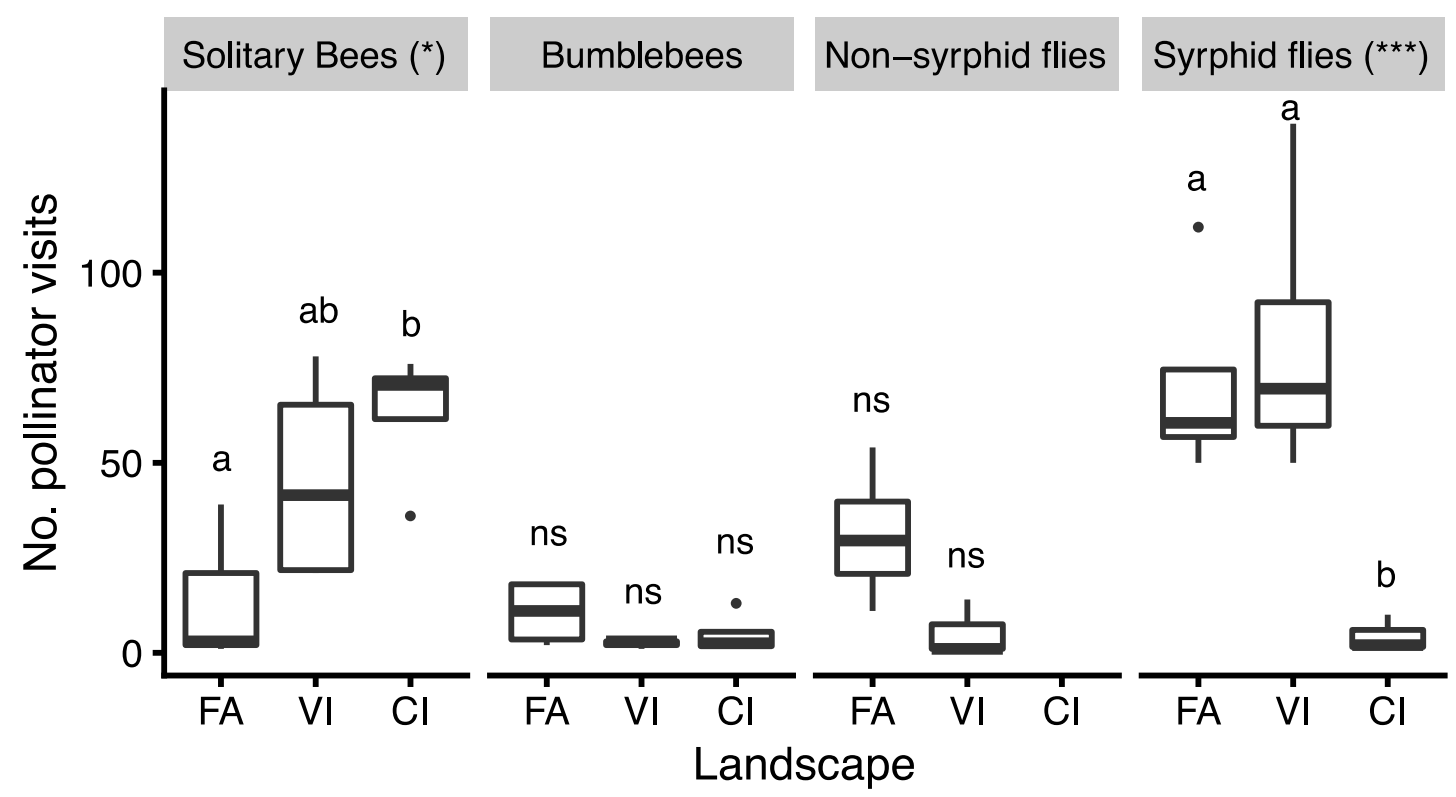

Fig. 4: Number of pollinator visits for each pollinator group. Syrphid flies exhibited more flower visits than the other pollinator groups $(\mathrm{p}<0.001)$ and had more visits in farmland and villages than in cities $(\mathrm{p}<0.001)$. Solitary bees showed the opposite trend with more visits in urban areas than in farmland $(\mathrm{p}=0.031) . \mathrm{N}_{\mathrm{FA}}=4, \mathrm{~N}_{\mathrm{VI}}=4, \mathrm{~N}_{\mathrm{CI}}=4$; $\mathrm{FA}=$ Farmland, $\mathrm{VI}=$ Village, $\mathrm{CI}=$ City. Bars that do not share the same letter show significant differences $(\mathrm{p}<0.05)$. NS $=$ no significant differences $(\mathrm{p}>0.05)$.
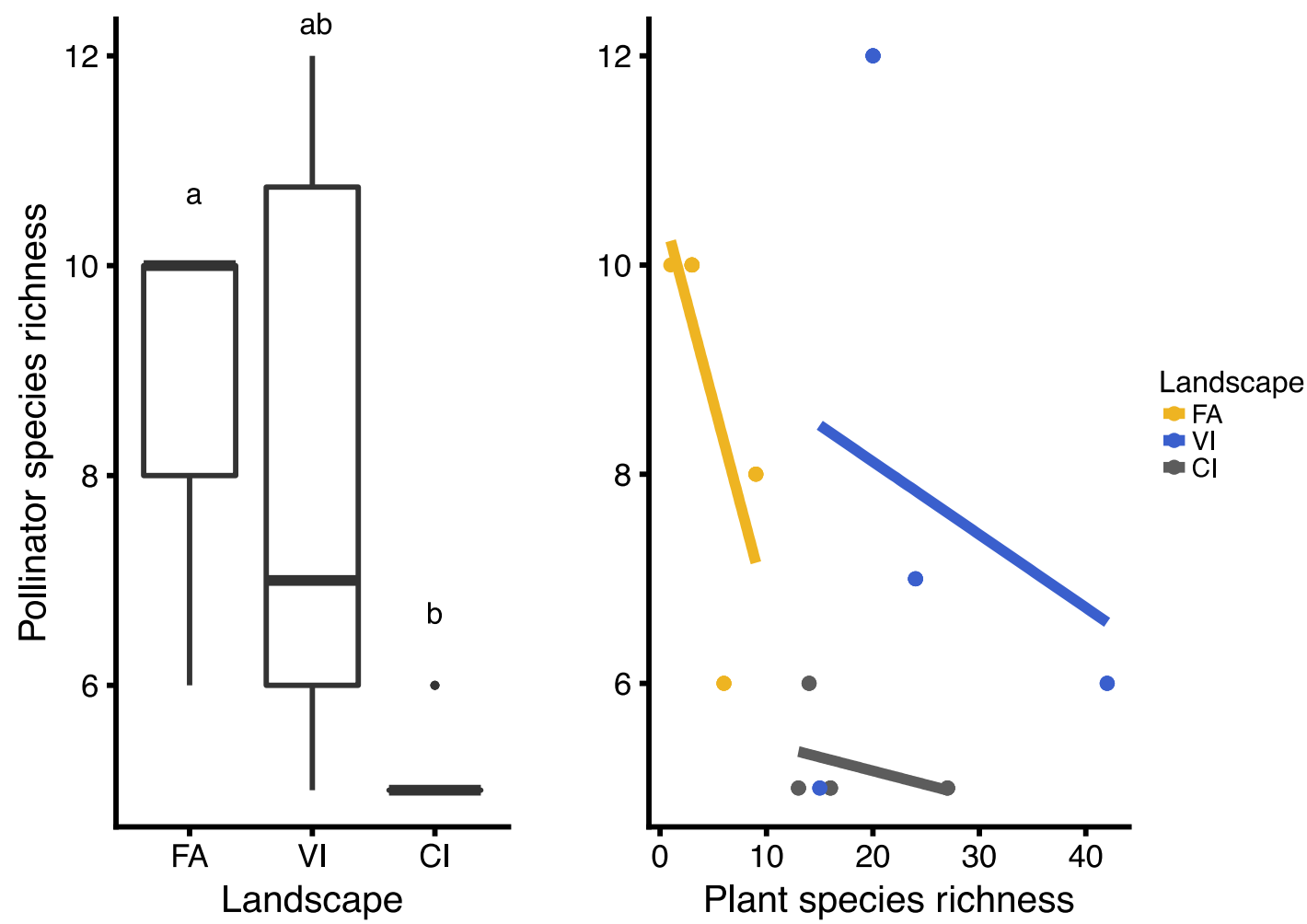

Fig. 5: Pollinator morphospecies richness was influenced by landscape type and plant species richness in the local surroundings. $\mathrm{N}_{\mathrm{FA}}=4, \mathrm{~N}_{\mathrm{VI}}=4, \mathrm{~N}_{\mathrm{CI}}=4 ; \mathrm{FA}=$ Farmland, $\mathrm{VI}=$ Village, $\mathrm{CI}=$ City. Bars that do not share the same letter show significant differences $(\mathrm{p}<0.05)$. 

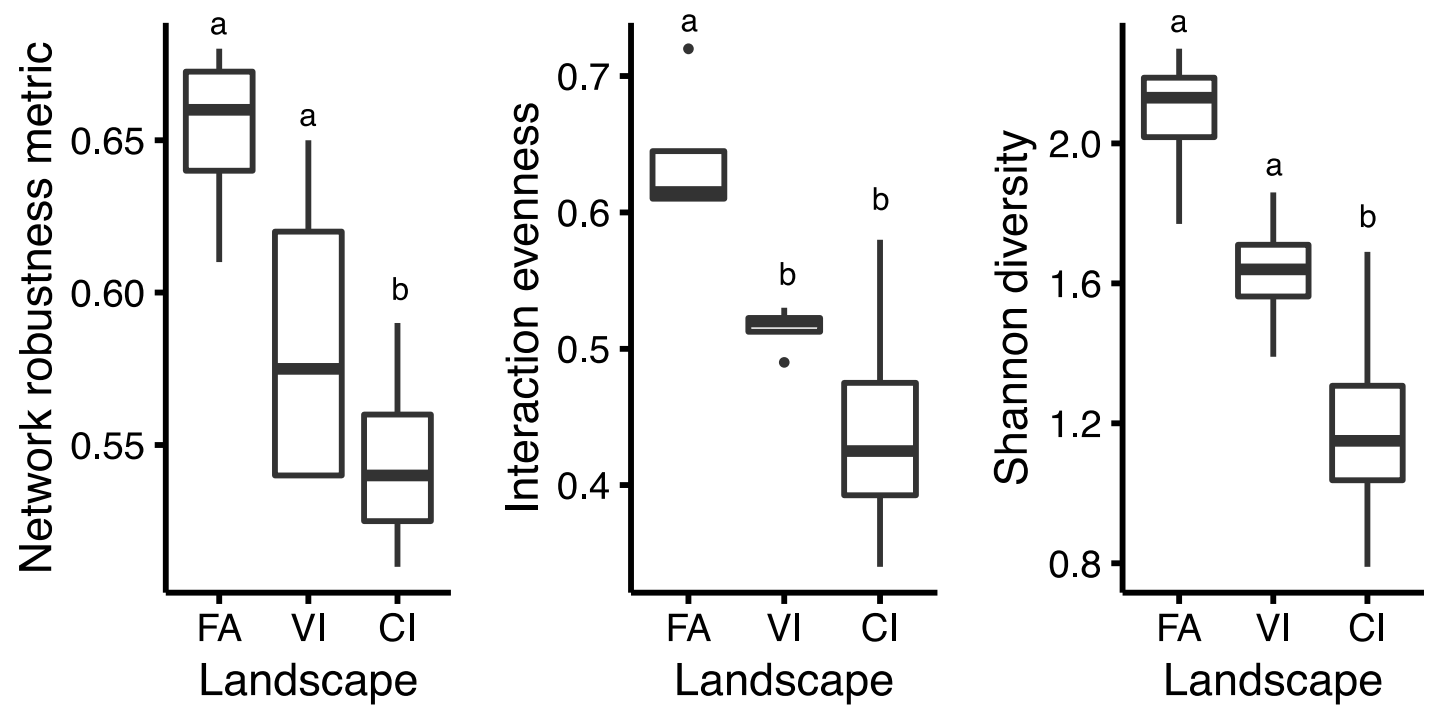

Fig. 6: Network metrics tested against the influence of landscape. Insect communities had significantly higher robustness $(p=0.014)$, interaction evenness $(p=0.007)$ and Shannon diversity $(\mathrm{p}=0.005)$ in farmland landscapes. $\mathrm{N}_{\mathrm{FA}}=4, \mathrm{~N}_{\mathrm{VI}}=4, \mathrm{~N}_{\mathrm{CI}}=4$; $\mathrm{FA}=$ Farmland, $\mathrm{VI}=$ Village, $\mathrm{CI}=$ City. Bars that do not share the same letter show significant differences $(\mathrm{p}<0.05)$. 


\section{Farmland}

14

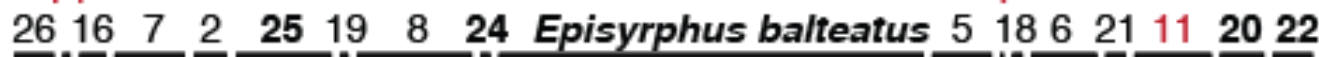

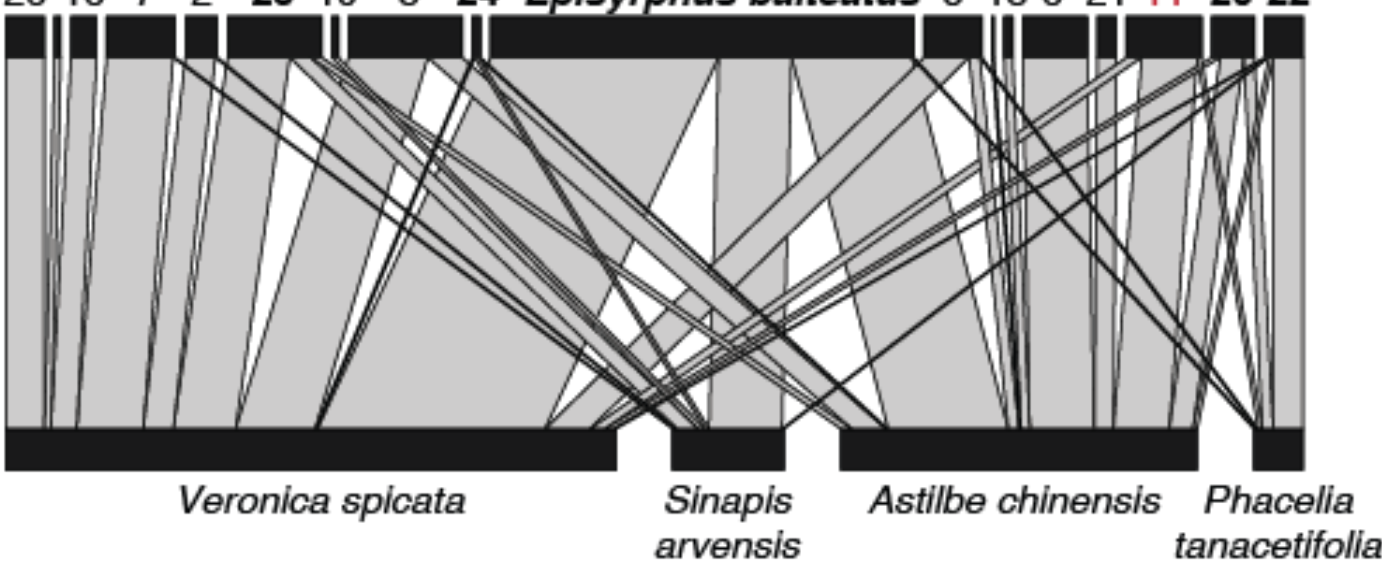

\section{Village}

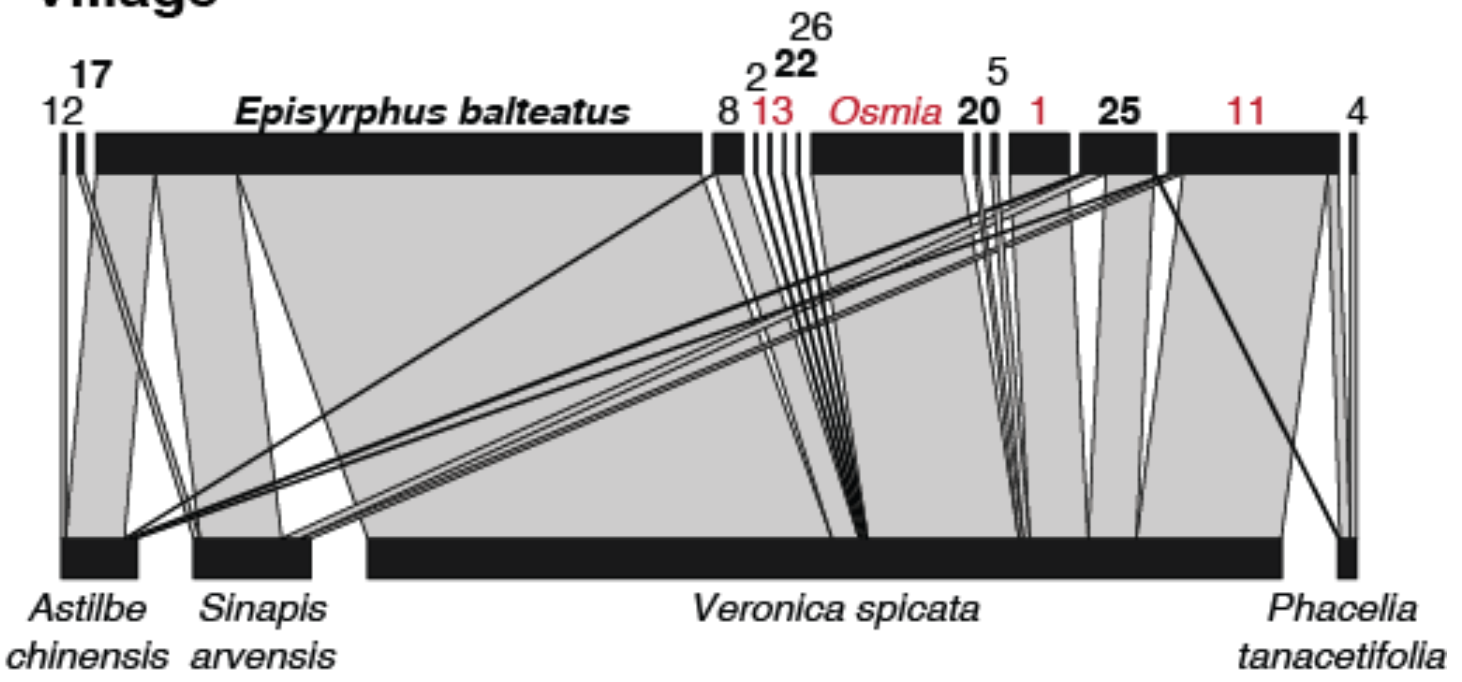

City

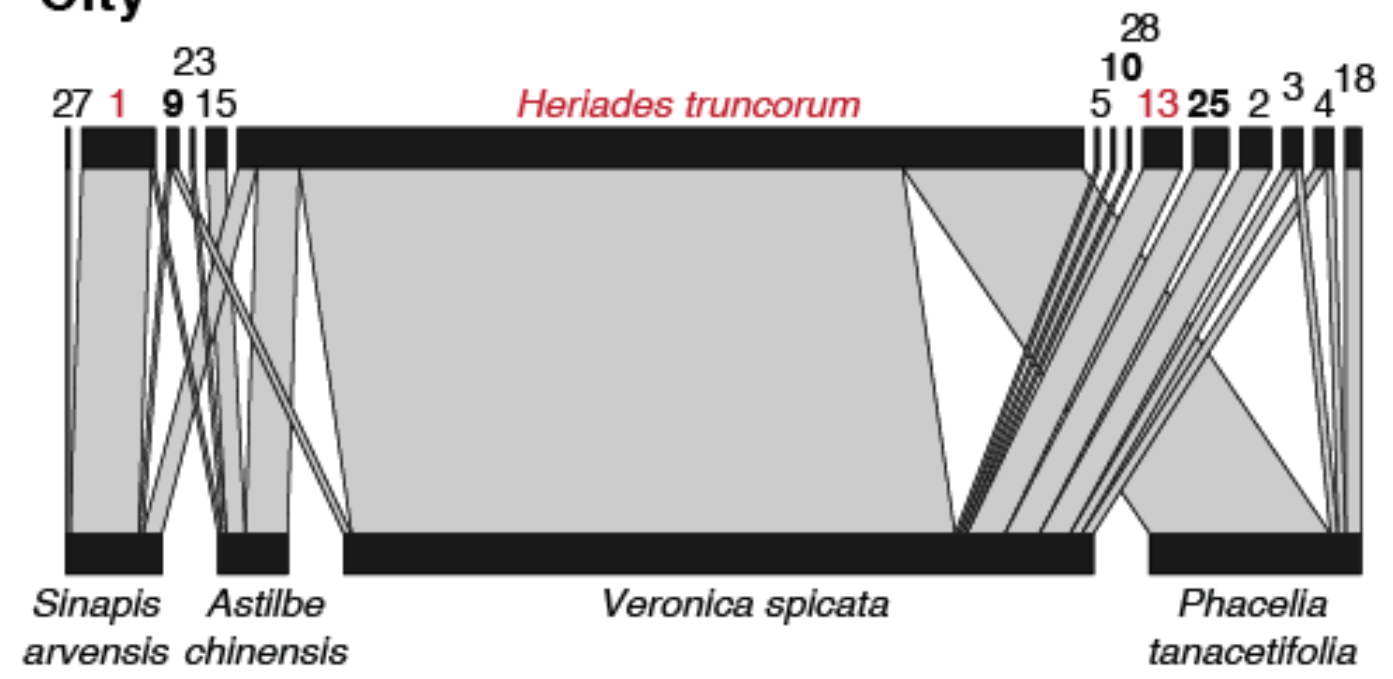

Fig. 7: Plant-pollinator networks in the different landscape types. Numbers correspond to morphospecies (Supplementary Table S1). $\mathrm{N}_{\text {Farmland }}=4, \mathrm{~N}_{\text {Village }}=4, \mathrm{~N}_{\text {City }}=4$; Lower section $=$ plant species, upper section $=$ pollinator morphospecies. Names coloured grey are solitary bees and bolded names are syrphid flies. 


\section{Discussion}

In the present study, we investigated the influence of city size on plant-pollinator community structure, using observations on experimental study plots along a farmland and village to urban landscape gradient. Our results clearly show that plant species richness was higher in urban areas, but that pollinator richness decreased in urban areas. The pollinators we observed were generalists, as they visited all plant species, regardless of which landscape they were in. The pollinator groups did show some preferences as solitary bees and bumblebees preferentially visited the blue flowering species (Phacelia tanacetifolia and Veronica spicata) and non-syrphid flies that preferentially visited Astilbe chinensis. The pollinator group identity influenced the number of pollinator visits, as solitary bees were mainly present in cities and syrphid flies were mainly present in farmland, while both were present in villages. These changes in pollinator richness and community composition contributed to the network structure, where robustness, interaction evenness and Shannon diversity were all highest in farmland and lowest in cities, with villages being intermediate. Solitary bees were more attracted by high flower diversity and flower cover of urban sites than syrphid flies.

We observed pollinators on experimentally standardised plant plots, which allowed us to directly correlate the pollinator insects with the surrounding landscape type. Theodorou et al. (2017) also used experimental plant communities to separate the influence of local from landscape influences and found that bee richness was positively influenced by high flowering richness in urban areas. We did not observe many pollinator morphospecies at our experimental plant plots, possibly because the four plant species were flowering for only a short time period. But, we observed little change in the pollinator morphospecies present from our first to second round of observations, thus the differences between treatments appear to be fairly robust for this time of the year. However, patterns may change with season and year.

Solitary bees were present in the farmland sites in low numbers, presumably because plant plots in these sites were surrounded only by farmland with few floral resources and little semi-natural areas within the $500 \mathrm{~m}$ radius considered. Solitary bees disperse several hundred meters throughout the landscape (Gathmann and Tscharntke 2002). Even though there are suitable nesting sites in farmland areas and some floral resources, these are not necessarily close enough to provide suitable resources for solitary bees to 
survive (Westrich 1996). Gardens in urban areas provided good habitat for solitary bees, while they had higher solitary bee abundances in cities than in villages. Heriades truncorum (no. 11 in Fig. 7), for example, was dominant in cities but its numbers decreased along the urban gradient, with lower abundance in villages and farmland. This supports findings from Banaszak-Cibicka and Zmihorski (2012) and Fortel et al. (2014), in that plant species richness was highest in villages and cities, and solitary bee richness increased in areas with high plant richness.

Syrphid flies showed the opposite relationship, as they were present mostly in farmland and villages, with very low abundance in cities (Jauker et al. 2009, Bates et al. 2011). This was especially apparent for Episyrphus balteatus (no. 9 in Fig. 7) as it dominated networks in farmland and village sites, but was rarely observed in city sites. This agrees with findings from Jauker et al. (2009). Syrphid larvae are ubiquitous in crop fields (Tenhumberg and Poehling 1995). The adults feed on pollen and nectar (Haslett 1989) so require floral resources, but as they do not require specific nesting habitat and are very mobile, the fragmentation of floral resources throughout farmland landscapes is not such a problem. These differing resource requirements may have been the reason why we did not observe syrphid flies in the pure urban habitat.

The structure of plant-pollinator networks was more robust and stable in farmland and villages, where also more pollinators were present than in cities. The higher diversity and higher interaction evenness indicate few dominating morphospecies. This absence of dominating (strong) links in a network contributes to network stability and robustness, explaining why these networks are more robust in the farmland sites (May 1973, Tylianakis et al. 2010). Our results of higher interaction evenness in farmland sites contradict those by Geslin et al. (2013) who found that interaction evenness was highest in an urban area compared with farmland, but they found higher numbers of interactions in farmland. The pollinator group present determined the patterns found: there was low interaction evenness in cities with fewer pollinators, which were dominated by solitary bees. In villages and farmland there was higher pollinator richness with no dominant morphospecies, resulting in higher evenness of interactions. Urban areas do support pollinator insect communities, but they are not optimal habitat, as resources are patchy and often isolated with many barriers to pollinator dispersal in the form of roads and buildings. The size of the built-up area had a strong influence on the pollinator community, as we found that the pollinator community in villages was a mixture of that found in urban areas and in farmland. This agrees with findings from 
Bates et al. (2011) who found more syrphid flies in farmland than in urban areas and with Sirohi et al. (2015) who found that native bee richness in urban areas is higher than in nearby farmland. Due to this crossover of farmland and urban insect communities in villages we suggest that habitat enrichment efforts should focus conservation in these areas to promote the largest pollinator richness possible.

In conclusion, conservation of green areas in urbanised landscapes promotes solitary bee communities, while a diverse pollinator community can be found in villages as this is where there is a crossover of the pollinator communities of farmland and urban areas.

\section{Acknowledgements}

This study was supported by the German Research Foundation (Deutsche Forschungsgemeinschaft; DFG) in the framework of the Research Training Group 1644 "Scaling Problems in Statistics" at the University of Goettingen. We thank everyone who let us work in their garden and on their farmland and especially Erin Treanore for help in setting up this experiment. We also thank Ingo Grass for statistical advice. 


\section{References}

Ahrne, K., J. Bengtsson, and T. Elmqvist. 2009. Bumble bees (Bombus spp) along a gradient of increasing urbanization. PLoS ONE 4:e5574.

Baldock, K. C. R., M. A. Goddard, D. M. Hicks, W. E. Kunin, N. Mitschunas, L. M. Osgathorpe, S. G. Potts, K. M. Robertson, A. V Scott, G. N. Stone, I. P. Vaughan, and J. Memmott. 2015. Where is the UK's pollinator biodiversity? The importance of urban areas for flower-visiting insects. Proceedings of the Royal Society B 282:1-10.

Banaszak-Cibicka, W., and M. Zmihorski. 2012. Wild bees along an urban gradient: Winners and losers. Journal of Insect Conservation 16:331-343.

Bates, A. J., J. P. Sadler, A. J. Fairbrass, S. J. Falk, J. D. Hale, and T. J. Matthews. 2011. Changing bee and hoverfly pollinator assemblages along an urban-rural gradient. PLOS ONE 6:e23459.

Bates, D., M. Maechler, B. Bolker, and S. Walker. 2015. Fitting linear mixed-effects models using lme4. Journal of Statistical Software 67:1-48.

Blüthgen, N., F. Menzel, and N. Blüthgen. 2006. Measuring specialization in species interaction networks. BMC Ecology 6:1-12.

Crawley, M. J. 2013. The R book. 2nd edition. John Wiley \& Sons, West Sussex.

Delignette-Muller, M. L., and C. Dutang. 2015. fitdistrplus: An R package for fitting distributions. Journal of Statistical Software 64:1-34.

Dormann, C. F., G. B., and J. Fruend. 2008. Introducing the bipartite package: Analysing ecological networks. R News 8:8-11.

Dunne, J. A., R. J. Williams, and N. D. Martinez. 2002. Network structure and biodiversity loss in food webs: Robustness increases with connectance. Ecology Letters 5:558567.

Ebeling, A., A. M. Klein, J. Schumacher, W. W. Weisser, and T. Tscharntke. 2008. How does plant richness affect pollinator richness and temporal stability of flower visits? Oikos 117:1808-1815.

Egerer, M. H., C. Arel, M. D. Otoshi, R. D. Quistberg, P. Bichier, and S. M. Philpott. 2017. Urban arthropods respond variably to changes in landscape context and spatial scale. Journal of Urban Ecology 3:1-10.

Fetridge, E. D., J. S. Ascher, and G. A. Langellotto. 2008. The bee fauna of residential gardens in a suburb of New York city (Hymenoptera: Apoidea). Annals of the Entomological Society of America 101:1067-1077.

Fortel, L., M. Henry, L. Guilbaud, A. L. Guirao, M. Kuhlmann, H. Mouret, O. Rollin, and B. E. Vaissière. 2014. Decreasing abundance, increasing diversity and changing structure of the wild bee community (Hymenoptera: Anthophila) along an urbanization gradient. PLoS ONE 9:1-12.

Gathmann, A., and T. Tscharntke. 2002. Foraging ranges of solitary bees. Journal of Animal Ecology 71:757-764.

Geslin, B., B. Gauzens, E. Thebault, and I. Dajoz. 2013. Plant pollinator networks along a gradient of urbanisation. PLoS ONE 8:e63421.

Hall, D. M., G. R. Camilo, R. K. Tonietto, J. Ollerton, K. Ahrné, M. Arduser, J. S. Ascher, K. C. R. Baldock, R. Fowler, G. Frankie, D. Goulson, B. Gunnarson, M. E. Hanley, J. I. Jackson, G. Langellotto, D. Lowenstein, E. S. Minor, S. M. Philpott, S. G. Potts, M. H. Sirohi, E. M. Spevak, G. N. Stone, and C. G. Threlfall. 2016. The city as a refuge for insect pollinators. Conservation Biology 31:24-29.

Haslett, J. R. 1989. Interpreting patterns of resource utilization: Randomness and selectivity in pollen feeding by adult hoverflies. Oecologia 78:433-442.

Jauker, F., T. Diekötter, F. Schwarzbach, and V. Wolters. 2009. Pollinator dispersal in an agricultural matrix: Opposing responses of wild bees and hoverflies to landscape structure and distance from main habitat. Landscape Ecology 24:547-555. 
Leong, M., L. C. Ponisio, C. Kremen, R. W. Thorp, and G. K. Roderick. 2016. Temporal dynamics influenced by global change: Bee community phenology in urban, agricultural, and natural landscapes. Global Change Biology 22:1046-1053.

May, R. 1973. Stability and Complexity in Model Ecosystems. Princeton University Press.

Mazerolle, M. J. 2016. AICcmodavg: Model selection and multimodel inferences based on (Q)AIC(c). R package version 2.1-0.

McCann, K. S. 2000. The diversity-stability debate. Nature 405:228-233.Memmott, J. 1999. The structure of a plant-pollination food web. Ecology Letters 2:276-280.

Orford, K. A., I. P. Vaughan, and J. Memmott. 2015. The forgotten flies: The importance of non-syrphid Diptera as pollinators. Proceedings of the Royal Society B 282:20142934.

Pritsch, G. 2007. Bienenweide. Franckh-Kosmos Verlag, Stuttgart.

Pyšek, P. 1998. Alien and native species in Central European urban floras: A quantitative comparison. Journal of Biogeography 25:155-163.

R core Team. 2016. R: A language and environment for statistical computing. Vienna Austria.

Sirohi, M. H., J. Jackson, M. Edwards, and J. Ollerton. 2015. Diversity and abundance of solitary and primitively eusocial bees in an urban centre: A case study from Northampton (England). Journal of Insect Conservation 19:487-500.

Tenhumberg, B., and H. Poehling. 1995. Syrphids as naturals enemis of cereals aphids in Germany: Aspects of their biology and efficacy in different years and regions. Agricultural Ecosystems and Environment 52:39-43.

Theodorou, P., K. Albiga, R. Radzevičiūte, J. Settele, O. Schweiger, T. E. Murray, and R. J. Paxton. 2017. The structure of flower-visitor networks in relation to pollination across an agricultural to urban gradient. Functional Ecology 31:838-847.

Tylianakis, J. M., E. Laliberté, A. Nielsen, and J. Bascompte. 2010. Conservation of species interaction networks. Biological Conservation 143:2270-2279.

Venables, W. N., and B. D. Ripley. 2002. Modern applied statistics with S. Fourth. Springer, New York.

Verboven, H. A. F., R. Uyttenbroeck, R. Brys, and M. Hermy. 2014. Different responses of bees and hoverflies to land use in an urban-rural gradient show the importance of the nature of the rural land use. Landscape and Urban Planning 126:31-41.

Westphal, C., I. Steffan-Dewenter, and T. Tscharntke. 2003. Mass flowering crops enhance pollinator densities at a landscape scale. Ecology Letters 6:961-965.

Westrich, P. 1996. Habitat requirements of central European bees and the problems of partial habitats. Pages 2-15The Conservation of Bees. Academic Press, London. 


\section{Supplementary Material}
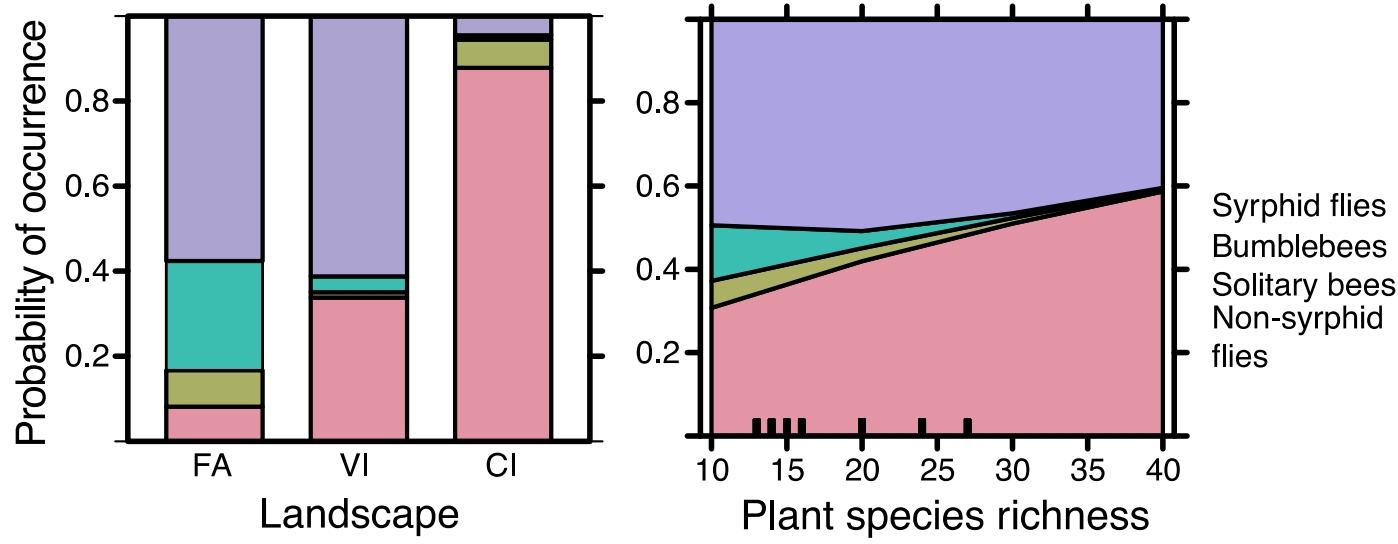

Fig. S1: Predicted probability of pollinator group occurrence in the different landscapes from the multinomial model. Probabilities were calculated using the 'allEffects' function in the effects package in $\mathrm{R}$, back-transforming probabilities from a logit scale with reference to the baseline category (Fox 2003; Fox \& Hong 2009). Syrphid flies were present significantly more often in farmland and village landscapes, while solitary bees were present significantly more often in city landscapes. $\mathrm{N}_{\text {total }}=12, \mathrm{~N}_{\mathrm{FA}}=4$, $\mathrm{N}_{\mathrm{VI}}=4, \mathrm{~N}_{\mathrm{CI}}=4 ; \mathrm{FA}=$ Farmland, $\mathrm{VI}=$ Village, $\mathrm{CI}=$ City.

Table S1: Pollinators corresponding to numbers in bipartite network diagrams (Fig. 4).

\begin{tabular}{|c|c|}
\hline Number & Pollinators \\
\hline 1 & Andrena spec. ${ }^{\perp}$ \\
\hline 2 & Bombus hortorum (L.) \\
\hline 3 & Bombus hypnorum (L.) \\
\hline 4 & Bombus pascuorum (Scopoli) \\
\hline 5 & Bombus terrestris (L.) \\
\hline 6 & Cynomyia spec. \\
\hline 7 & Empididae \\
\hline 8 & Empis spec. \\
\hline 9 & Episyrphus balteatus $^{2}$ (De Geer) \\
\hline 10 & Eristalis spec. $^{2}$ \\
\hline 11 & Heriades truncorum $^{1}$ (L.) \\
\hline 12 & Hydrotaea spec. \\
\hline 13 & Hylaeus confuses ${ }^{1}$ (Nylander) \\
\hline 14 & Hylaeus styriacus $^{1}$ (Förster) \\
\hline
\end{tabular}




\begin{tabular}{|c|c|}
\hline 15 & Ichneumonidae gen. spec. \\
\hline 16 & Maniola jurtina (L.) \\
\hline 17 & Meliscaeva cinctella $^{2}$ (Zetterstedt) \\
\hline 18 & Osmia spec. \\
\hline 19 & Pieris brassicae (L.) \\
\hline 20 & Platycheirus spec. $^{2}$ \\
\hline 21 & Sarcophaga carnaria (L.) \\
\hline 22 & Sphaerophoria scripta $^{2}$ (L.) \\
\hline 23 & Symmorphus spec. \\
\hline 24 & Syrphidae $^{2}$ gen. spec. \\
\hline 25 & Syrphus ribesii $^{2}$ (L.) \\
\hline 26 & Thymelicus lineola (Ochsenheimer) \\
\hline 27 & Vespula spec. \\
\hline 28 & Vespula vulgaris (L.) \\
\hline
\end{tabular}

${ }^{1}$ Solitary bees

${ }^{2}$ Syrphid flies 


\section{Chapter 5}

\section{Arthropod Diversity across an Urbanisation Gradient of City Size}

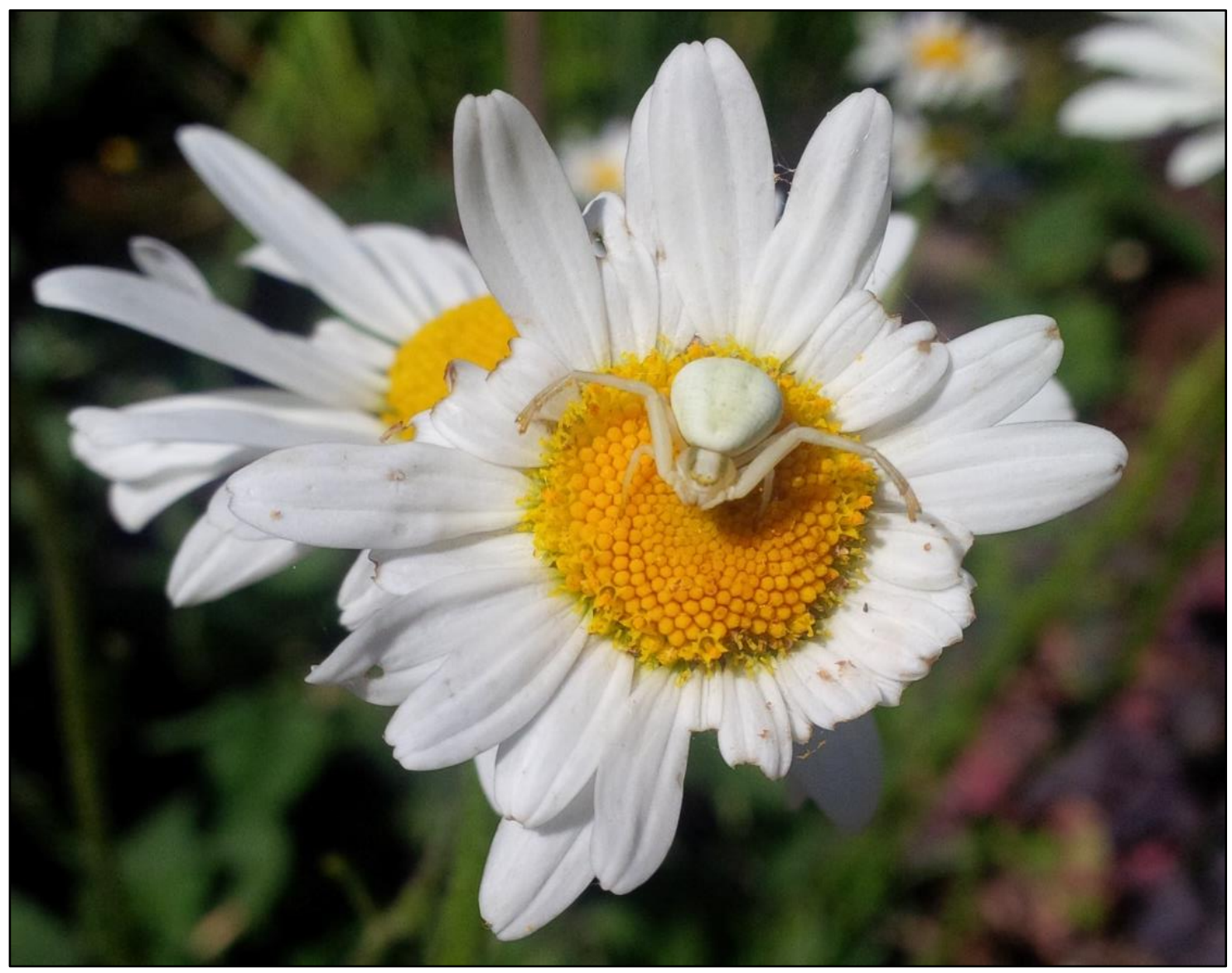

Misumena vatia (Clerck) on Leucanthemum vulgare(Vaill.) (May 2015, ( ) Kristy Udy)

Authors:

Kristy Leah Udy*, Hannah Reininghaus*, Christoph Scherber and Teja Tscharntke

* These authors contributed equally to this work. 


\begin{abstract}
Urban areas may support a diverse arthropod community, but increasing levels of urbanisation affect taxa differently. Also arthropod taxa may have different responses to local or landscape scale factors. We tested the influence of increasing urbanisation along an gradient of different sizes of urban areas and in different positions in the urban areas, comparing edge vs. centre, on functional groups of Coleoptera, Araneae and Hymenoptera. We also tested the influence of green area type (garden vs. grassland) and plant richness on these arthropod communities. Local (i.e. plant species richness) and landscape factors (i.e. increasing urbanisation) influenced Coleoptera and Araneae, while Hymenoptera were influenced by only local factors. Species richness of Hymenoptera was higher in gardens than grassland, whereas species richness of Coleoptera, in particular that of herbivores, carnivores and omnivores, was higher in grasslands and responded negatively to plant richness. Size of urban area was positively related to species richness of Araneae, but mostly negatively to that of Coleoptera. Our study exhibits contrasting responses of arthropod communities to urbanisation, with different influences at local and landscape scales, which may explain the heterogeneous patterns found in the literature. It deepens our understanding of how arthropod communities respond to urbanisation, as it is the first study to investigate the influence of both urban area size and position in an urban area.
\end{abstract}

Keywords: urban area size; arthropod richness; Coleoptera; Araneae; Hymenoptera. 


\section{Introduction}

Land use change causes widespread loss of biodiversity in anthropogenic landscapes. Urban areas are a dominant part of landscapes worldwide and do support some arthropod diversity (McKinney 2008). Gardens, public green spaces and semi-natural habitats within urban areas provide resources for arthropods (Pereira-Peixoto et al. 2016). The amount of arthropod diversity supported could be related to size of the urban area, which has a positive influence on plant species richness (Pyšek 1998). This trend in plant species richness is due to increasing numbers and dominance of non-native species, which are also more prevalent at the city edge than centre (McKinney 2006).

So far, urbanisation gradients were always tested in a single city (Egerer et al. 2017) and are generally defined by the amount of built-up area or density of people at different locations from the edge to the centre (McDonnell and Hahs 2008). Green areas in the centre of cities are more isolated due to the presence of physical barriers such as roads and buildings (Peralta et al. 2011) and their distance from the urban edge. Studies that examine rural-urban gradients find lower diversity of insects in the middle of an urban area (McKinney 2006, Bates et al. 2011). The same results are found for hostparasitoid communities, but they are related to local habitat quality and to isolation of the study site, since green areas on the edge of an urban area may be colonised from the adjacent habitat and can support higher species richness than green areas in the centre of an urban area (Pereira-Peixoto et al. 2014). The influences of urbanisation on arthropods depend on which taxa they are, as pollinators are positively affected (Baldock et al. 2015, Sirohi et al. 2015), whereas forest-dependent ground beetles are negatively affected (McKinney 2008, Vergnes et al. 2014). This diversity of responses indicates the existence of multi-causality and individualistic or trait-dependent species responses (Gleason 1926, McDonnell and Hahs 2008). A similar relationship to what is found with increasing urbanisation from the edge to the centre of a city could be expected with increasing urban area size.

The type of urban habitat should also have a strong effect, as, for example, gardens have a diverse structure with lawns, flowers, shrubs and trees within a small area, whereas parks are dominated by short grass and few wild herbs and trees with an occasional flower bed (Mata et al. 2017). Both these green area types are highly managed, as dead branches and often leaf litter are removed from under trees, grassland 
is frequently mown and flower beds are regularly weeded to remove any unwanted plants (Pyšek 1998, Mata et al. 2017).

Differences in habitat type could also be characterised by the local plant species richness, as gardens have a higher number of plant species present and also higher flower cover, which could positively influence flower-visiting insects (Pyšek 1998, Baldock et al. 2015). Other aspects than plant species richness, such as vegetation type, are also important for arthropod species, as spiders may thrive in habitats with larger extents of woody areas (Vergnes et al. 2014), which are more extensive in parks.

We investigated how local vs. landscape scale variables structure plant and arthropod communities in urban areas. The influence of the urban landscape on arthropod communities in gardens and grassland was tested for the first time along an urbanisation gradient from small villages to a mid-size city, while also analysing the role of the position in an urban area (edge or centre). The arthropods sampled were functional groups of Coleoptera, Araneae and Hymenoptera.

\section{Material and Methods}

Arthropods were sampled from 15 urban areas (Fig. 1; Table S1) that covered a size gradient from villages (150 residents, $\left.0.1 \mathrm{~km}^{2}\right)$ to cities $\left(118,000\right.$ residents, $\left.16.6 \mathrm{~km}^{2}\right)$. Urban areas were selected using ArcGIS (v. 10.4.1, ESRI), where the size in $\mathrm{km}^{2}$ of all settlements within a $30 \mathrm{~km}$ radius of Göttingen was calculated by overlaying a polygon over each settlement. Urban area boundary was defined as the urban edge where buildings and gardens border agriculture or forest (Fig. 1 inset). Three similar sized small villages and three similar sized mid-size cities were used to sample both ends of the size gradient more completely. Urban areas were categorised by size from 1-11 $(1=$ small village, $11=$ mid-size city, both replicated three times; categories 2-10 were replicated once) and we randomly selected an urban area within each category. All urban areas had a similar proportion of green area within their urban boundaries (Fig. S1). 


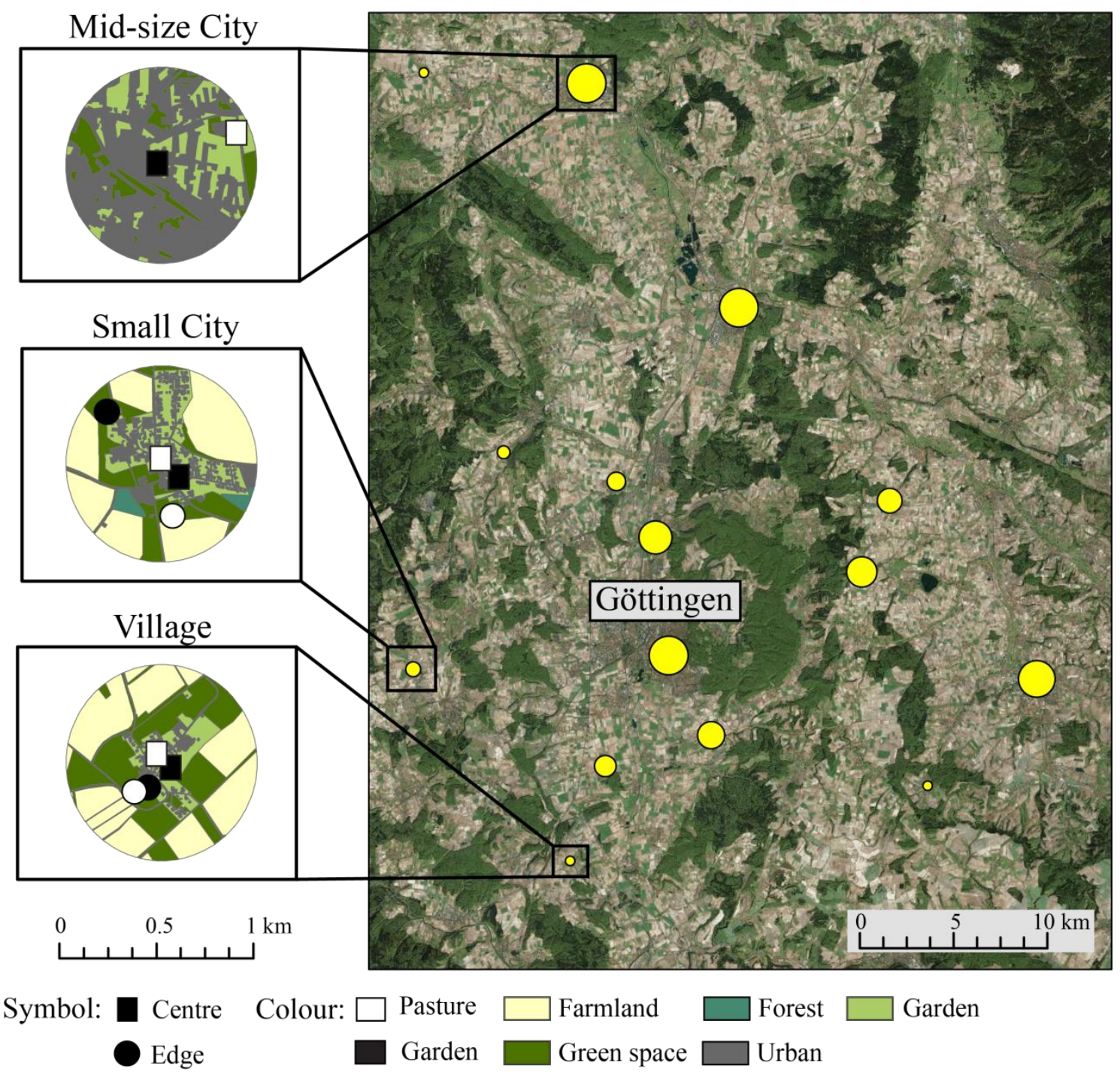

Fig. 1: Map of all urban areas, size of circles corresponds to urban area size. Insets show examples of plot positions in the urban areas and their structure within a $500 \mathrm{~m}$ radius. The symbols and colours relate to the inset maps.

To test the effect of the surrounding landscape, we sampled in green areas at different positions in the urban areas, both the centre and the edge of all urban areas. Green areas were home gardens and grasslands, either parks or pastures, as they are ubiquitous in all urban areas and have a similar structure (grassland and trees/shrubs). Both parks (grassland with shrubs and trees) and pastures were used as grasslands. All green areas (gardens and grasslands) had a size of $1,000 \mathrm{~m}^{2}-3,000 \mathrm{~m}^{2}$. Within each urban area two gardens and two grasslands were selected, one garden and one grassland (within $100 \mathrm{~m}$ of each other) at both the centre and edge of an urban area (60 sites in total; Fig. 1 inset). The urban centre was defined as the geographical centre, with approximately equal distance from all edges, while the urban edge was defined as where houses and 
gardens bordered on the surrounding landscape (always farmland). We created GIS maps for each site and measured the amount of urban area (buildings and roads), home gardens, grasslands, forest and agriculture within a $500 \mathrm{~m}$ radius.

Arthropod sampling was repeated three times from spring (late April) until late summer (end of August) in 2014. Each sampling round took four weeks with four urban areas sampled per week.

Arthropods were sampled using: pan traps, pitfall traps and sweep nets. Two pan traps and pitfall traps were placed in each garden and grassland and were separated by a minimum of five metres. Pan traps were bowls $(11 \mathrm{~cm}$ diameter, $7 \mathrm{~cm}$ depth) painted yellow with an additional UV top-coat, these were placed in the lawn edge/pasture edge and staked to the ground. Pitfall traps were constructed using a bottle and funnel placed inside a tube $(11 \mathrm{~cm}$ diameter) that was buried in the ground so that the funnel edge was flush with the soil surface. A cover was placed above the funnel at a height of $15 \mathrm{~cm}$ so that detritus could not fall in and block the pitfall trap. Pan traps and pitfall traps were filled with water mixed with liquid soap and were set for three days. Sweep netting was done along four $15 \mathrm{~m}$ long transects; we swept the lawn and the flowerbeds in gardens and the grass and any flowerbeds in grasslands. Sweep netting was done when it was not raining during the period the pan traps and pitfall traps were set. Arthropod samples were preserved in ethanol and were sorted in the lab to order level and identified to species level by taxonomists. The orders we had identified were: Coleoptera, Araneae and Hymenoptera. These arthropods were separated into functional groups using information from insect identification keys (Royal Entomological Society: Hymenoptera) and from the database compiled by Gossner et al. (2015). Functional groups for Coleoptera were: carnivore, omnivore, fungivore, detritivore and herbivore. Araneae were split into hunting mode: hunter or web-builder and Hymenoptera were split by functional groups of: wasp, wild bee and parasitoid. Red list status was obtained from the IUCN (2013).

All plants within each garden and grassland were identified to species level and we recorded which species were flowering during each sampling round. Flower cover within each garden and grassland was also estimated per sampling round. 


\section{Statistics}

The arthropod samples were combined from all different trapping methods for statistical analysis. Species richness was calculated using the exponential of the Shannon Diversity Index (hereafter SR) as this method is numbers equivalent (assumes equal abundance for each species; Jost 2007) and allows comparison across multiple taxa.

All analyses were performed using $\mathrm{R}$ (version 3.3.0; R core Team 2016). We used Principle Components Analysis to derive linearly independent variables as indicators of amount of urbanisation and plant species richness (Oksanen et al. 2017); we used urban area size and total plant Shannon richness, which were not correlated (Pearson correlation $=-0.02$; Fig. S2; Crawley 2013). Community dissimilarity between edge and centre of urban areas along our urbanisation gradient was calculated with the vegdist function using the Bray-Curtis index and significance was tested with a permutation test that utilises pseudo F-ratios (Permutational Multivariate Analysis of Variance Using Distance Matrices; Oksanen et al. 2017). The community dissimilarity was then visualised using nonmetric multidimensional scaling (metaMDS Crawley 2013, Oksanen et al. 2017). Our experimental design was nested, thus we always used mixed effects models with a random error term composed of position in urban area (centre or edge) nested in urban area (random effect: urban area name/position in urban area; Bates et al. 2015). SR was calculated per site and per functional group for all taxa and was tested against the experimental variables of urban area size, urban area section and green area type (e.g. glmer(SR urban_area, urban_position, green_area + (1|city/urban_position); Bates et al. 2015). The arthropod response variables were tested against plant SR in a separate model, not including the experimental design variables, as plant SR was itself influenced by our urban gradient and by the green area type (e.g. glmer(SR plant_SR+ (1|city/urban_position); Fig. 2). Response variables tested were always rounded SR (to the nearest integer), to convert them to true count data; therefore, models used were always Poisson or Negative Binomial (depending on which provided best model fit based on AICc; Bates et al. 2015). All models with experimental variables were simplified using a list of candidate models with all possible combinations of experimental variables and interactions; models were ranked based on AICc and the model with the lowest AICc value was used (Information Theoretic approach; Mazerolle 2016). 


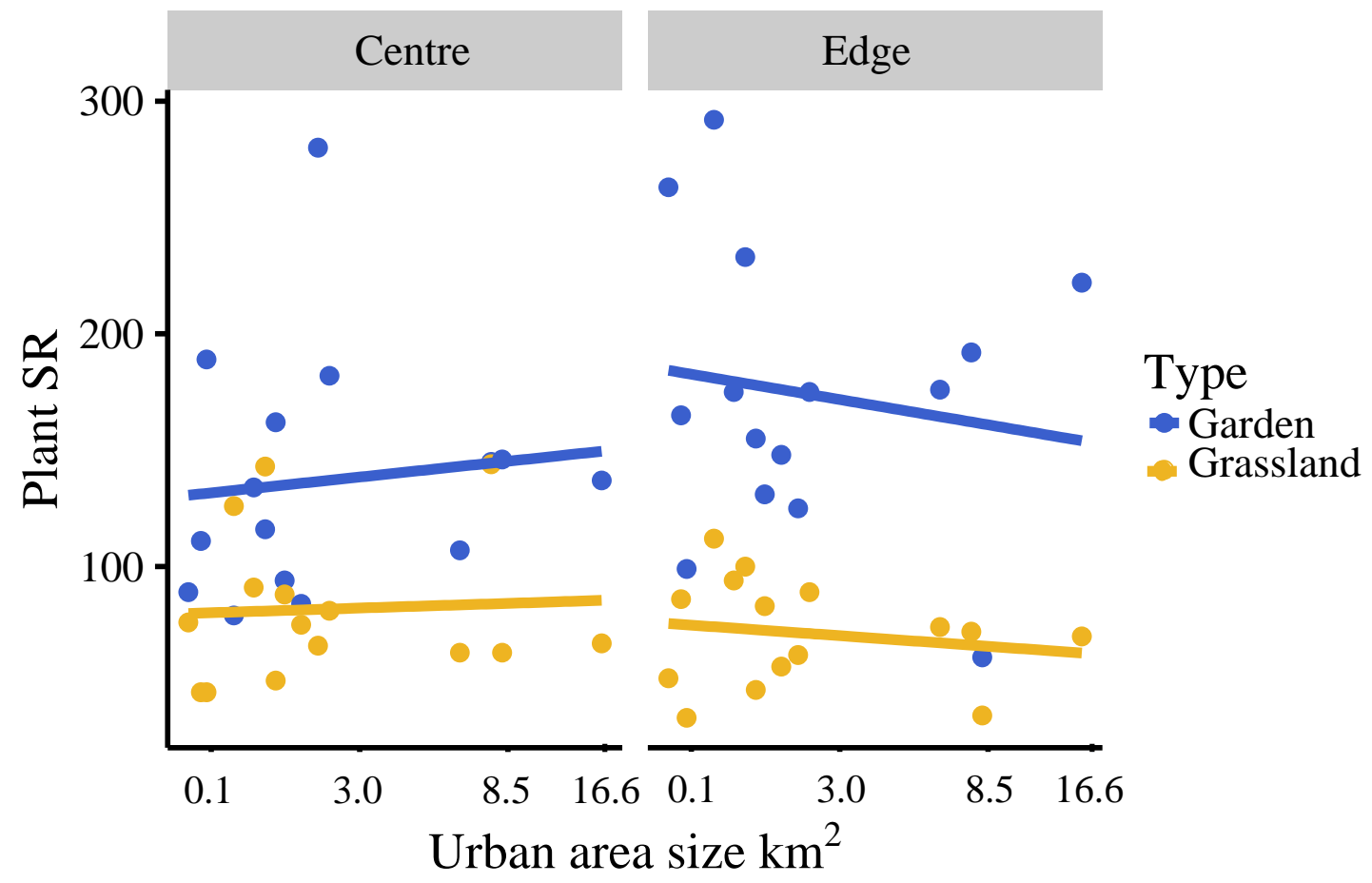

Fig. 2: Plant SR (Shannon richness) influenced by experimental variables. Green area type had a significant influence (Chi-square $=72.3$, d.f. $=1, \mathrm{p}<0.001$ ).

\section{Results}

We caught a total of 17,229 Coleoptera from 634 different species, 36 of which have a red list status of threatened. 15,475 Araneae were caught from 202 species, 5 of which are threatened and 33,881 from 177 species of Hymenoptera were captured.

Plant SR was higher in gardens than grasslands (Chi-square $=72.333$, d.f. $=1$, p $<0.001$; Fig. 2) and was higher in gardens at the edge than gardens in the centre of urban areas (Chi-square $=4.242$, d.f. $=1, \mathrm{p}=0.039$ ).

Urban area size had no direct influence on Coleoptera SR but did interact with urban area section (Chi-square $=8.447$, d.f. $=1, p=0.004 ;$ Fig. 3 ) and with green area type $($ Chi-square $=5.66$, d.f. $=1, \mathrm{p}=0.017)$, as Coleoptera SR decreased with increasing urban area size except in edge grasslands. Coleoptera SR was higher at the edge than the centre of urban areas (Chi-square $=8.44$, d.f. $=1, \mathrm{p}=0.004$; Fig. 3). Coleoptera community similarity in our largest size urban areas was significantly different between urban area edge and centre (Pseudo F-ratio $=2.24_{1,10}, p=0.008$; Fig. S3). Urban area size directly positively influenced Araneae SR (Chi-square = 7.8, d.f. $=1, \mathrm{p}=0.005 ;$ Fig. 3). 
Of the different functional groups from the different taxa, fungivorous Coleoptera SR was higher in the centre of urban areas (Chi-square $=6.867$, d.f. $=1, p=0.009$; Fig. 4) and hunting Araneae richness was higher at the edge of urban areas (Chisquare $=10.27$, d.f. $=1, p=0.001)$. The other functional groups were not influenced by urban area size or green area type.

Coleoptera SR was higher in grasslands than in gardens $($ Chi-square $=7.258$, d.f. $=1, p=0.007$; Fig. 3) and highest when plant SR was low (Chi-square $=4.985$, d.f. $=1, p=0.026)$. This is because plant SR was lowest in grasslands where Coleoptera SR was highest (Fig. 2). Of these two variables, green area type had a stronger influence as the R-squared was higher (green area type model $=14.5$, plants model $=9.3$ ) and model fit was better (green area type model AICc $=482.04$, plants model AICc $=484.773$ ). Coleoptera SR for the feeding groups of carnivores (Chisquare $=8.318$, d.f. $=1, p=0.004$; Fig. 4), omnivores (Chi-square $=3.962$, d.f. $=1$, $\mathrm{p}=0.047)$ and herbivores (Chi-square $=8.169$, d.f. $=1, p=0.004$ ) was higher in grasslands than in gardens. Carnivorous Coleoptera SR was also negatively influenced by plant SR (Chi-square $=22.91$, d.f. $=1, \mathrm{p}<0.001$; Fig. 4 ), which had a stronger influence than green area type as the R-squared was higher (plant model $=54.3$, green area type model $=50$ ) and model fit was better (plant model AICc $=95.273$, green area type model AICc $=117.15$ ).

Plant SR positively influenced Hymenoptera SR (Chi-square $=23.817$, d.f. $=1$, p < 0.001; Fig. 3). Wild bee and wasp SR were positively influenced by plant SR (wild bees: Chi-square $=16.13 .467$, d.f. $=1, \mathrm{p}<0.001$; wasps: Chi-square $=9.728$, d.f. $=1$, $p=0.002$; Fig. 4) and wasp SR was higher in gardens than in grasslands (Chisquare $=8.49$, d.f. $=1, \mathrm{p}=0.004$ ). Plant SR had a slightly stronger influence on wasp SR (plant model R-squared $=17.6$, green area type model $=15.3$ ) with a slightly better model fit (plant model AICc $=255.942$, green area type model $=257.165$ ). 

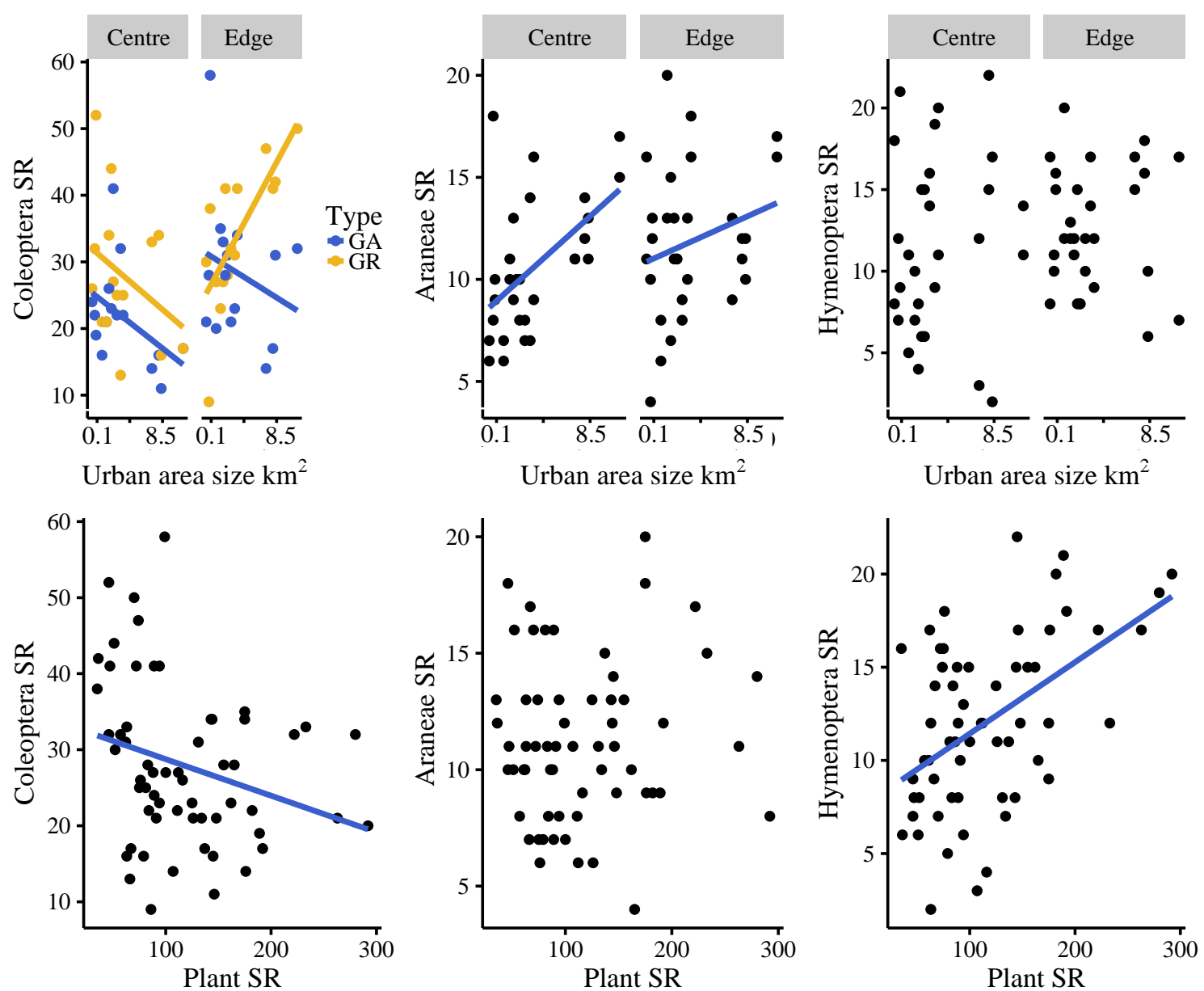

Fig. 3: Shannon richness (SR) relationships for all taxa against experimental variables and plant SR. Coleoptera SR was significantly influenced by an interaction between urban area size and both position in an urban area and green area type. Araneae SR was significantly influenced by urban area size and Coleoptera and Hymenoptera SR was significantly influenced by plant SR. GA = Garden, GR = Grassland. 

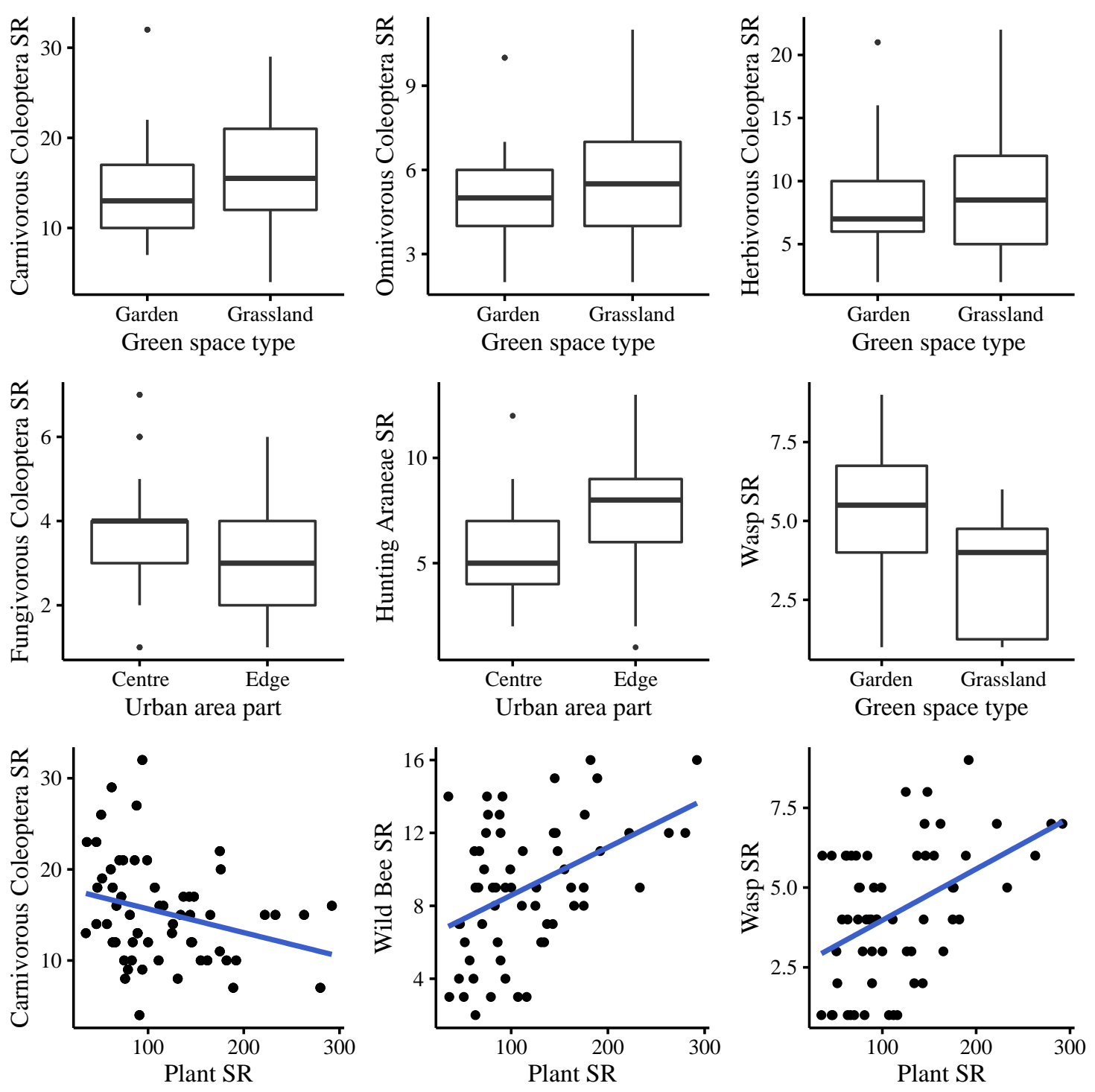

Fig. 4: Functional group Shannon richness (SR) was tested against experimental variables and plant SR. Only functional groups with significant responses are shown.

\section{Discussion}

This is the first study to investigate urban area size influences along a gradient from villages to cities on Coleoptera, Araneae and Hymenoptera, while simultaneously investigating the influence of position in an urban area. We found that landscape scale variables (urban area size and centre vs. edge) influenced species richness of Coleoptera and Araneae, while only local variables (garden vs grassland and plant species richness) influenced that of Hymenoptera. 


\section{Landscape variables}

Coleoptera SR was negatively influenced by urban area size, except at the edge in grasslands where Coleoptera SR increased with urban area size. Fungivorous Coleoptera, but not the other functional groups (carnivores, detritivores, herbivores or omnivores), were influenced by the surrounding landscape, with higher species richness found in the centre of urban areas. Some studies have found no difference in Coleoptera richness with increasing urbanisation (Elek and Lovei 2007, Hartley et al. 2007). But Niemela et al. (2002) found a decrease in carabid species richness with increasing urbanisation, which agrees with our findings. The pattern of higher richness at the edge in grassland could be due to spill over from adjacent agriculture of species that specialise on grassy habitats.

Araneae species richness was positively influenced by urban area size and hunting Araneae species richness was highest at the edge of urban areas. This latter effect is likely due to spill over from the adjacent farmland, which positively enhances species richness in these edge areas. Sattler et al. (2010) found that Araneae are more influenced by local scale variables, which is in direct contrast to our results where we found that Araneae were only influenced by landscape variables. This could be because they sampled across a gradient of increasing management in urban areas and found that Araneae communities are negatively influenced in intensively managed areas. They sampled in gardens and public green areas as well, but their experiment was specifically setup to test management intensity. Kaltsas et al. (2014) also found a negative trend in Araneae richness with increasing urbanisation, but they only worked with Araneae from the Gnaphosidae family. Araneae can disperse up to $10 \mathrm{~km}$ (Vergnes et al. 2014) and could therefore be mainly influenced by landscape factors rather than the local surroundings. Additionally, Araneae species richness is positively influenced by increasing urbanisation (distance from urban area edge) and is highest at approximately $50 \%$ built-up area, as habitat at intermediate levels of urbanisation is more heterogeneous and therefore allows increased species coexistence (Vergnes et al. 2014). This pattern in Araneae richness could explain our finding of highest Araneae species richness in larger urban areas where amount of built-up areas was highest (roughly 50\%; Fig. S1).

We sampled in urban areas with significant amounts of green area, but patterns in arthropod richness could be different for other urban areas with higher proportions of built-up area. For example, in large cities like Paris, there is a sharp decline in arthropod 
richness from the suburbs to the heavily built-up central areas (Vergnes et al. 2014). However, our results are generalisable across urban areas with a high proportion of green area. Furthermore, we found that when the distance from urban area edge is greater than approximately $600 \mathrm{~m}$, the Coleoptera community became distinct with different community composition in the urban centre compared with the urban edge (Fig. S3: city, Table S1). Therefore, when sampling in green areas further than $600 \mathrm{~m}$ from the urban edge, the species present may change and become distinct to those present in the adjacent landscape.

\section{Local variables}

Coleoptera were the only taxon influenced by green area type, as they had higher species richness in grassland than in gardens. They were also negatively influenced by increasing plant species richness, but this was correlated with green area type, as plant species richness was lowest in grassland where Coleoptera species richness was highest. Coleoptera functional groups species richness were also influenced by the local scale experimental variable of green area type, as carnivores, omnivores and herbivores all had higher species richness in grasslands than in gardens. These findings agree with other studies that found higher arthropod richness, specifically herbivores and predators, in grassland habitats (golf courses) than in gardens (Colding and Folke 2009, Mata et al. 2017). These differences in functional groups species richness between gardens and grassland could be due to the local habitat structure and extent, as in parks and pastures there are large expanses of lawn/grass mixed with herbs bordered by shrubs and trees, whereas in gardens these same habitat types are present but in smaller areas (Colding and Folke 2009, Mata et al. 2017). Therefore it makes sense that herbivorous Coleoptera had higher species richness in grasslands than gardens, as they require larger extents of grassy habitat. This could also be due to presence of a smaller predator community present in urban areas (Hanks and Denno 1993) and corroborates findings by Denys and Schmidt (1998), who found higher herbivore abundance in urban areas than in rural areas.

Hymenoptera species richness was only influenced by the local variable of increasing plant species richness (positive effect), as were the functional groups of wasps and wild bees. Wasps exhibited highest species richness in gardens where plant species richness was highest, plant species richness had the strongest affect. The results for wild bees are well corroborated in the literature where plant species richness has a 
positive influence on wild bee species richness and urban areas support a diverse community (Ahrne et al. 2009, Hall et al. 2016). We found no influence of urban area size or position in an urban area on Hymenoptera species richness. However, Hymenoptera abundance was higher at the edge of urban areas than in the centre (Fig. S4), which agrees with findings from other urban studies (McKinney 2008, Ahrne et al. 2009). For wasps, there have been no effects found of urbanisation on total wasp richness and abundance (Zanette et al. 2005, Christie and Hochuli 2009). However, there is a positive influence of flowering plants on wasps (Pereira-Peixoto et al. 2014), which agrees with what we found. This could be because wasps feed on herbivores that are found on flowering plants and they also benefit from nectar resources (PereiraPeixoto et al. 2014).

\section{Conclusions}

The influence of urbanisation depends strongly on the taxonomic group and the scale studied at as we found that Coleoptera and Araneae richness was influenced by increasing urbanisation and that Hymenoptera richness was influenced only by local plant richness. This highlights the need to investigate in more detail how and why arthropods respond to increasing urbanisation. We provide evidence that differences found by other urban studies may be due to differences in the surrounding landscape and the size of the city. Our study deepens our understanding of how arthropod communities respond to urbanisation, as it is the first to investigate the influence of both urban area size and position in an urban area.

\section{Acknowledgements}

This study was supported by the German Research Foundation (Deutsche Forschungsgemeinschaft; DFG) in the framework of the Research Training Group 1644 "Scaling Problems in Statistics" at the University of Goettingen. We want thank everyone who let us work in their garden and on their farmland and especially our many field and lab assistants for help with insect sampling and identification. We also thank Józan Zsolt, Theo Blick, Lydia Betz and Andreas Weigel for identifying our invertebrates. 


\section{References}

Ahrne, K., J. Bengtsson, and T. Elmqvist. 2009. Bumble bees (Bombus spp) along a gradient of increasing urbanization. PLoS ONE 4.

Baldock, K. C. R., M. A. Goddard, D. M. Hicks, E. Kunin, N. Mitschunas, L. M. Osgathorpe, S. G. Potts, K. M. Robertson, A. V Scott, G. N. Stone, I. P. Vaughan, and J. Memmott. 2015. Where is the UK' s pollinator biodiversity? The importance of urban areas for flower- visiting insects. Proceedings of the Royal Society of Britain 282:20141849

Bates, A. J., J. P. Sadler, A. J. Fairbrass, S. J. Falk, J. D. Hale, and T. J. Matthews. 2011. Changing bee and hoverfly pollinator assemblages along an urban-rural gradient. PLoS ONE 6:e23459.

Bates, D., M. Maechler, B. Bolker, and S. Walker. 2015. Fitting linear mixed-effects models using lme4. Journal of Statistical Software 67:1-48.

Christie, F. J., and D. F. Hochuli. 2009. Responses of wasp communities to urbanization: effects on community resilience and species diversity. Journal of Insect Conservation 13:213-221.

Colding, J., and C. Folke. 2009. The role of golf courses in biodiversity conservation and ecosystem management. Ecosystems 12:191-206.

Crawley, M. J. 2013. The R book. Page (M. J. Crawley, Ed.), 2nd edition. John Wiley \& Sons, West Sussex.

Denys, C., and H. Schmidt. 1998. Insect communities on experimental mugwort (Artemisia vulgaris L .) plots along an urban gradient. Oecologia 113:269-277.

Egerer, M. H., C. Arel, M. D. Otoshi, R. D. Quistberg, P. Bichier, and S. M. Philpott. 2017. Urban arthropods respond variably to changes in landscape context and spatial scale. Journal of Urban Ecology 1-10.

Elek, Z., and G. L. Lovei. 2007. Patterns in ground beetle (Coleoptera: Carabidae) assemblages along an urbanisation gradient in Denmark. Acta Oecologica 32:104111.

Gleason, H. A. 1926. The individualistic concept of the plant association. Bulletin of the Torrey Botanical Club 53:7-26.

Gossner, M. M., N. K. Simons, R. Achtziger, T. Blick, W. H. O. Dorow, F. Dziock, F. Köhler, W. Rabitsch, and W. W. Weisser. 2015. A summary of eight traits of Coleoptera, Hemiptera, Orthoptera and Araneae, occurring in grasslands in Germany. Scientific data 2:15013.

Hall, D. M., G. R. Camilo, R. K. Tonietto, J. Ollerton, K. Ahrné, M. Arduser, J. S. Ascher, K. C. R. Baldock, R. Fowler, G. Frankie, D. Goulson, B. Gunnarson, M. E. Hanley, J. I. Jackson, G. Langellotto, D. Lowenstein, E. S. Minor, S. M. Philpott, S. G. Potts, M. H. Sirohi, E. M. Spevak, G. N. Stone, and C. G. Threlfall. 2016. The city as a refuge for insect pollinators. Conservation Biology 31:24-29.

Hanks, L. M., and R. F. Denno. 1993. Natural enemies and plant water relations influence the distribution of an armored scale insect. Ecology 74:1081-1091.

Hartley, D. J., M. J. Koivula, J. R. Spence, R. Pelletier, and G. E. Ball. 2007. Effects of urbanization on ground beetle assemblages (Coleoptera, Carabidae) of grassland habitats in western Canada. Ecography 30:673-684.

IUCN. 2013. The IUCN red list of threatened species. http://www.iucnredlist.org.

Jost, L. 2007. Partitioning diversity into independent alpha and beta components. Ecology 88:2427-2439.

Kaltsas, D., E. Panayiotou, M. Chatzaki, and M. Mylonas. 2014. Ground spider assemblages (Araneae: Gnaphosidae) along an urban-rural gradient in the city of 
Heraklion, Greece. European Journal of Entomology 111:59-67.

Mata, L., C. G. Threlfall, N. S. G. Williams, A. K. Hahs, M. Malipatil, N. E. Stork, and S. J. Livesley. 2017. Conserving herbivorous and predatory insects in urban green spaces. Scientific Reports 7:40970.

Mazerolle, M. J. 2016. AICcmodavg: Model selection and multimodel inferences based on (Q)AIC(c). R package version 2.1-0.

McDonnell, M. J., and A. K. Hahs. 2008. The use of gradient analysis studies in advancing our understanding of the ecology of urbanizing landscapes: Current status and future directions. Landscape Ecology 23:1143-1155.

McKinney, M. L. 2006. Urbanization as a major cause of biotic homogenization. Biological Conservation 127:247-260.

McKinney, M. L. 2008. Effects of urbanization on species richness: A review of plants and animals. Urban Ecosystems 11:161-176.

Niemela, J., D. J. Kotze, S. Venn, L. Penev, I. Stoyanov, J. Spence, D. Hartley, and E. M. de Oca. 2002. Carabid beetle assemblages (Coleoptera, Carabidae) across urban-rural gradients: An international comparison. Landscape Ecology 17:387401.

Oksanen, J., G. F. Blanchet, M. Friendly, R. Kindt, P. Legendre, D. McGlinn, P. R. Minchin, R. O’Hara, G. L. Simpson, P. Solymos, M. H. H. Stevens, E. Szoecs, and H. Wagner. 2017. vegan: Community ecology package. R package version 2.4-2.

Peralta, G., M. S. Fenoglio, and A. Salvo. 2011. Physical barriers and corridors in urban habitats affect colonisation and parasitism rates of a specialist leaf miner. Ecological Entomology 36:673-679.

Pereira-Peixoto, M. H., G. Pufal, C. F. Martins, and A. M. Klein. 2014. Spillover of trap-nesting bees and wasps in an urban-rural interface. Journal of Insect Conservation 18:815-826.

Pereira-Peixoto, M. H., G. Pufal, M. Staab, C. Feitosamartins, and A.-M. Klein. 2016. Diversity and specificity of host-natural enemy interactions in an urban-rural interface. Ecological Entomology 41:241-252.

Pyšek, P. 1998. Alien and native species in Central European urban floras: A quantitative comparison. Journal of Biogeography 25:155-163.

Sattler, T., D. Borcard, R. Arlettaz, F. Bontadina, P. Legendre, M. K. Obrist, and M. Moretti. 2010. Spider, bee, and bird communities in cities are shaped by environmental control and high stochasticity. Ecology 91:3343-3353.

Sirohi, M. H., J. Jackson, M. Edwards, and J. Ollerton. 2015. Diversity and abundance of solitary and primitively eusocial bees in an urban centre: A case study from Northampton (England). Journal of Insect Conservation 19:487-500.

Vergnes, A., V. Pellissier, G. Lemperiere, C. Rollard, and P. Clergeau. 2014. Urban densification causes the decline of ground-dwelling arthropods. Biodiversity and Conservation 23:1859-1877.

Zanette, L. R. S., R. P. Martins, and S. P. Ribeiro. 2005. Effects of urbanization on Neotropical wasp and bee assemblages in a Brazilian metropolis. Landscape and Urban Planning 71:105-121. 


\section{Supplementary Material}

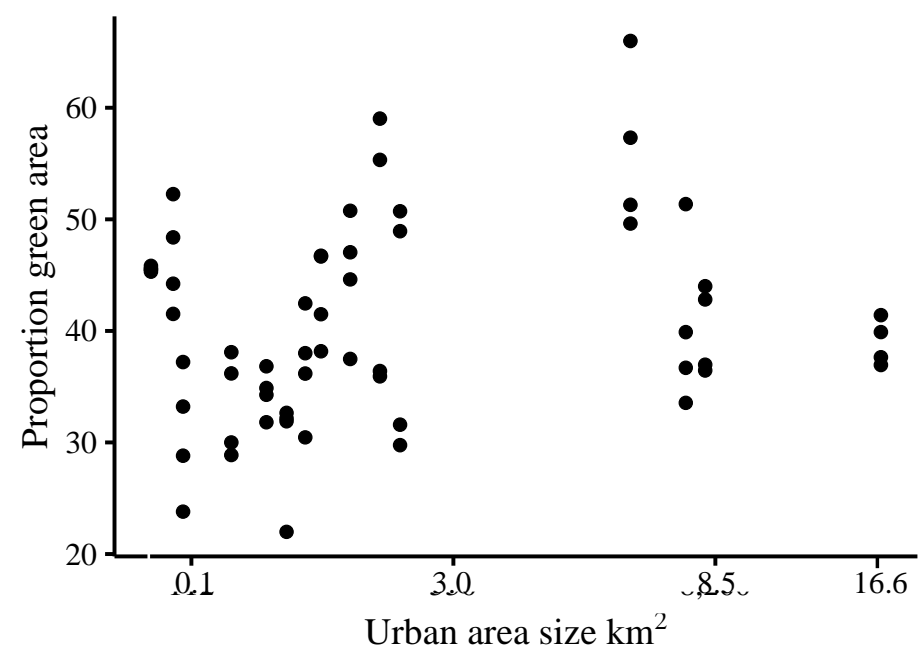

Fig. S1: Proportion of green area measured inside urban area boundaries plotted against urban area size in $\mathrm{km}^{2}$.

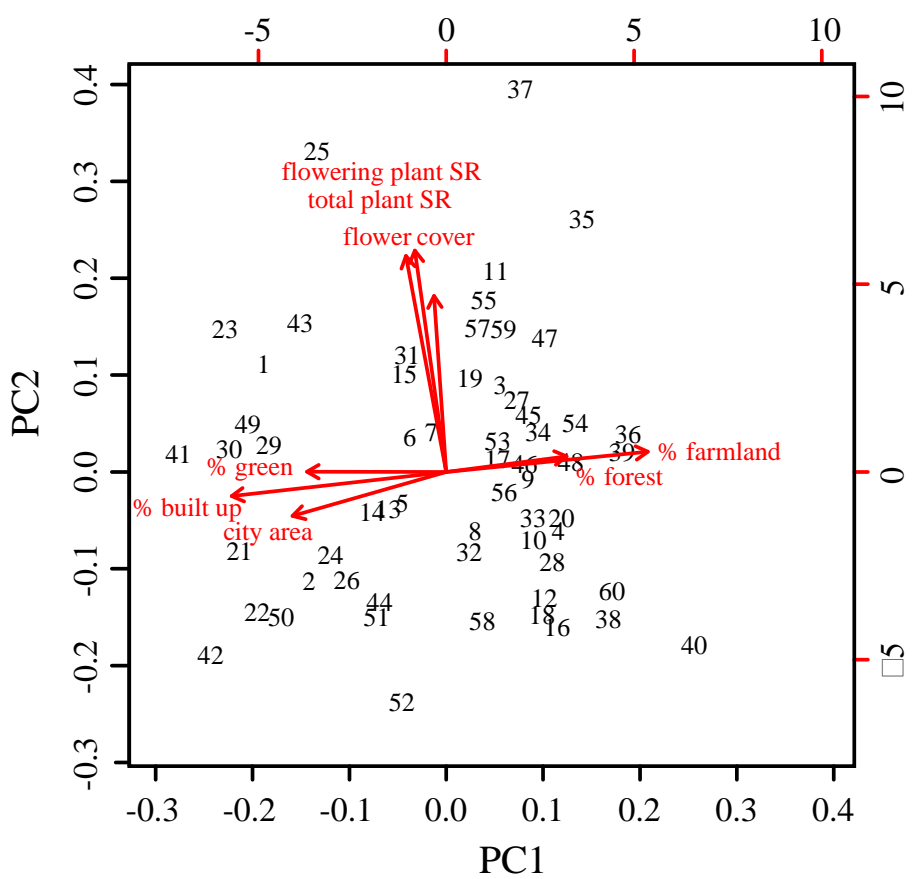

Fig. S2: Principle components analysis of our variables. GIS variables calculated in a $500 \mathrm{~m}$ radius for each site: $\%$ green $=$ proportion of urban area that is green (urban gardens + parks/pastures), $\%$ built up = proportion of urban area that is built up (buildings and roads + gardens; everything within the urban boundary), $\%$ farmland = proportion of farmland, $\%$ forest $=$ proportion of forest. City area (urban area size) is calculated in $\mathrm{km}^{2}$. Plant variables are calculated per site in the gardens and grassland: flower cover, flowering plant SR $=$ Shannon richness of flowering plants, total plant SR $=$ Shannon richness of all plants (flowering + nonflowering). 

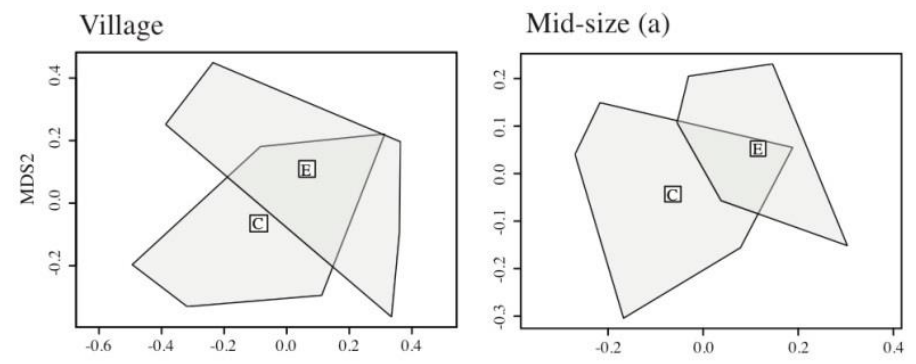

(b)

(c)
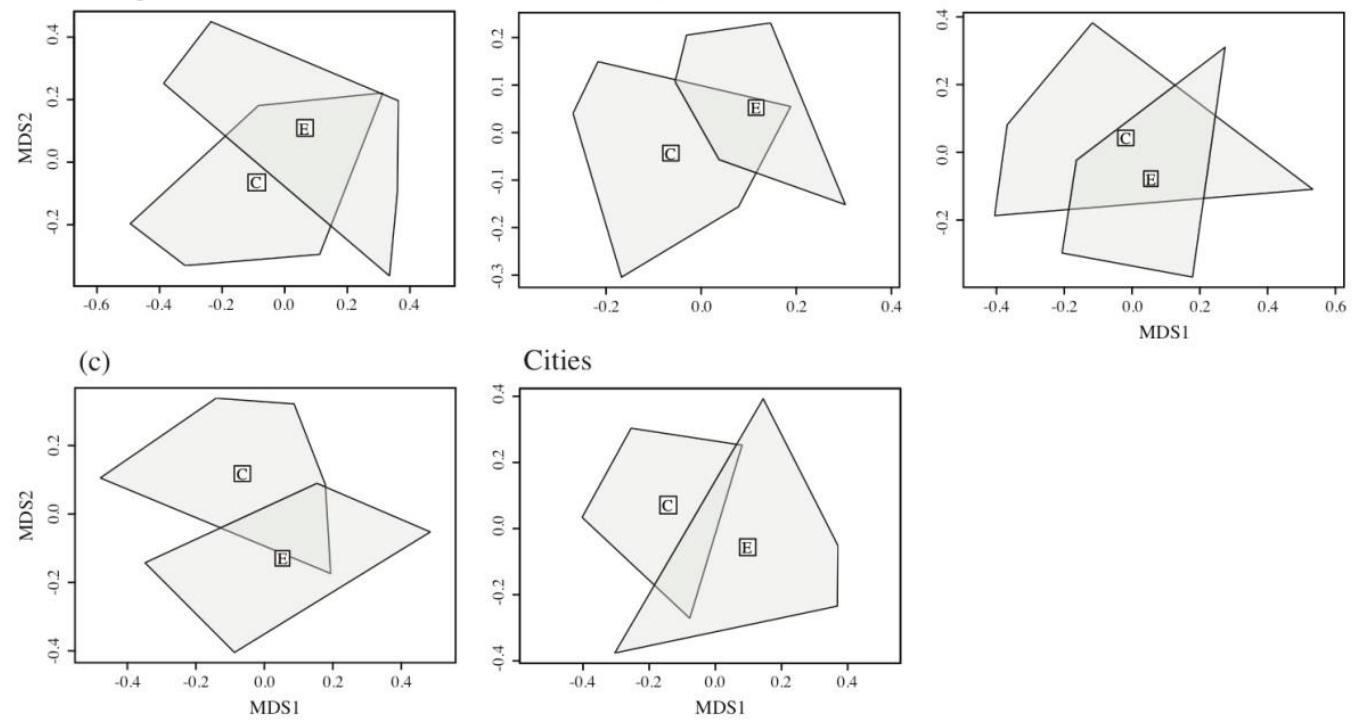

Fig. S3: Ordination plots for Coleoptera in different size categories of urban areas comparing differences between centre $(C)$ and edge $(E)$. Urban areas were grouped by size into categories and NMDS ordinations using the Bray-Curtis method were calculated. The 15 urban areas were grouped by three i.e. three urban areas per plot.
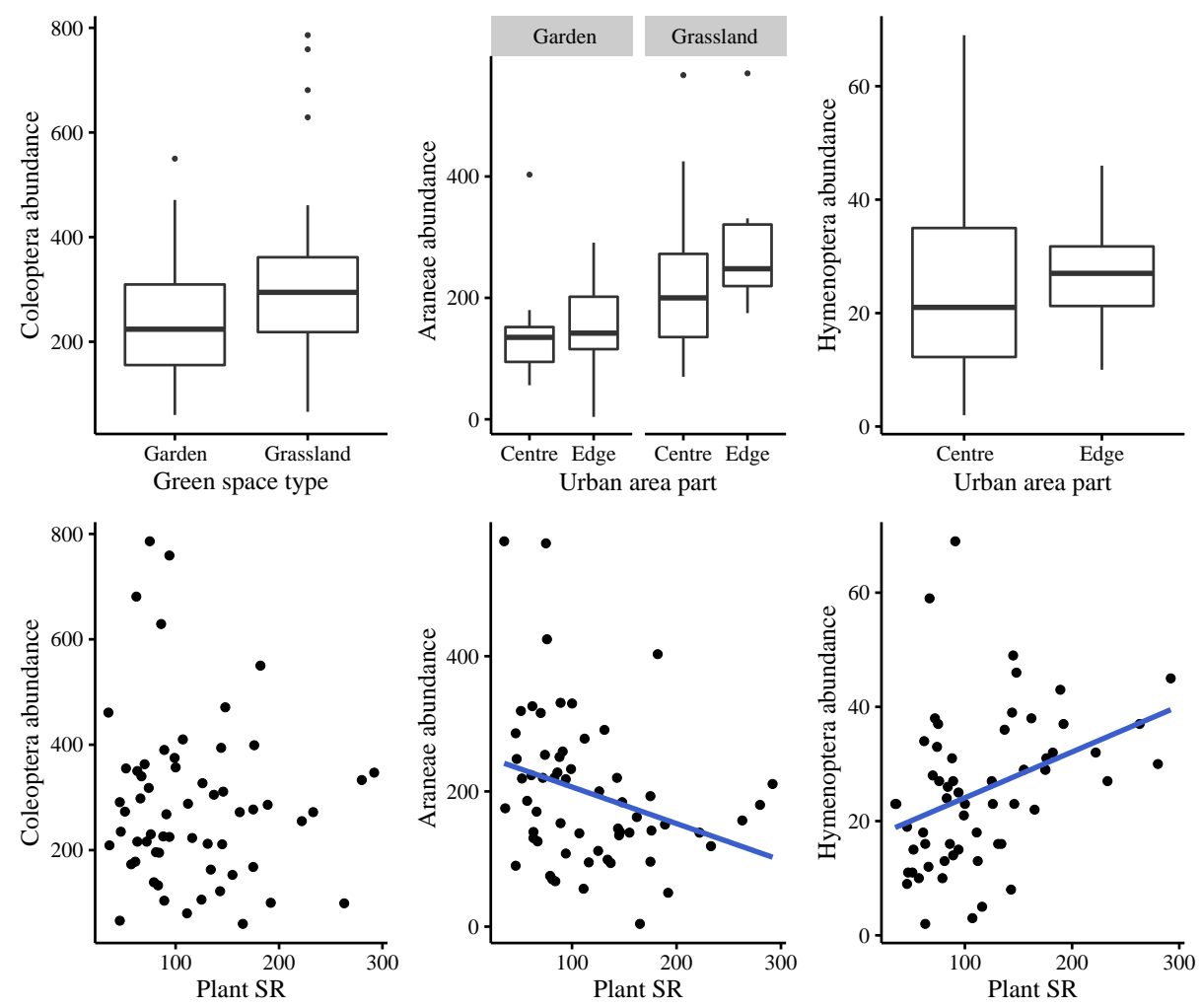

Fig. S4: Abundance relationships for all taxa against experimental variables and plant SR. Only significant relationships are plotted. 
Table S1: Urban area size, position in latitude and longitude and distance to centre garden for all urban areas arthropods were sampled in.

\begin{tabular}{|l|r|l|l|r|}
\hline Urban area & Area (km2) & Latitude & Longitude & Distance (m) \\
\hline Deiderode & 0.1 & $51^{\circ} 25^{\prime} 21.24^{\prime \prime} \mathrm{N}$ & $9^{\circ} 51^{\prime} 49.25^{\prime \prime} \mathrm{E}$ & 100 \\
\hline Deitersen & 0.1 & $51^{\circ} 49^{\prime} 28.25^{\prime \prime} \mathrm{N}$ & $9^{\circ} 44^{\prime} 15.56^{\prime \prime} \mathrm{E}$ & 60 \\
\hline Etzenborn & 0.1 & $51^{\circ} 27^{\prime} 38.58^{\prime \prime} \mathrm{N}$ & $10^{\circ} 9^{\prime} 56.71^{\prime \prime} \mathrm{E}$ & 90 \\
\hline Ellierode & 0.2 & $51^{\circ} 37^{\prime} 54.16^{\prime \prime} \mathrm{N}$ & $9^{\circ} 48^{\prime} 27.09^{\prime \prime} \mathrm{E}$ & 110 \\
\hline Imbsen & 0.3 & $51^{\circ} 31^{\prime} 16.32^{\prime \prime} \mathrm{N}$ & $9^{\circ} 43^{\prime} 52.60^{\prime \prime} \mathrm{E}$ & 130 \\
\hline Parensen & 0.3 & $51^{\circ} 36^{\prime} 54.90^{\prime \prime} \mathrm{N}$ & $9^{\circ} 54^{\prime} 17.39^{\prime \prime} \mathrm{E}$ & 130 \\
\hline Sieboldshausen & 0.4 & $51^{\circ} 28^{\prime} 13.99^{\prime \prime} \mathrm{N}$ & $9^{\circ} 53^{\prime} 35.04^{\prime \prime} \mathrm{E}$ & 220 \\
\hline Bodensee & 0.4 & $51^{\circ} 36^{\prime} 23.07^{\prime \prime} \mathrm{N}$ & $10^{\circ} 7^{\prime} 57.66^{\prime \prime} \mathrm{E}$ & 230 \\
\hline Diemarden & 0.5 & $51^{\circ} 29^{\prime} 13.24^{\prime \prime} \mathrm{N}$ & $9^{\circ} 58^{\prime} 58.73^{\prime \prime} \mathrm{E}$ & 210 \\
\hline Ebergotzen & 0.7 & $51^{\circ} 34^{\prime} 14.32^{\prime \prime} \mathrm{N}$ & $1^{\circ} 6^{\prime} 27.41^{\prime \prime} \mathrm{E}$ & 180 \\
\hline Bovenden & 2.7 & $51^{\circ} 35^{\prime} 11.18^{\prime \prime} \mathrm{N}$ & $9^{\circ} 56^{\prime} 0.81^{\prime \prime} \mathrm{E}$ & 570 \\
\hline Duderstadt & 4.5 & $51^{\circ} 30^{\prime} 45.79^{\prime \prime} \mathrm{N}$ & $1^{\circ} 15^{\prime} 34.68 " \mathrm{E}$ & 800 \\
\hline Einbeck & 7.1 & $51^{\circ} 49^{\prime} 13.29^{\prime \prime} \mathrm{N}$ & $9^{\circ} 52^{\prime} 6.14 " \mathrm{E}$ & 1,000 \\
\hline Northeim & 8.5 & $51^{\circ} 42^{\prime} 21.76^{\prime \prime} \mathrm{N}$ & $9^{\circ} 59^{\prime} 48.62^{\prime \prime} \mathrm{E}$ & 1,600 \\
\hline Göttingen & 16.6 & $51^{\circ} 32^{\prime} 28.61^{\prime \prime} \mathrm{N}$ & $9^{\circ} 54^{\prime} 56.89^{\prime \prime} \mathrm{E}$ & \\
\hline
\end{tabular}




\section{Acknowledgement}

First, I want to thank my supervisors Christoph Scherber and Teja Tscharntke for the opportunity to be part of the research training group "Scaling Problems in Statistics" and the Agroecology group. I am grateful for all their support and guidance during my project development, their good ideas and valuable notes and excellent advice. I also thank Thomas Kneib for his support in statistics and Holger Kreft for stepping in for my defence.

I would also like to thank Kristy Udy for nearly four years of perfect team work. It is a pleasure to be your friend.

I sincerely thank the Agroecology Group, for sharing their ecological ideas with me and for their support and assistance. I greatly appreciate Susannes and Brigittes help during my field work, and thank Jutta and Heike for creating a very good working atmosphere. I am grateful to all the student workers, who helped during field work especially for identification of a huge variety of garden plants. I thank Rüdiger, Victoria, Felix, Chrissie, Verena, Moritz, Nina, Anne, Niklas and Christoph for hours of sorting insects, creating GIS maps and pollen identification.

I would like to thank Erin Treanore for half a year of scientific and non-scientific discussions and good ideas during my field work preparation and especially for her willingness to visit gardens in the middle of the night.

I am thankful to all garden owners and farmers, who made my projects possible when they allowed us to work in their gardens and for their support with ice-cream and tea. I thank the University of Göttingen for the allowance to work on their experimental sites. I thank the Kreis Göttingen and Northeim for providing insect capture authorisation.

I would like to acknowledge and thank the RTG "Scaling Problems in Statistics" for the good atmosphere during courses and seminars and I especially thank Barbara Strauß and Dörte Dede for their patience in answering every question.

My research was made possible due to financial support from the German Research foundation (DFG).

I am grateful for my family and friends, who always supported me and are always there when I need them. Special thanks to my mother for highly effective help in data entry and plant identification. 


\section{Overview publications}

1. Reininghaus, H., K L. Udy, E. Treanore, T. Tscharntke, and C. Scherber. Reversed Importance of Local vs. Landscape Flower Resources for Bumblebee Foraging and Colony Performance along Farmland-Urban Gradients. In prep.

2. Reininghaus, H., K L. Udy, T. Tscharntke, and C. Scherber. Season and Flower Composition affect Bumblebee Foraging Behaviour across a Farmland-Urban Gradient. In prep.

3. Udy, K. L*., Reininghaus H.*, C. Scherber, and T. Tscharntke. Arthropod Diversity across an Urbanisation Gradient of City Size. In prep.

* These authors contributed equally to this work.

4. Udy K. L., H. Reininghaus H., C. Scherber, and T. Tscharntke. Plant-Pollinator Interactions along an Urbanisation Gradient from Cities and Villages to Farmland Landscapes. In prep.

5. Udy, K. L., M. Fritsch, I. Grass, F. Hartig, T. Kneib, H. Kreft, C. Kukunda, K. Meyer, G. Pe'er, H. Reininghaus, B. Tietjen, T. Tscharntke, C. S. van Waveren, $\mathrm{K}$. Wiegand. Environmental heterogeneity predicts global species richness better than area. In prep. 